\title{
Wind Shear for Large Wind Turbine Generators at Selected Tall Tower Sites
}

D. L. Elliott

April 1984

Prepared for the U.S. Department of Energy under Contract DE-AC06-76RLO 1830

Pacific Northwest Laboratory Operated for the U.S. Department of Energy by Battelle Memorial Institute 


\title{
DISCLAIMER
}

This report was prepared as an account of work sponsored by an agency of the United States Government. Neither the United States Government nor any agency thereof, nor any of their employees, makes any warranty, express or implied, or assumes any legal liability or responsibility for the accuracy, completeness, or usefulness of any information, apparatus, product, or process disclosed, or represents that its use would not infringe privately owned rights. Reference herein to any specific commercial product, process, or service by trade name, trademark, manufacturer, or otherwise, does not necessarily constitute or imply its endorsement, recommendation, or favoring by the United States Government or any agency thereof. The views and opinions of authors expressed herein do not necessarily state or reflect those of the United States Government or any agency thereof.

\author{
PACIFIC NORTHWEST LABORATORY \\ operated by \\ BATTELLE \\ for the \\ UNITED STATES DEPARTMENT OF ENERGY \\ under Contract DE-AC06-76RLO 1830
}

\begin{tabular}{|c|c|}
\hline \multirow{2}{*}{\multicolumn{2}{|c|}{ Printed in the United States of America }} \\
\hline \multirow{2}{*}{\multicolumn{2}{|c|}{$\begin{array}{c}\text { Available from } \\
\text { Nationatice }\end{array}$}} \\
\hline & \\
\hline \multicolumn{2}{|c|}{$\begin{array}{l}\text { National Technical Information Service } \\
\text { United States Department of Commerce }\end{array}$} \\
\hline \multicolumn{2}{|c|}{5285 Port Royal Road } \\
\hline \multicolumn{2}{|c|}{ Springfield, Virginia 22161} \\
\hline \multicolumn{2}{|c|}{ NTIS Price Codes } \\
\hline \multicolumn{2}{|c|}{ Microfiche A01 } \\
\hline \multicolumn{2}{|c|}{ Printed Copy } \\
\hline & Price \\
\hline Pages & Codes \\
\hline $001-025$ & $\mathrm{~A} 02$ \\
\hline $026-050$ & $\mathrm{A03}$ \\
\hline $051-075$ & $\mathrm{~A} 04$ \\
\hline $076-100$ & A05 \\
\hline $101-125$ & A06 \\
\hline $126-150$ & $\mathrm{~A} 07$ \\
\hline 151.175 & $A 08$ \\
\hline $176 \cdot 200$ & $A 09$ \\
\hline $201-225$ & A010 \\
\hline $226-250$ & A011 \\
\hline $251-275$ & $\mathrm{~A} 012$ \\
\hline $276-300$ & A013 \\
\hline
\end{tabular}


WIND SHEAR FOR LARGE WIND TURBINE GENERATORS AT SELECTED TALL TOWER SITES

D. L. Elliott

Apri1 1984

Prepared for the U.S. Department of Energy under Contract DE-ACO6-76RLO 1830

Pacific Northwest Laboratory Richland, Washington 99352 
The objective of the study described in this report is to examine the nature of wind shear profiles and their variability over the height of large horizontal-axis wind turbines and to provide information on wind shear relevant to the design and operation of large wind turbines. Wind turbine fatigue life and power quality are related through the forcing functions on the blade to the shapes of the wind shear profiles and their fluctuations over the disk of rotation.

Of primary interest here are characteristics of instantaneous shear profiles that are experienced by a rotating blade, not time-averaged profiles representing mean conditions. Comparisons of the frequency distributions of shear profiles based on 10-s instantaneous sampled winds and hourly averaged winds measured over a $1-y r$ period at several levels on a tall tower in Oklahoma were made in a previous study by Elliott, Wendell, and Heflick (1982). That study demonstrated that a rotating blade would experience a much wider range of wind shear profiles and a higher percentage of extreme shears than indicated by hourly averaged winds. That study also showed that 2-min instantaneous sampled data may be used to estimate the frequency distribution of wind shear profiles as reliably as 10-s samples.

In this study, wind data from anemometers mounted at multiple levels on tall towers in three different regions of the United States were selected to investigate wind shear profiles and their variability in these varied climatic, topographic, and wind regimes. Criteria used in selecting the appropriate data were the height of the wind measurements (at least 3 levels up to at least $100 \mathrm{~m}$ above ground), the data sampling frequency (at least 2-min instantaneous samples), and the wind energy resource (at least $300 \mathrm{~W} / \mathrm{m}^{2}[6.4 \mathrm{~m} / \mathrm{s}]$ annual wind power at $50 \mathrm{~m}$ above ground level). Three locations selected with the appropriate wind data available for use in this 
study were 1) the KYTV tower site near Oklahoma City, Oklahoma, 2) the Bureau of Reclamation tower site at Medicine Bow, Wyoming, and 3) the Department of Energy tower site at Goodnoe Hills, Washington.

To characterize the large variation of the wind shear profiles that could be experienced by a large wind turbine, a matrix of 56 different profile shapes was established for the analysis. Each profile shape is described in terms of the velocity difference across the top-to-hub versus hub-to-bottom of the disk of rotation.

Analyses of the percent frequency of occurrence, mean duration, and mean fluctuation of each wind shear profile within the matrix are presented for selected wind turbine configurations for each of the tall tower sites using data from selected winter and summer periods at each site. Only data from windy hours, that is, hours for which the average wind speed was at least $7 \mathrm{~m} / \mathrm{s}$ at hub-height level, are used in the analysis.

For the KYTV tower site in Oklahoma, analyses of the shear profiles are presented for three different configurations of large horizontal-axis wind turbines: $91 \mathrm{~m}$ rotor diameter with $15 \mathrm{~m}$ ground clearance (Type 1), $128 \mathrm{~m}$ rotor diameter with $12 \mathrm{~m}$ ground clearance (Type 2 ), and $78 \mathrm{~m}$ rotor diameter with $41 \mathrm{~m}$ ground clearance (Type 3). For Goodnoe Hills and Medicine Bow, the wind shear analyses are carried out only for a Type 1 configuration, because the upper level of wind data at these sites is significantly lower than the top of the rotor disks of the Type 2 and Type 3 turbine configurations.

Comparisons of the wind shear profiles at the three sites are presented for a Type 1 turbine for winter versus summer and day versus night, using 2-min instantaneous sampled data from each site. Duration probability exceedance curves, which show the percentage time that a wind shear profile exceeded a given duration, are also presented. A comparison of the analysis results using $10-5$ versus 2 -min instantaneous sampled wind data from the KYTV tower are presented for identical time periods. 
Major conclusions from this study are as follows:

- Significant differences exist among three types of wind turbines in the distribution of shear profiles and in the duration and fluctuation of the profiles. The Type 3 turbine experiences considerably less variability in the occurrence of shear profiles and fewer extreme profiles than either the Type 1 and Type 2 turbines. Shear profiles persist longer and fluctuate less over the disk of rotation of the Type 3 turbine than either the Type 1 or Type 2 turbine.

- Large differences exist among the three locations in the distribution of shear profiles and in the duration and fluctuation of the profiles. All three locations show a large variety of wind shear profiles; however, Goodnoe Hills experiences a greater variety of wind shear profiles than either Medicine Bow or KYTV.

- Large variations exist between winter and summer at all three locations in the distribution of shear profiles and in the duration and fluctuation of the profiles. The winter-summer variation is greater at Goodnoe Hills than at KYTV or Medicine Bow.

- The distribution of wind shear profiles varies dramatically between day and night at each location. Wind shears are, on the average, much greater at night than in day. Nightime shear profiles vary considerably in duration and magnitude of the fluctuations, in contrast to daytime profiles which generally have short durations and large fluctuations.

The analyses presented in this study showed remarkably different wind shear profile characteristics among the three locations. The analyses are not intended, however, to represent $c$ limatological (long-term) averages of these locations. Their primary purpose is to provide insight into the variety of wind shear profiles and their fluctuations and the nature of the seasonal and diurnal variations of the profile characteristics that can occur in different regions of the United States. 
The variety of profile shapes, and the variations in durations and fluctuations of the profiles, indicate that the consideration of the wind shear profiles and their fluctuation over the upper and lower halves of the rotor disk is an important factor in estimating the fatigue life and power quality of large horizontal-axis wind turbines. These types of information are presented for evaluation and comment from turbine design engineers for the purpose of making the development of the input for an analysis of fatigue and power quality more effective and appropriate.

While rotational sampling provides a more accurate description of the wind shear and turbulence experienced by a rotating blade, use of conventional tower data such as these used in this study are valuable in a preliminary estimation of the variety of wind shear profile conditions and in the identification of extreme shear conditions that could be experienced by a rotating blade. This information would be useful in making siting decisions and in determining under what conditions more detailed and accurate measurements may be needed.

Therefore, it is recommended that measurements appropriate to this type of analysis be considered as a part of the siting criteria for the installation of large turbines, especially in regions where terrain features or land-water proximity suggest the possibility of physical phenomena conducive to severe and unusual wind shear profiles. Additionally, these types of information may also be important and useful for smaller turbines than addressed in this study. Considerable data from more than 20 locations throughout the United States are available for carrying out these types of wind shear analyses for heights up to $50 \mathrm{~m}$. Much of these data were collected for the U.S. Department of Energy Candidate Site Program. 


\section{ACKNOWLEDGMENTS}

Appreciation is expressed to Joe Savino of NASA-Lewis Research Center, Paul Veers of Sandia National Laboratory, George Tennyson of DOE, and Jim Connell of PNL for their special attention to the report and for providing review comments on the report. Gratitude is expressed to the Bureau of Reclamation for supplying data from the tower at Medicine Bow, Wyoming. The author thanks Mike Kosorok for his many hours of assistance in writing the computer programs and in generating the wind shear analyses. 


\section{CONTENTS}

SUMMARY

ACKNOWLEDGMENTS.

1.0 INTRODUCTION

2.0 METHODOLOGY AND DATA USED IN ANALYSES $. \quad . \quad . \quad . \quad . \quad . \quad . \quad 5$

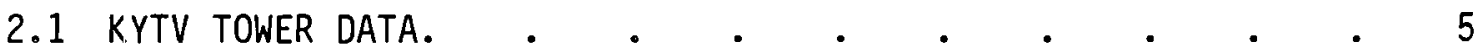

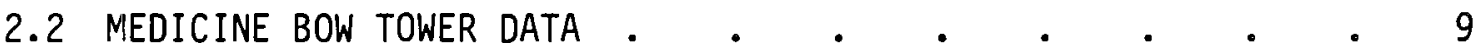

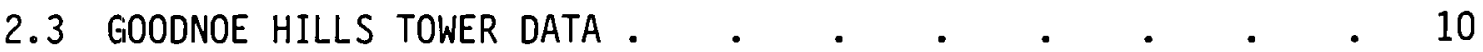

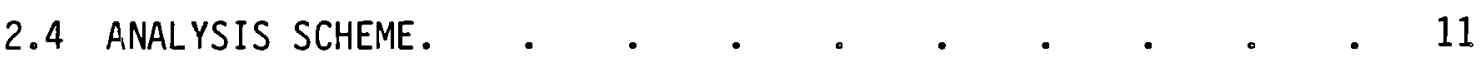

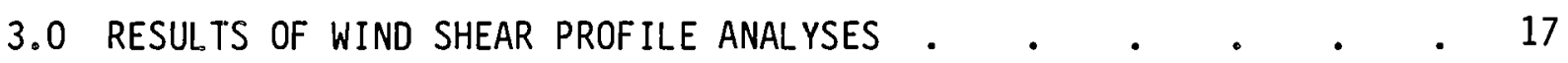

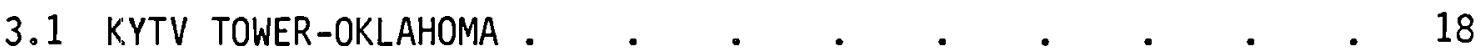

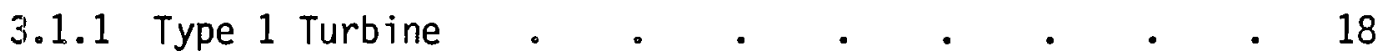

3.1 .2 Type 2 Turbine $\quad . \quad$. $\quad . \quad$. $\quad . \quad$. 23

3.1.3 Type 3 Turbine . . . . . . . . 27

3.1.4 Duration Exceedance Curves . . . . . . 32

3.1.5 Comparison of Results: 10-s Versus 2-min Data . $\quad 37$

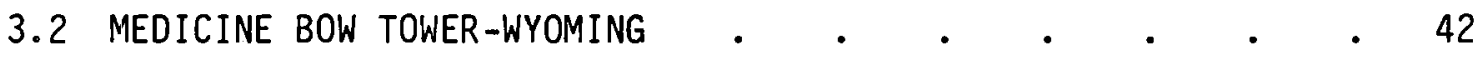

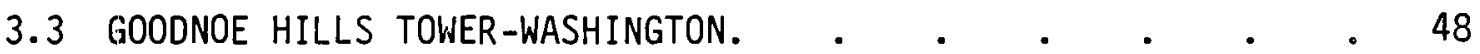

3.4 COMPARISON OF SHEAR PROF ILES AT THE THREE LOCATIONS • $\quad$ • 55

3.4.1 Winter Profiles . . . . . . . . . 55

3.4 .2 Summer Profiles . . . . . . . . 59

3.4.3 Duration Exceedance Curves . . . . . . 60

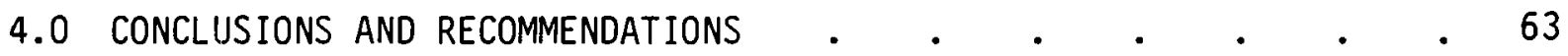

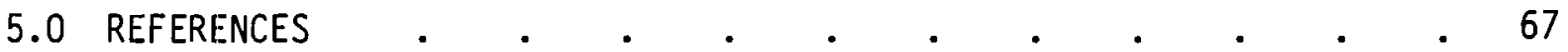





\section{FIGURES}

2-1 Sequential 10-s Wind Profiles Derived From KYTV Tower Data Beginning at 1830:00 CST, March 10, 1977

2-2 Schematic of a Wind Shear Profile with $\Delta V_{L}=4 \mathrm{~m} / \mathrm{s}$ and $\Delta V_{U}=1 \mathrm{~m} / \mathrm{s}$ Across a Hypothetical Wind Turbine of $70 \mathrm{~m}$ Rotor Diameter and $60 \mathrm{~m}$ Hub Height . . . . . . 12

2-3 Matrix of Wind Shears Profiles Established for the Analysis.

2-4 Examples of the Magnitude of the Fluctuation Between

Sequential Wind Shear Profiles . . . . . . . 15

3-1 Frequency of Occurrence, Mean Duration, and Mean Fluctuation of Wind Shear Profiles for a Type 1 Turbine using 10-s Sampled Winds from the KYTV Tower in Oklahoma City, Ok lahoma, for (a) Winter and (b) Summer

3-2 KYTV Oklahoma City, Oklahoma, Type 1 Turbine for (a) Winter Day and (b) Winter Night . . . . . . 20

3-3 KYTV Oklahoma City, Oklahoma, Type 1 Turbine for (a) Summer Day and (b) Summer Night . . . . . . 21

3-4 KYTV Oklahoma City, Ok lahoma, Type 2 Turbine for

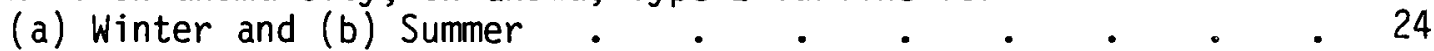

3-5 KYTV Ok lahoma City, Oklahoma, Type 2 Turbine for (a) Winter Day and (b) Winter Night . . . . . . 25

3-6 KYTV Oklahoma City, Ok lahoma, Type 2 Turbine for (a) Summer Day and (b) Summer Night . • . . . . 26

3-7 KYTV Oklahoma City, Oklahoma, Type 3 Turbine for (a) Winter and (b) Summer . . . . . . . . . 28

3-8 KYTV Oklahoma City, Oklahoma, Type 3 Turbine for (a) Winter Day and (b) Winter Night . . . . . . . 29

3-9 KYTV Oklahoma City, Oklahoma, Type 3 Turbine for (a) Summer Day and (b) Summer Night 
3-10 Average Percentage of Time That an Individual Wind

Shear Profile Across a Type 1 Turbine Exceeded a Given

Duration During (a) Winter and (b) Summer Using

Instantaneous 10-s Sampled Winds from KYTV Tower,

Ok l ahoma.

3-11 Percentage of Time That Selected Wind Shear Profiles

Across a Type 1 Turbine Exceeded a Given Duration during

(a) Winter Day and (b) Winter Night Using Instantaneous

10-s Sampled Winds from KYTV Tower, Oklahoma $\quad . \quad$. $\quad . \quad$. 34

3-12 Percentage of Time That Selected Wind Shear Profiles Across

a Type 1 Turbine Exceeded a Given Duration during (a) Summer

Day and (b) Summer Night Using Instantaneous 10-Sampled Winds

From KYTV Tower, Oklahoma $\quad . \quad$. $\quad . \quad . \quad . \quad . \quad$.

3-13 Average Percentage of Time That an Individual Wind Shear Profile Across a Type 3 Turbine Exceeded a Given Duration during (a) Winter and (b) Summer Using Instantaneous 10-s Sampled Winds From KYTV Tower, OKlahoma . . . . . 38

3-14 Frequency of Occurrence, Mean Duration, and Mean Fluctuation of Wind Shear Profiles for a Type 1 Turbine Using 2-min

Instantaneous Winds from the KYTV Tower in Oklahoma City,

3-15 Average Percentage of Time That an Individual Wind Shear Profile Across a Type 1 Turbine Exceeded a Given Duration during (a) Winter and (b) Summer Using Instantaneous 2-min Sampled Winds From KYTV Tower, Oklahoma $\quad . \quad$. . . .

3-16 Frequency of 0ccurrence, Mean Duration and Mean Fluctuation of Wind Shear Profiles for a Type 1 Turbine using 2-min Instantaneous Winds from Medicine Bow, Wyoming, for (a) Winter and (b) Summer

3-17 Medicine Bow, Wyoming, Type 1 Turbine for (a) Winter Day and (b) Winter Night

3-18 Medicine Bow, Wyoming, Type 1 Turbine for (a) Summer Day and (b) Summer Night

3-19 Average Percentage of Time That an Individual Wind Shear Profile Across a Type 1 Turbine Exceeded a Given Duration during (a) Winter and (b) Summer Using Instantaneous 2-min Sampled Winds from Medicine Bow 
3-20 Frequency of Occurrence, Mean Duration, and Mean Fluctuation of Wind Shear Profiles for a Type 1 Turbine Using 2-min Instantaneous Winds from Goodnoe Hills, Washington, for (a) Winter and (b) Summer . . . . . . . .

3-21 Goodnoe Hills, Washington, Type 1 Turbine for (a) Winter Day and (b) Winter Night

3-22 Goodnoe Hills, Washington, Type 1 Turbine for (a) Summer Day and (b) Summer Night

3-23 Average Percentage of Time That an Individual Wind Shear Profile Across a Type 1 Turbine Exceeded a Given Duration during (a) Winter and (b) Summer Using Instantaneous 2-min Sampled Winds from Goodnoe Hills.

3-24 Frequency of Occurrence, Mean Duration and Mean Fluctuation of Wind Shear Profiles in Winter for a Type 1 Turbine using 2-min Instantaneous Winds from (a) KYTV Tower, Oklahoma, (b) Medicine Bow, Wyoming, and (c) Goodnoe Hills, Washington . . . .

3-25 Frequency of Occurrence, Mean Duration and Mean Fluctuation of Wind Shear Profiles in Summer for a Type 1 Turbine using 2-min Instantaneous Winds from (a) KYTV Tower, Ok1ahoma, (b) Medicine Bow, Wyoming, and (c) Goodnoe Hills, Washington

3-26 Average Percentage of Time That an Individual Wind Shear Profile Across a Type 1 Turbine Exceeded a Given Duration during Winter and Summer Using Instantaneous 2-min Winds from (a) KYTV Tower, Oklahoma, (b) Medicine Bow, Wyoming, and (c) Goodnoe Hills, Washington. 
. 


\section{TABLES}

2-1 Wind Turbine Configurations Used in the Wind Shear Analyses . . . 8

2-2 Determination of Day, Night and Transition Periods at Goodnoe Hills . • • • • • • • • • . • . 16 



\subsection{INTRODUCTION}

The advent of horizontal-axis wind turbines with blade diameters greater than $76 \mathrm{~m}(250 \mathrm{ft})$ and hub heights of more than $61 \mathrm{~m}(200 \mathrm{ft})$ has raised questions about the nature of the wind shear that will be encountered by these large turbines. The conventional concept of the increase of wind speed with height in the lowest $150 \mathrm{~m}$ (492 ft) above ground level is based on time-averaged conditions. This has led to the use of the classical logarithmic profile and the power law concept to extrapolate wind speeds from lower heights to higher heights.

A potential problem in applying the average profile concept to a rotating turbine blade in design or operational considerations is that the blade does not encounter an average wind profile. Rather, the blade experiences the wind shear and fluctuations that occur during the 2 to 4 seconds that it takes to complete one rotation. A high percentage of extreme shears occurring over this short time scale could have an effect on the amount of fatigue experienced by the blades and on the quality of power produced by the turbine.

Spectra of wind speed fluctuations encountered by a rotating blade have been measured by Connel1 (1982). These measurements revealed that the spectrum contains narrow-band spikes of turbulence energy centered on the frequency of rotor rotation and multiples of that frequency. An empirical model of rotationaly sampled winds has been developed by Connell and George (1983) that processes turbulence measurements from a single meteorological tower to estimate the turbulence spectra experienced by wind turbines. This model indicated that both small and large turbines will experience previously unanticipated turbulence in the higher-frequency region. Further, the high frequency variance of the rotationally sampled wind speed is shown to vary with the magnitude of the wind speed, the shape of the wind shear profile, the turbulent fluctuations of the shear profile, and the turbine diameter, hub height, and rotation rate. 
In order to estimate the variation in wind shear profiles that a large turbine will experience and the subsequent effects on fatigue life and power quality, it is extremely important to obtain and analyze wind data for the appropriate height ranges of large wind turbines with a high sampling rate over a wide range of atmospheric conditions.

In a study by Elliott, Wendell and Heflick (1982), an analysis scheme was developed to establish a climatology of wind shear profiles derived from 10-s sampled winds and hourly average winds measured over a 1-yr period at several levels on a tall tower. Because of the sensitivity of the forcing function variability to profile shape, the analyses performed and presented were in the form of joint frequency distributions of velocity differences of the top-to-hub versus the hub-to-bottom portion of disks of rotation for three turbine configurations. A simple analysis of different shear profiles under steady flow conditions was presented to provide insight for relating the wind forcing experienced by a rotating blade to the results of the statistical analysis of wind shear conditions.

An available data set that was used in that study was one year of wind measurements sampled once every $10 \mathrm{~s}$ at four levels between $26 \mathrm{~m}(85 \mathrm{ft})$ and $177 \mathrm{~m}(580 \mathrm{ft})$ on the KYTV tower near Oklahoma City, Oklahoma. Two comparisons were made in the analysis. In the first, the frequency of occurrence of shear conditions from 10-s samples was compared with hourly average shear conditions. In the second, shear conditions experienced by different configurations of large wind turbines were compared.

The joint frequency distributions of 10-s sampled winds indicated that a rotating blade would experience a much wider range of shear conditions and a higher percentage of extreme shears than indicated by hourly averaged data. The joint frequency distributions of wind shear profiles were significantly different for the three wind turbine configurations. 
It must be pointed out that these results are not universally applicable, because they are based on wind data from a single location in gently rolling terrain with the climatic conditions associated with the southern Great Plains of the continental United States. Moreover, in addition to the analyses of the frequency distribution of wind shear profiles, statistics on the duration of the wind shear profiles and on the magnitude of the fluctuation of the wind shear profiles would also be useful information for providing more complete wind shear analyses for large wind turbines.

In this report, analyses of the frequency of occurrence, duration and fluctuation of wind shear profiles are carried out for three different locations with the appropriate tall tower data:

1) the KYTV tower site near Oklahoma City, Oklahoma

2) the Bureau of Reclamation tower site at Medicine Bow, Wyoming

3) the Department of Energy tower site at Goodnoe Hills, Washington.

Although the wind measurements at the latter two sites were sampled only once every $2 \mathrm{~min}$, previous analyses showed that 2-min instantaneous samples may be used to estimate the frequency distribution of wind shear profiles as reliably as 10 -s samples.

Comparisons of the wind shear analyses at all three locations are made for winter versus summer and day versus night. Only data from windy hours, i.e., hours with a mean hourly average wind speed greater than or equal to $7 \mathrm{~m} / \mathrm{s}$ at turbine hub-height level, are used in the wind shear analyses. For the KYTV tower in OKlahoma, analyses are carried out for the following three wind turbine configurations: 1) Type 1, $91 \mathrm{~m}(300 \mathrm{ft}$ ) rotor diameter with $15 \mathrm{~m}(50 \mathrm{ft})$ ground clearance, 2) Type 2, $128 \mathrm{~m}(420 \mathrm{ft})$ rotor diameter with $12 \mathrm{~m}(40 \mathrm{ft})$ ground clearance, and 3) Type 3, $78 \mathrm{~m}(256 \mathrm{ft})$ rotor diameter with $41 \mathrm{~m}(135 \mathrm{ft})$ ground clearance. For Goodnoe Hills, Washington, and Medicine Bow, Wyoming, wind shear analyses are carried out only for a Type 1 turbine. This is because the upper level of wind data at these sites is significantly lower than the upper sampling levels (top of the rotor disks) of the Type 2 and Type 3 turbines. 
Section 2 of this report describes the methodology and data used in the analysis of wind shear profiles. In Section 3, the results of the analyses are presented and described for each of the three locations. The percent frequency of occurrence, mean duration (in minutes), and mean fluctuation (in $\mathrm{m} / \mathrm{s}$ ) of a matrix of 56 different wind shear profile shapes are presented for winter, summer, day and night periods. In addition, cumulative frequency distributions of the duration of various profile shapes are presented and described. Comparisons among the three locations are made of the wind shear profile characteristics over the height range of a Type 1 turbine. For the KYTV tower, comparisons of the wind shear profile characteristics are made for all three wind turbine configurations. A comparison of the analysis results using 10-s versus 2-min instantaneous sampled wind data from the KYTV tower is presented for identical time periods. 


\subsection{METHODOLOGY AND DATA USED IN ANALYSES}

Wind data from anemometers mounted at multiple levels on tall towers in three different regions of the United States provided the opportunity to investigate wind shear profiles and their variability in varied climatic, topographic, and wind regimes. Important considerations in choosing the appropriate wind data for these analyses were 1) wind measurements up to at least $100 \mathrm{~m}$ above ground leve1, 2) at least three levels of wind measurements at heights appropriate for estimating the wind shear over both the upper and lower halves of a turbine's disk of rotation, 3) at least 2-min or more frequent instantaneous wind measurement samples, 4) data from an area of good wind energy potential, i.e., at least Class 3 or higher annual average wind power as defined in the regional wind energy atlases (Pacific Northwest Laboratory 1980). Three locations found to have the appropriate wind data available for use in this study were 1) the KYTV tower site near Oklahoma City, Oklahoma, 2) the Bureau of Reclamation tower site at Medicine Biow, Wyoming, and 3) the Department of Energy tower site at Goodnoe Hills, Washịngton.

\subsection{KYTV TOWER DATA}

The wind measurements from the 481-m KYTV tower were made by the National Severe Storms Laboratory, National Oceanic and Atmospheric Administration, at 10-s intervals. One year's wind data (October 1976 through September 1977) were available from the tower.

The tower is located $10 \mathrm{~km}$ northeast of Oklahoma City, Oklahoma. The area surrounding the tower consists of gently rolling terrain with no more than a $40-\mathrm{m}$ change in elevation within a $4-\mathrm{km}$ radius of the tower. The 1 and area is used for agriculture. Wooded areas are spotty and confined generally either to gullies or near small ponds. 
The heights and levels of the anemometers on the KYTV tower provided the opportunity to investigate wind shear profiles over a range of multimegawatt turbine sizes. The elevations of the anemometers in the lowest $200 \mathrm{~m}$ of the tower are indicated in Figure 2-1 in relation to the dimensions of three large turbine types selected to be representative of a range of blade size and hub heights. The blade diameters, hub heights, highest and lowest sampling points and rotation rate for each of the three turbine types are shown in Table 2-1.

A 1-min sequence of 10-s measurements is shown in Figure 2-1 to illustrate the variability that can occur in the wind profile. Between 10 and 20 seconds, a strong surge in the wind speed near the $92-\mathrm{m}(300-\mathrm{ft})$ level caused a strong shear condition, which weakened over the next 20 seconds to a very low shear condition. Over the last 20 seconds there was a short excursion to a reversal of the strong shear condition at 20 seconds and then the low shear condition returned.

Interpolating wind speeds over the height range of the blade diameters of the three types of turbines required wind data from four levels on the KYTV tower: $26 \mathrm{~m}, 45 \mathrm{~m}, 89 \mathrm{~m}$ and $177 \mathrm{~m}$. The wind speeds were linearly interpolated to each wind turbine's hub height and upper and lower sampling heights.

Only windy hours during which a large wind turbine would be operating a substantial part of the time were selected. Since hourly average wind speed data were also available from the KYTV tower for the same time period as the 10-s data, the hourly average data were used to screen the windy periods. A winter month, January, and a summer month, July, were chosen for the analysis of wind shear profiles at the KYTV tower. Those hours of each month having a mean hourly speed of at least $7 \mathrm{~m} / \mathrm{s}$ at either the $45-$ or 89-m level were selected for the analysis. 

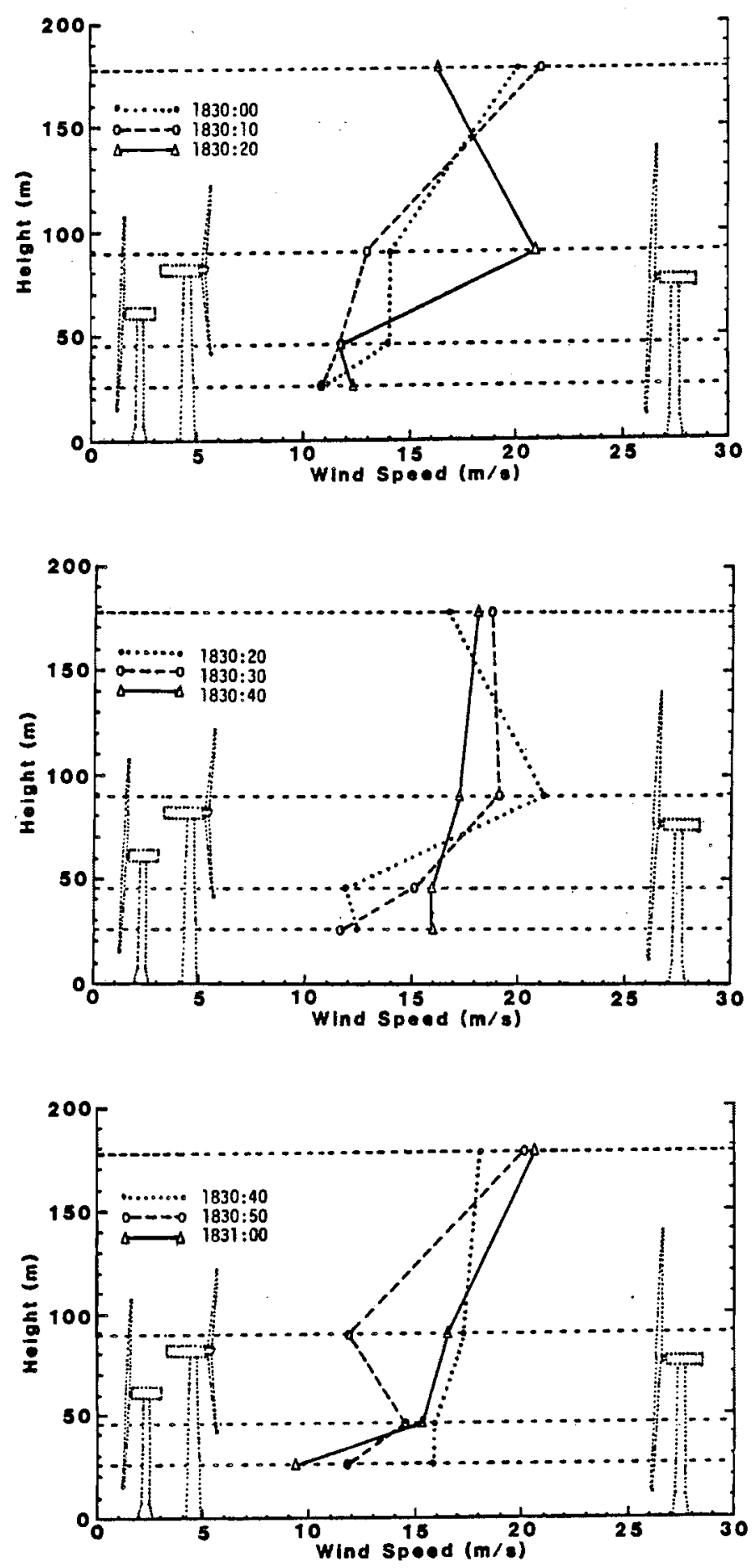

FIGURE 2-1. Sequential 10-s Wind Profiles Derived From KYTV Tower Data Beginning at 1830:00 CST, March 10, 1977. The dashed horizonta 1 lines indicate the levels of the anemometers. The dotted turbine outlines are included to show relative size and represent from left to right Type 1, Type 3, and Type 2 wind turbines. 
TABLE 2-1. Wind Turbine Configurations Used in the Wind Shear Analyses

\begin{tabular}{|c|c|c|c|c|c|}
\hline Turbine & $\begin{array}{l}\text { Rotor } \\
\text { Diameter } \\
\mathrm{m}(\mathrm{ft})\end{array}$ & $\begin{array}{l}\text { Hub } \\
\text { Height } \\
m(f t)\end{array}$ & $\begin{array}{c}\text { Upper } \\
\text { Sampling } \\
\text { Level (a) } \\
\text { m (ft) }\end{array}$ & $\begin{array}{c}\text { Lower } \\
\text { Sampling } \\
\text { Level ( } \mathrm{a}) \\
\mathrm{m}(\mathrm{ft})\end{array}$ & $\begin{array}{l}\text { Rotation } \\
\text { Rate } \\
\text { (rpm) }\end{array}$ \\
\hline $\begin{array}{c}\text { Type } 1 \\
\text { MOD-2 Size) }\end{array}$ & $91.4(300)$ & $61.0(200)$ & $106.7(350)$ & $15.2(50)$ & 17.5 \\
\hline $\begin{array}{c}\text { Type } 2 \\
\text { MOD-5 Size) }\end{array}$ & $128.0(420)$ & $76.2(250)$ & $140.2(460)$ & $12.2(40)$ & $10-15$ \\
\hline $\begin{array}{l}\text { Type } 3 \\
\text { WTS-4 Size) }\end{array}$ & $78.2(256)$ & $80.2(263)$ & $119.2(391)$ & $41.2(135)$ & 30 \\
\hline
\end{tabular}

(a) These values are based on the total distance from the hub to each blade tip. 


\subsection{MEDICINE BOW TOWER DATA}

The wind measurements from the Bureau of Reclamation tower at Medicine Bow, Wyoming, were made at three levels: $15.2 \mathrm{~m}(50 \mathrm{ft}), 61.0 \mathrm{~m}(200 \mathrm{ft})$ and $106.7 \mathrm{~m}(350 \mathrm{ft})$. The levels corresponded precisely to the hub height and upper and lower sampling level shown in Table 2-1 for the Type 1 turbine. Instantaneous wind measurements sampled every 2 min were available for each level.

Wind turbines of the Type 1 and Type 3 sizes have been installed near the Medicine Bow meteorological tower. Therefore, this was an added incentive for choosing this location to analyze wind shear profiles and their variability, especially since the appropriate data were available at the preferred levels for the Type 1 turbine size. Time-averaged wind shear profiles, based on hourly averaged data, have been investigated at the Medicine Bow tower by Martner and Gilmer (1981).

The terrain in the vicinity of the tower is open and mostly flat. It is devoid of trees with only low prairie grass and sparse sagebrush for vegetation (Water Power Resources Service 1979).

Because the upper levels of disks of rotation for a Type 2 and Type 3 wind turbine are substantially above the highest measurement level at the Medicine Bow tower, wind shear profile analyses were carried out only for the Type 1 turbine. Since the wind measurement levels were at the specified hub height and upper and lower sampling heights for a Type 1 turbine, no interpolation of the wind speeds was required.

Two-minute instantaneous wind data from the winter months (December 1980 through February 1981) and the summer months (June 1980 through August 1980) were used for the wind shear analyses. The data recovery when all three levels were recording data simultaneously was about $50 \%$ for the winter season and about $85 \%$ for the summer season. Only those hours having at least $7 \mathrm{~m} / \mathrm{s}$ mean hourly wind speed at the hub-height level were selected for the analysis of the 2-min data. 


\subsection{GOODNOE HILLS TOWER DATA}

The Goodnoe Hills tower located near Goldendale, Washington, is atop a 760-m ridge oriented approximately east-west. There is a steep dropoff to the Columbia River to the south, and a somewhat gentler dropoff to the north and west to the Klickitat Valley. Juniper Point, a peak of $954 \mathrm{~m}$ altitude, is the next significant topographic feature $13 \mathrm{~km}$ to the westsouthwest along the same ridge chain. The prevailing winds are from the west through northwest. Spring and summer are the principal seasons of strong winds at Goodnoe Hills.

The vegetation in the vicinity of the tower is mostly low grass and sagebrush. Trees are confined to gullies and spotty areas on the slopes below the crest of the ridge.

Selected periods of 2-min instantaneous wind measurement samples were available for four levels: $10 \mathrm{~m}(33 \mathrm{ft}), 15.2 \mathrm{~m}(50 \mathrm{ft}), 61.0 \mathrm{~m}(200 \mathrm{ft})$ and $106.7 \mathrm{~m}(350 \mathrm{ft})$. The upper three levels correspond precisely to the hub height and upper and lower sampling level shown in Table 2-1 for the Type 1 turbine. The 10-m level data were not used in the wind shear analysis.

Three Type 1 size wind turbines have been installed at Goodnoe Hills. Thus, this was a major consideration in choosing this location for an analysis of wind shear profiles. As with Medicine Bow, wind shear profile analyses were carried out only for the Type 1 turbine, because the upper levels of disks of rotation for a Type 2 and Type 3 wind turbine are substantially above the highest measurement level at the Goodnoe Hills tower.

Wind data collection at the Goodnoe Hills tower began in July 1980 with 2-min instantaneous wind measurement samples. Data from July and August 1980 were used to represent the summer period in the wind shear analys is for this location. Data from November and December 1980 were used to represent the winter period analysis. Two-min instantaneous data were not available for additional winter months, because the tower collapsed in January 1981. A new tower was installed in May 1981. A new measurement 
system installed in the summer of 1981 collected 2-min averaged data, and the 2-min instantaneous data sampling was discontinued. In March 1983, the 2-min instantaneous data sampling was initiated again, in addition to collecting the 2-min averaged data.

Only those hours having at least $7 \mathrm{~m} / \mathrm{s}$ mean hourly wind speed at $61 \mathrm{~m}$ (the hub-height level for a Type 1 turbine) were selected for the wind shear analysis.

\subsection{ANAL YSIS SCHEME}

The analyses of wind shear profiles are presented in terms of velocity differences $(\Delta V)$ for top-to-hub versus hub-to-bottom across the disk of rotation in $\Delta V$ intervals of $1 \mathrm{~m} / \mathrm{s}$. For convenience, $\Delta V$ across top-to-hub is referred to as $\Delta V$ upper or $\Delta V_{U}$, whereas $\Delta V$ across hub-to-bottom is referred to as $\Delta V$ lower or $\Delta V_{L}$. Figure 2-2 is a schematic of a wind shear profile with a $\Delta V_{L}$ of $4 \mathrm{~m} / \mathrm{s}$ and $\Delta V_{U}$ of $1 \mathrm{~m} / \mathrm{s}$ across a hypothetical wind turbine with a 70-m rotor diameter and 60-m hub height. The dashed 1 ine is inserted merely for reference in comparing profiles and approximates the $1 / 7$ power 1 aw for hub-height wind speeds of about $9 \mathrm{~m} / \mathrm{s}$. Typical ranges of velocity differences across the upper and lower halves of the disk of rotation for the three types of turbines used in the analyses were found in an earlier study by Elliott (1982) to be on the order of $-2 \mathrm{~m} / \mathrm{s}$ to $5 \mathrm{~m} / \mathrm{s}$ at the KYTV tower in OKlahoma.

For this reason, a matrix of 56 wind shear profiles, shown in Figure 2-3, was established to cover this large variation in wind shear profile conditions. Each wind shear profile is defined in $\Delta V$ intervals of $1 \mathrm{~m} / \mathrm{s}$ with a lower 1 imit of $\Delta V-0.50 \mathrm{~m} / \mathrm{s}$ and an upper 1 imit of $\Delta V+0.49 \mathrm{~m} / \mathrm{s}$. For example, a shear profile of $\Delta V_{L}=1.4, \Delta V_{U}=0.5$ falls into the cell $\Delta V_{L}=1, \Delta V_{U}=1$.

Sketches of the 30 innermost wind shear profiles of the matrix are displayed in Figure 2-3 for a hypothetical wind turbine with a 100-m rotor diameter and 75-m hub height, using the graphical display format shown in Figure 2-2. In this example, the $1 / 7$ power law shear profile approximates 


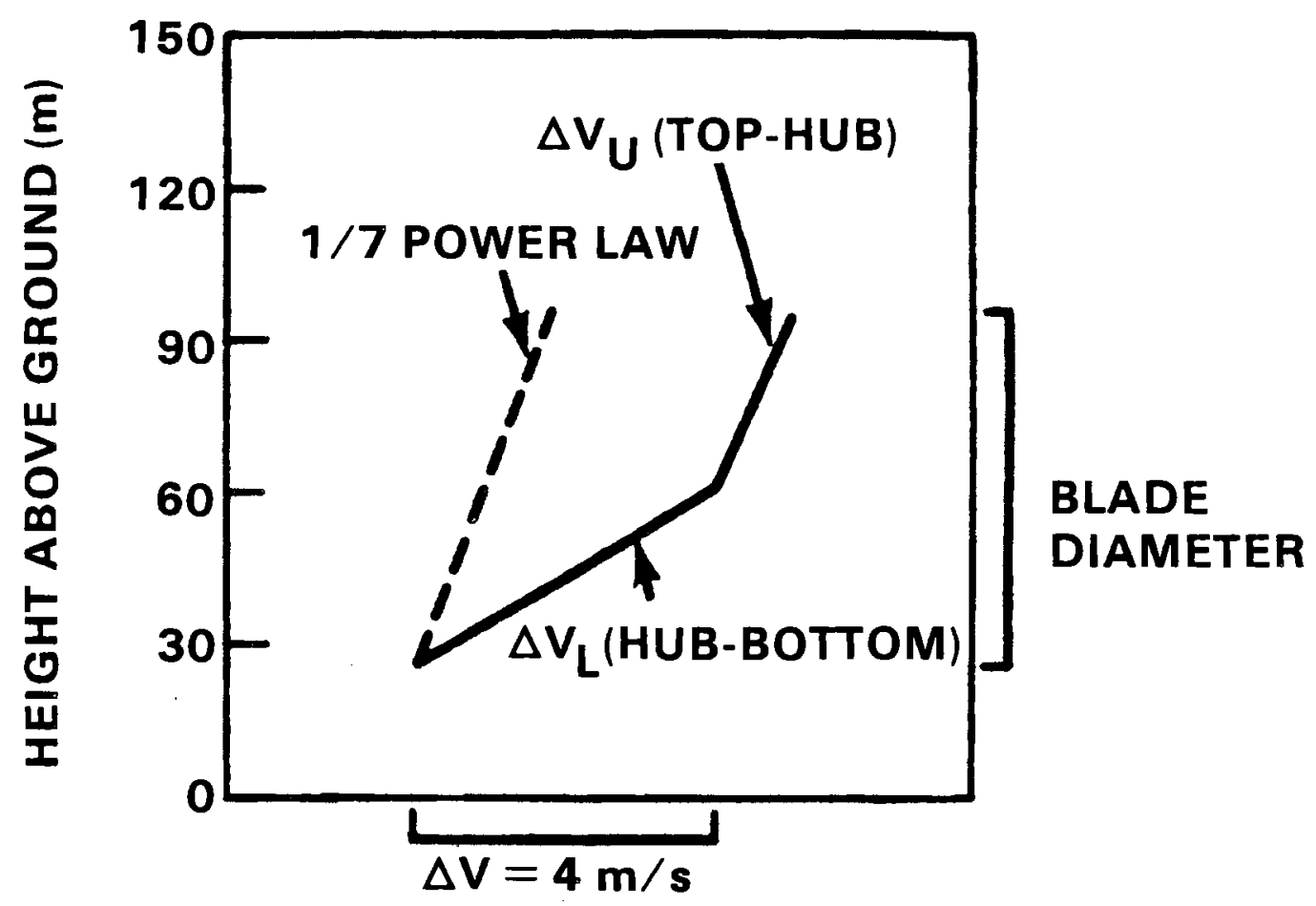

FIGURE 2-2. Schematic of a Wind Shear Profile with $\Delta V_{b}=4 \mathrm{~m} / \mathrm{s}$ and $\Delta V_{\mu}=1 \mathrm{~m} / \mathrm{s}$ Across a Hypothetical Wind Turbine of $70 \mathrm{~m}$ Rotor Diameter and $60 \mathrm{~m}$ Hub Height. In the example above, the $x$-axis $(\Delta V)$ is scaled to $10 \mathrm{~m} / \mathrm{s}$ across the length of the cel1. See Fiaure 2-3 for the total matrix of wind shear profiles. 


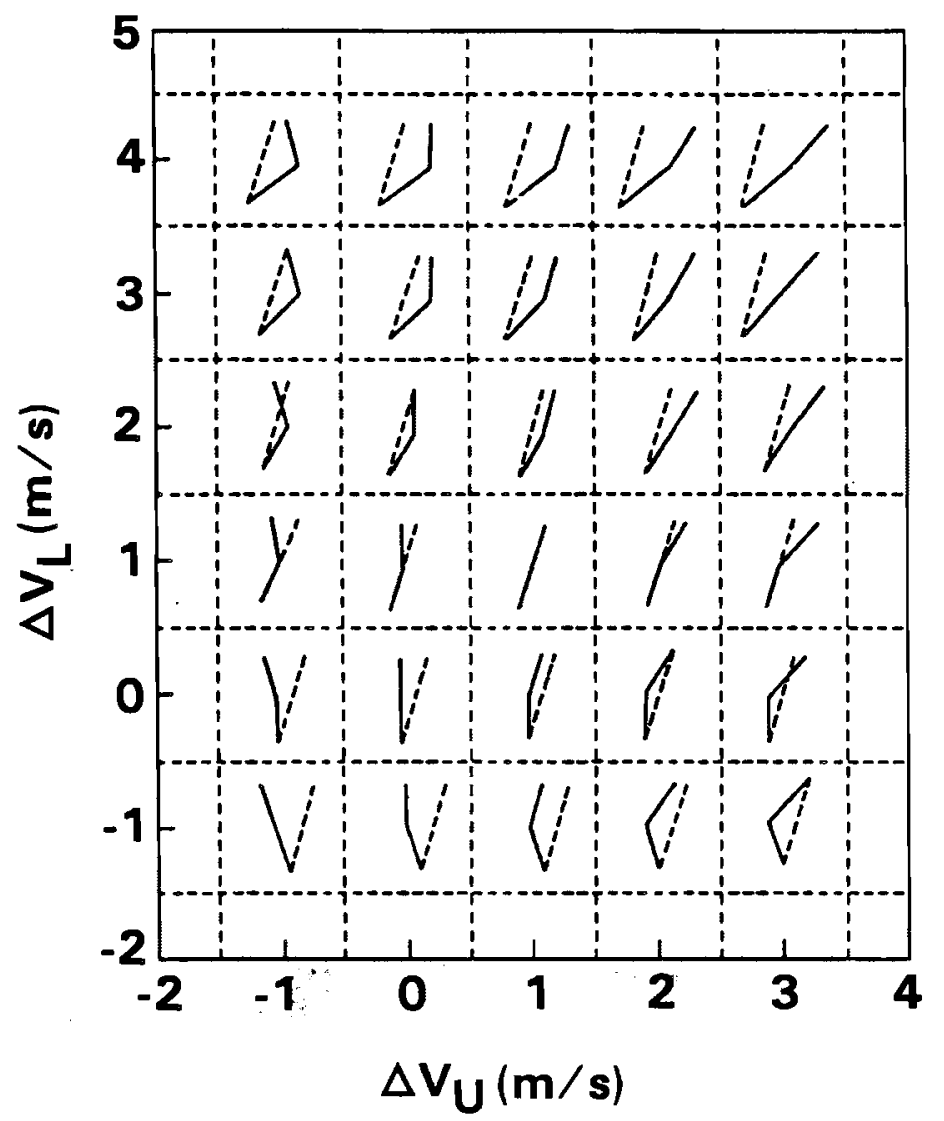

FIGURE 2-3. Matrix of Wind Shear Profiles Established for the Analysis. Sketches of the 30 innermost profiles are shown for a hypothetical wind turbine of $100-\mathrm{m}$ rotor diameter and 75-m hub height, using the graphical display format in Figure 2-2. 
a $\Delta V_{L}$ and $\Delta V_{U}$ of $1 \mathrm{~m} / \mathrm{s}$. A variety of profile shapes are represented here from very strong positive shears (large $+\Delta V)$ across the rotor diameter in the upper $r i g h t$, to no shear $(\Delta V=0)$, to large negative shear (large $-\Delta V$ ) in the lower left. Profile conditions with a maximum wind speed at hub height are indicated in the upper left, and profiles with a minimum speed at hub height in the lower right.

The percent frequency of occurrence, mean duration (in min) and mean fluctuation (in $\mathrm{m} / \mathrm{s}$ ) of the matrix of 56 wind shear profiles are presented in the analyses for each location for the selected wind turbine configuration(s), as shown in Figure 3-1 and succeeding figures. For consistency in comparing the analyses, the same matrix of wind shear profiles is used for all locations and for all wind turbine configurations.

The duration (or persistence) of a given wind shear profile is determined by allowing $\Delta V \pm 1 / 2 \mathrm{~m} / \mathrm{s}$ for sequential profiles. For example, given an initial profile in the cell $\Delta V_{L}=1, \Delta V_{U}=1$, sequential profiles must be within $0.00 \leq \Delta V_{L} \leq 1.99$ and $0.00 \leq \Delta V_{U} \leq 1.99$ to continue the duration of that cell. The duration of each wind shear profile is defined in minutes from the initial occurrence. For example, three consecutive 10-s wind shear profiles within the same cell give a duration of $0.50 \mathrm{~min}$. The minimum possible duration (10 s) appears as $0.17 \mathrm{~min}$ in the mean duration analyses. In the case of 2-min instantaneous sampled data, the minimum duration is 2 min.

Fluctuation is defined as the absolute value of the magnitude of the sum of the $\Delta V$ changes (in $\mathrm{m} / \mathrm{s}$ ) in sequential profiles. In terms of a mathematical expression, fluctuation can be expressed as

$$
F=\left|\Delta V_{L}(t)-\Delta V_{L}(t-1)\right|+\left|\Delta V_{U}(t)-\Delta V_{U}(t-1)\right|
$$

where $t=$ current time and $t-1=$ previous $t$ ime. 
Examples of fluctuation are shown in Figure 2-4.

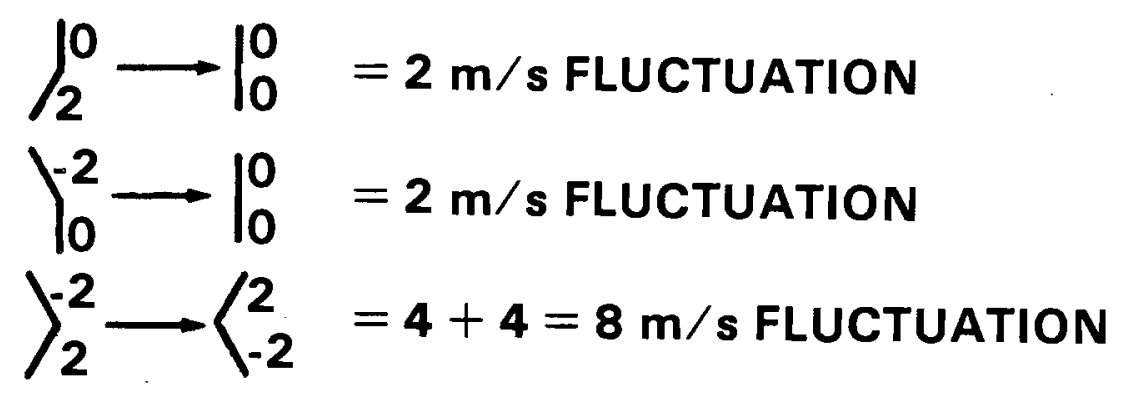

FIGURE 2-4. Examples of the Magnitude of the Fluctuation Between Sequential Wind Shear Profiles

The percent frequency of occurrence, mean duration and mean fluctuation of each wind shear profile within the matrix were computed for the selected wind turbine configuration(s) for each location using data from windy hours from selected winter and summer periods at each location. In addition to the analyses over all windy hours in each seasonal period, analyses were carried out for day and night periods within each season.

For each seasonal period used, the mean number of daylight hours were computed using the appropriate latitude for each location. To allow for variations of the sunrise and sunset times throughout a seasonal period and for longitudinal variations within a time zone, a transition period of four hours was allowed around the computed mean sunrise and mean sunset times. The daytime period used was from two hours after the mean sunrise to two hours before the mean sunset. The nighttime period was from two hours after the mean sunset to two hours before the mean sunrise. Allowing for these transition periods served to provide for a more representative comparison of the wind shear profile characteristics for day and night periods. Additionally, the shear profile characteristics of the transition periods could be analyzed, providing an indication of the changes in the wind shear profile characteristics through the whole diurnal cycle. 
Table 2-2 gives the day, night and transition periods determined for use in the analysis of wind shear profiles at Goodnoe Hills. Note that the length of the day and night periods vary considerably from summer to winter. The fact that the day and night are not of equal length must be kept in mind in the interpretation of the wind shear profile analyses.

TABLE 2-2. Determination of Day, Night and Transition Periods at Goodnoe Hills. The wind data used for the summer period were from July-August 1980, and the data used for the winter period were from November-December 1980. Al1 times are LST in decimal hours.

\begin{tabular}{|c|c|c|}
\hline & $\begin{array}{c}\text { Mean } \\
\text { Sunrise } \\
\text { (LST) } \\
\end{array}$ & $\begin{array}{c}\text { Mean } \\
\text { Sunset } \\
\text { (LST) } \\
\end{array}$ \\
\hline July-August (Summer) & 5.44 & 18.56 \\
\hline November-December (Winter) & 7.74 & 16.26 \\
\hline
\end{tabular}

\begin{tabular}{|c|c|c|c|c|c|c|}
\hline \multirow[b]{2}{*}{ Period } & \multicolumn{2}{|c|}{ (LST) } & \multicolumn{2}{|c|}{ (LST } & \multicolumn{2}{|c|}{ Hours } \\
\hline & Summer & Winter & Summer & Winter & Summer & Winter \\
\hline Day & 7.44 & 9.74 & 16.56 & 14.26 & 9.12 & 4.52 \\
\hline Night & 20.56 & 18.26 & 3.44 & 5.74 & 6.88 & 11.48 \\
\hline Transition-to-Day & 3.44 & 5.74 & 7.44 & 9.74 & 4.00 & 4.00 \\
\hline Transition-to-Night & 16.56 & 14.26 & 20.56 & 18.26 & 4.00 & 4.00 \\
\hline
\end{tabular}




\subsection{RESULTS OF WIND SHEAR PROFILE ANALYSES}

This section presents the results of the wind shear profile analyses for each of the three locations in Oklahoma, Wyoming and Washington and provides a comparison of shear profiles at the three locations. Analyses of the percent frequency of occurrence, mean duration and mean fluctuation of a matrix of 56 wind shear profiles are described for all three types of wind turbine configurations at the Oklahoma tower location and for the Type 1 turbine at the tower locations in Wyoming and Washington. At each location, the analyses are presented for winter versus summer and day versus night. The analyses at the Oklahoma location are based on 10-s instantaneous wind measurement samples, whereas the analyses at the Wyoming and Washington locations are based on 2-min instantaneous wind measurement samples. Comparisons of the analysis results using 10-s data versus 2-min data from the KYTV Tower in Oklahoma are presented for identical time periods.

Duration probability exceedance curves are presented for each location for winter versus summer and day versus night. From these curves, the average percentage of time that an individual wind shear profile exceeded a given duration can be determined. Duration probability exceedance curves are also presented for selected wind shear profiles, to provide an indication of the variability of the duration distribution with respect to different wind shear profiles.

The contours used in the analyses of percent occurrence and mean duration are $0.5,1.0,2: 0$, and subsequently in intervals of 2.0. The contours of mean fluctuation are in intervals of 0.5 ; e.g., $0.5,1.0,1.5$, etc. Values are shown only for the 30 innermost wind shear profiles of the matrix, whereas values are contoured for the entire matrix of 56 profiles. 


\subsection{KYTV TOWER-OKLAHOMA}

Contour analyses of the percent frequency of occurrence, mean duration and mean fluctuation of the matrix of wind shear profiles are shown for winter versus summer and day versus night periods for the three types of wind turbines in Figures 3-1 through 3-9. These analyses are based on instantaneous 10-s sampled winds from windy hours at the KYTV tower.

\subsubsection{Type 1 Turbine}

Analyses of winter versus summer for a Type 1 turbine are shown in Figure 3-1. A broader distribution in the occurrence of wind shear profiles in winter than summer is indicated. There is a greater frequency of strong wind shears (e.g., $\Delta V \geq 6 \mathrm{~m} / \mathrm{s}$ over the rotor diameter) in winter than in summer, whereas the summer exhibits a greater frequency of weak shears $\left(\Delta V_{L}\right.$ and $\left.\Delta V_{U} \approx 0 \mathrm{~m} / \mathrm{s}\right)$ than the winter. Strong shears in the winter, depicted by cells in the upper right part of the matrix in Figure 3-1, usually persist for longer durations and fluctuate less than other profiles in the matrix. A notable exception is the shear profile $\Delta V_{L}=2$ and $\Delta V_{U}=-1$, which has a relatively long mean duration of $2.5 \mathrm{~min}$. This shear profile has a maximum wind speed at hub-height level, and for such a long duration may be indicative of a low-level jet associated with very stable atmospheric conditions. This condition occurred only in the transition to day period and, for this reason, is not evident in the daytime or nighttime analyses shown in Figures 3-2 and 3-3.

The maximum mean duration in winter for a wind shear profile is $7.1 \mathrm{~min}$, associated with the profile $\Delta V_{L}=4$ and $\Delta V_{U}=2$. This duration corresponds to an average of over 42 consecutive 10 -s occurrences of this wind shear profile. The mean fluctuation of this shear profile is only $1.2 \mathrm{~m} / \mathrm{s}$. Exclusive of the strong shear conditions and the low-level jet anomaly, mean durations in winter are generally less than $0.5 \mathrm{~min}$, which corresponds to less than 3 consecutive 10-s occurrences. This indicates that the wind 

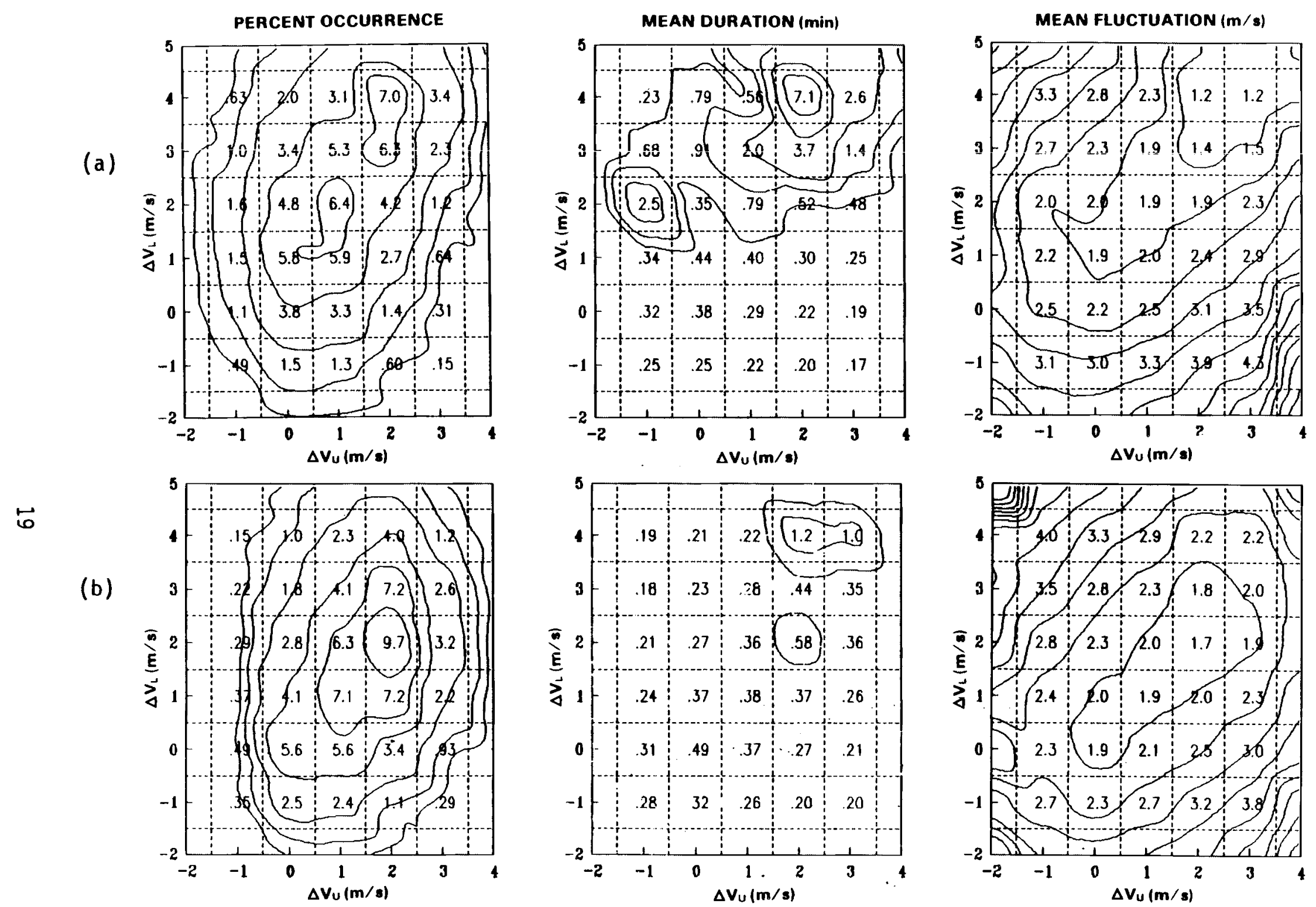

FIGURE 3-1. Frequency of Occurrence, Mean Duration, and Mean Fluctuation of Wind Shear Profiles for a Type 1 Turbine using 10-s Sampled Winds from the KYTV Tower in Oklahoma City, Oklahoma, for (a) Winter (January 1977) and (b) Summer (July 1977). 
(a)
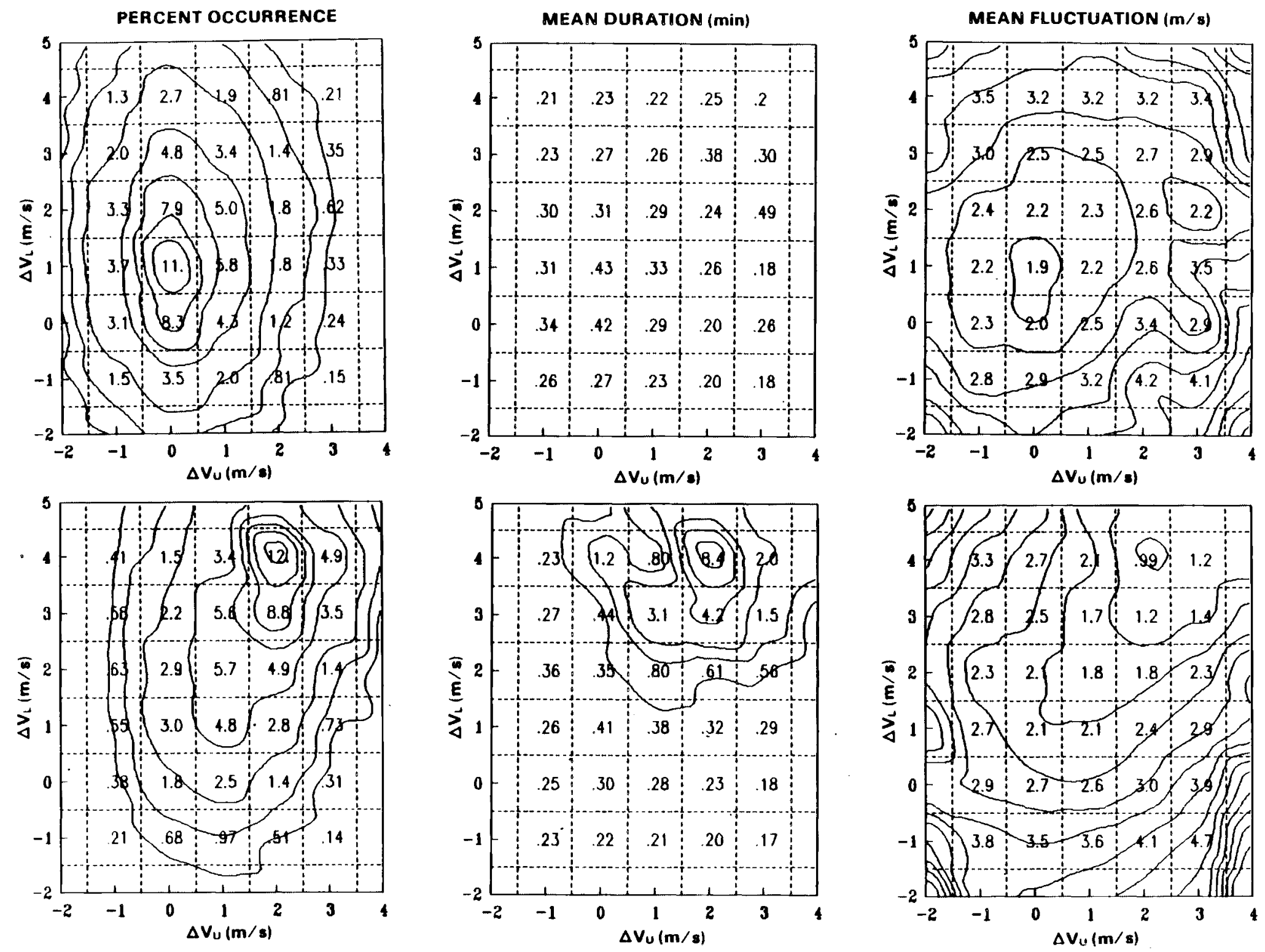

FIGURE 3-2. KYTV Oklahoma City, Oklahoma, Type I Turbine for (a) Winter Day and (b) Winter Night. See Figure 3-1 for detail. 
(a)

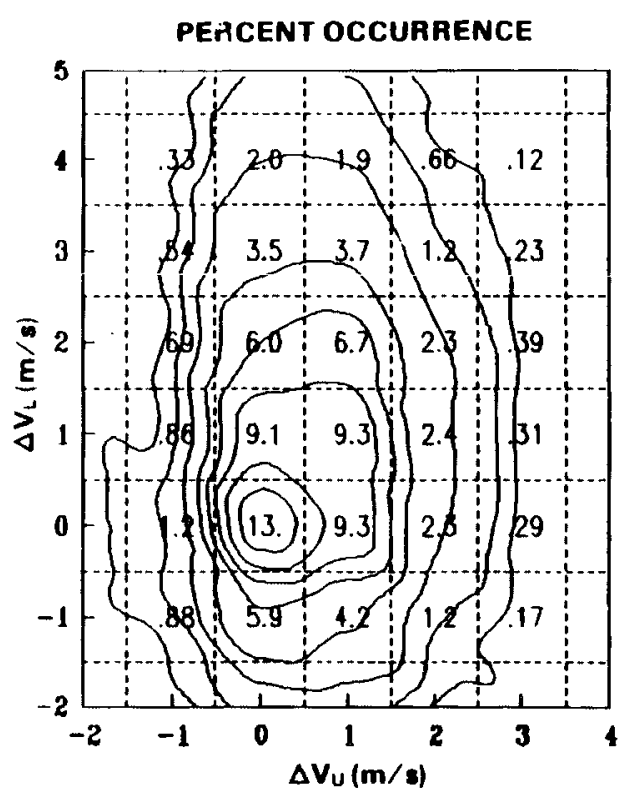

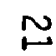

(b)

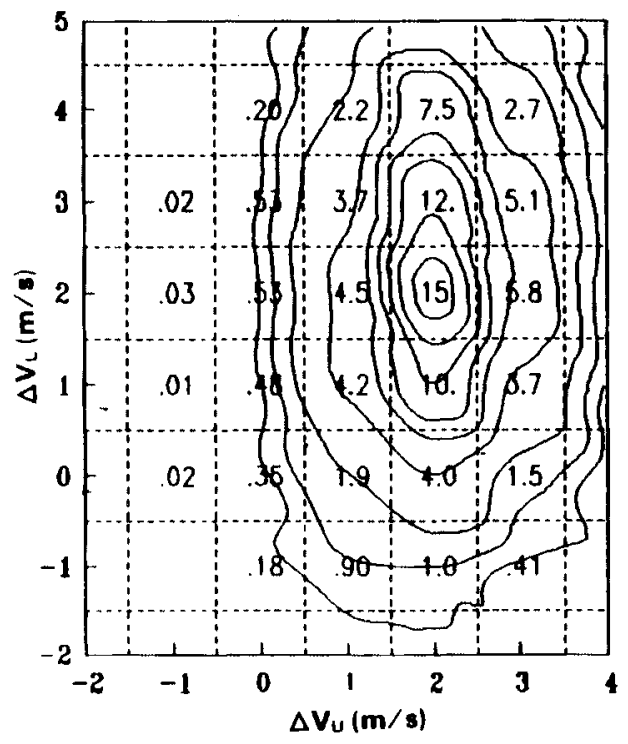

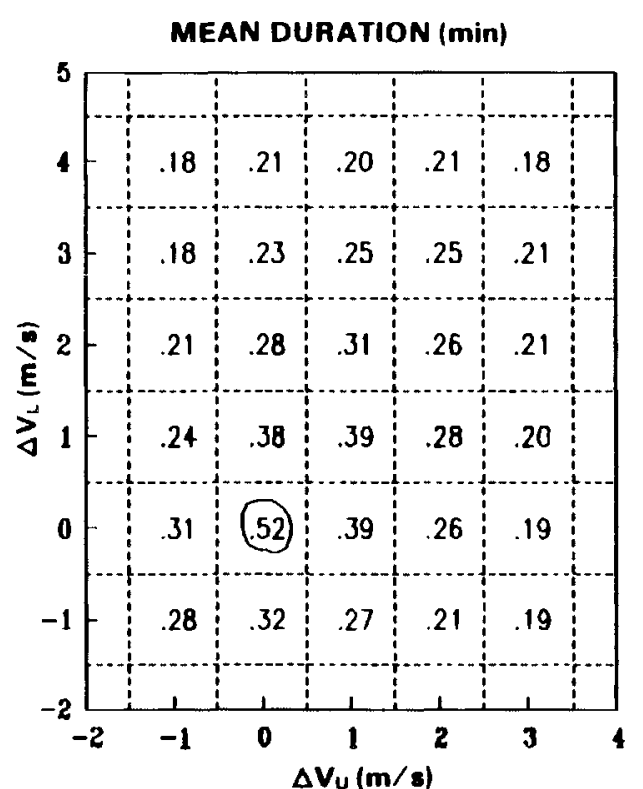
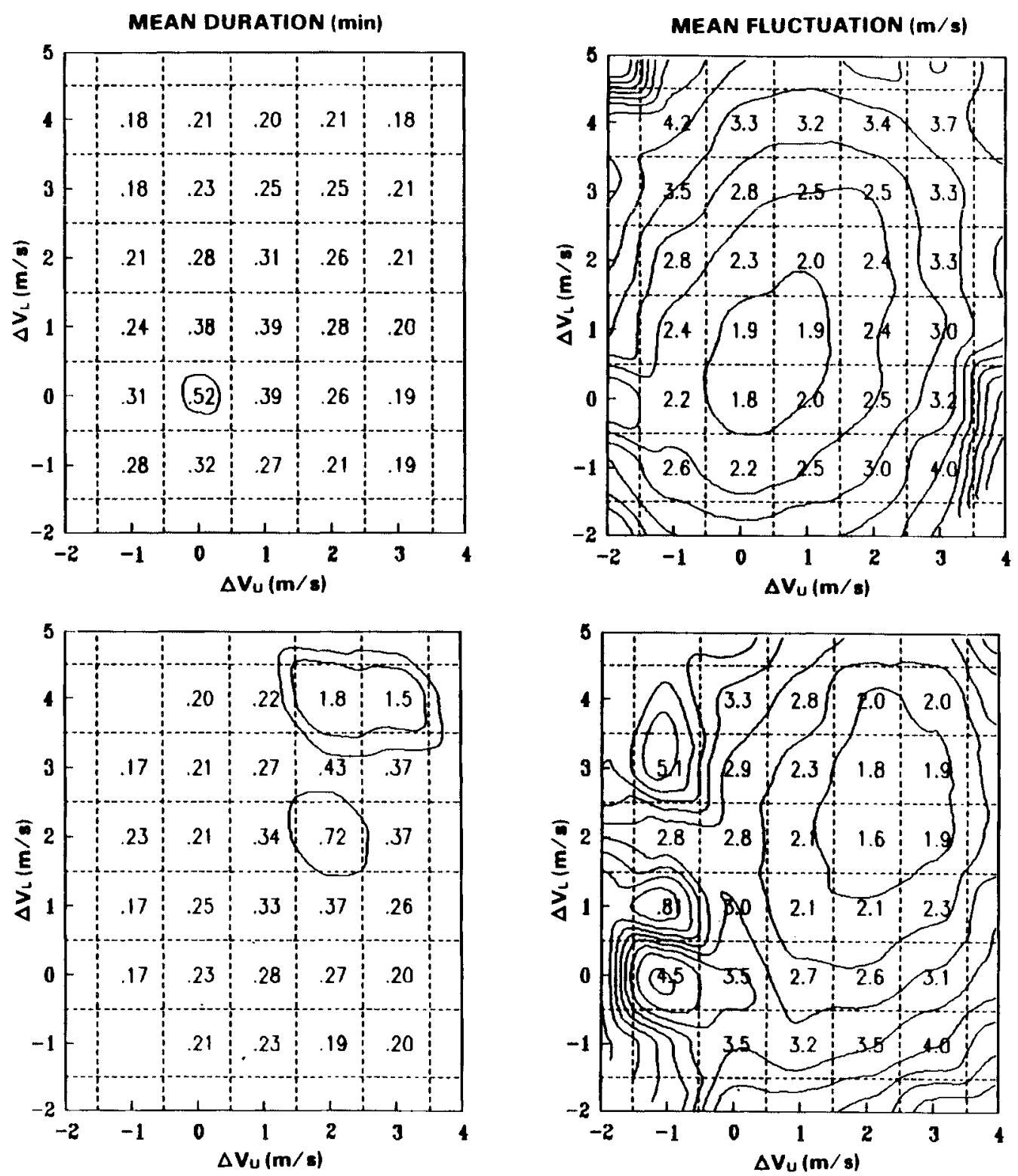

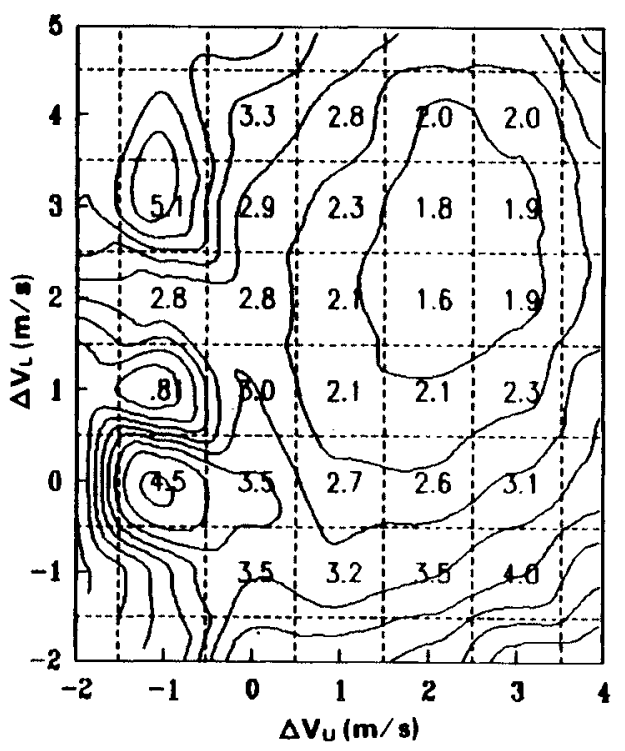

FIGURE 3-3. KYTV 0klahoma City, Oklahoma, Type 1 Turbine for (a) Summer Day and (b) Summer Night. See Figure 3-l for detail. 
shear profiles are frequently changing several times in a minute, with mean fluctuations on the order of 2 to $3.5 \mathrm{~m} / \mathrm{s}$. Mean fluctuations greater than $3.5 \mathrm{~m} / \mathrm{s}$ are shown only for the infrequent shear profiles in upper left ( large $\Delta V_{L}$ and negative $\Delta V_{U}$ ) and lower right (negative $\Delta V_{L}$ and large $\Delta V_{U}$ ) portions of the matrix.

In summer, mean durations are relatively short ( $<0.5 \mathrm{~min}$.$) for the$ majority of wind shear profiles. The maximum mean duration in summer for a wind shear profile is only $1.2 \mathrm{~min}$, compared to $7.1 \mathrm{~min}$ for the same shear profile in winter. Mean fluctuations in summer are comparable to those in winter, except for strong shears (in the upper right) which fluctuate less in winter than in summer.

Analyses of day versus night periods are shown in Figure 3-2 for winter and in Figure 3-3 for summer. In winter, there are dramatic differences between day and night in the distribution of the percent occurrence, mean duration, and mean fluctuation of shear profiles. Nighttime shears are typically much stronger (larger $\Delta V$ across the rotor diameter), persist longer, and fluctuate less than daytime profiles in winter. However, only strong nighttime shear conditions (in the upper right) have long mean durations in winter. All other wind shear profiles during the nighttime have relatively short mean durations. In the daytime, all wind shear profiles have relatively short mean durations $(<0.5 \mathrm{~min})$. Strong shears in the daytime are infrequent and of short durations. Strong nighttime shears in the summer persist for shorter durations and have larger fluctuations than strong nighttime shears in winter. For the daytime period in summer, all shear profiles have short mean durations $(<0.5 \mathrm{~min})$. The most frequent shear profile in summer daytime is $\Delta V_{L}=0$ and $\Delta V_{U}=0$, the no-shear condition. This profile rarely occurs at night. The no-shear condition, or uniform wind speed throughout the height of the turbine, is of short duration and is indicative of well-mixed, turbulent atmospheric conditions.

The mean duration and mean fluctuation of daytime shear profiles in summer are very comparable to those of daytime profiles in winter. However, nighttime shows considerable difference between winter and summer in the 
intensity of the shears and in the distribution of mean durations and mean fluctuations. Summer nights appear to have a substantially higher percentage of turbulent, fluctuating shear profiles than do winter nights.

\subsubsection{Type 2 Tubrine}

Analyses for the Type 2 turbine are shown in Figures 3-4 through 3-6. This is the largest of the three turbine configurations, spanning a rotor diameter of $128 \mathrm{~m}(420 \mathrm{ft})$ with a ground clearance of $12 \mathrm{~m}(40 \mathrm{ft})$. In these analyses, $\Delta V_{L}$ represents a height range from $12 \mathrm{~m}$ to $76 \mathrm{~m}(40 \mathrm{ft}$ to $250 \mathrm{ft}$ ), and $\Delta V_{U}$ represents a height range from $76 \mathrm{~m}$ to $140 \mathrm{~m}$ (250 ft to $460 \mathrm{ft}$ ).

It is apparent from Figure 3-4 that $\Delta V_{L}$ has a much wider distribution than $\Delta V_{U}$, especially in winter. The analysis indicates that, in winter, shears are frequently three to five times greater in lower half of the disk of rotation than in the upper half. It is evident from Figure 3-5 that these profile conditions predominantly occur at night and are generally of long duration and small fluctuation, indicative of laminar flow in stable atmospheric conditions. However, the most persistent (greatest mean duration) nighttime profile in winter is $\Delta V_{L}=5$ and $\Delta V_{U}=0$, very strong shear in the lower half of the disk of rotation and no shear in the upper half.

The frequency distribution of nighttime profiles in winter is significantly different from that in summer. In summer nighttime, a high percentage of strong shears with equal magnitude over the upper and lower half occurs (such as $\Delta V_{L}=3$ and $\Delta V_{U}=3$ ), whereas in winter night there is a higher percentage of strong shears in the lower half associated with weak shears in the upper half (such as $\Delta V_{L}=5$ and $\Delta V_{U}=1$ ).

There is a dramatic difference in the frequency distribution of wind shear profiles for summer day versus summer night. The most frequent shear profiles in day (e.g., $\Delta V_{L}=0$ and $\Delta V_{U}=0$ ) are practically nonexistent at night, whereas the most frequent shear profiles at night (e.g., $\Delta V_{L}=3$ and $\Delta V_{U}=3$ ) are practically nonexistent in day. In winter, the differences in the day versus night frequency distributions of wind shear profiles are also large, but not as dramatic as in the summer. 

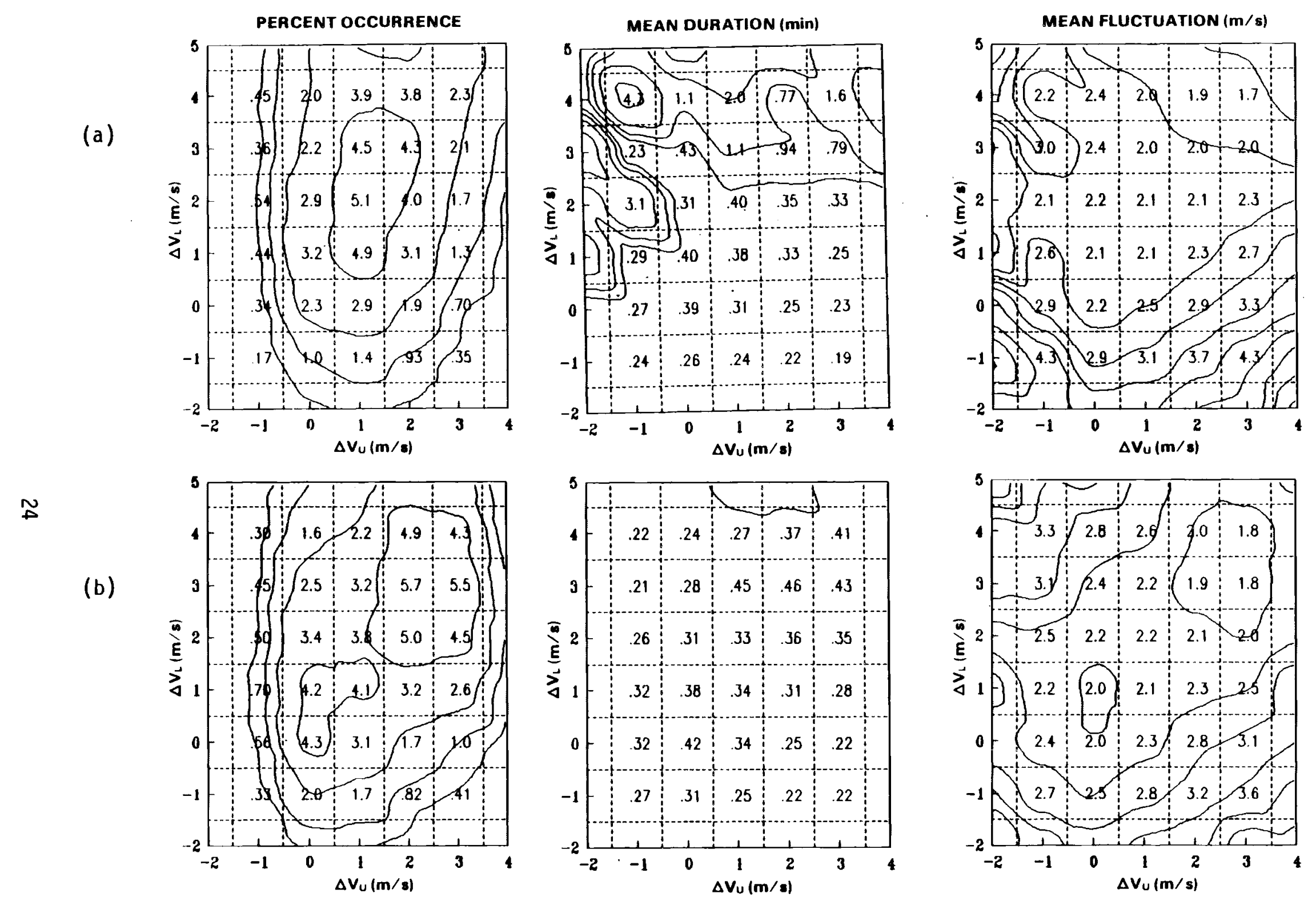

FIGURE 3-4. KYTV 0klahoma City, Oklahoma, Type 2 Turbine for (a) Winter and (b) Summer. See Figure 3-1 for detail. 
(a)
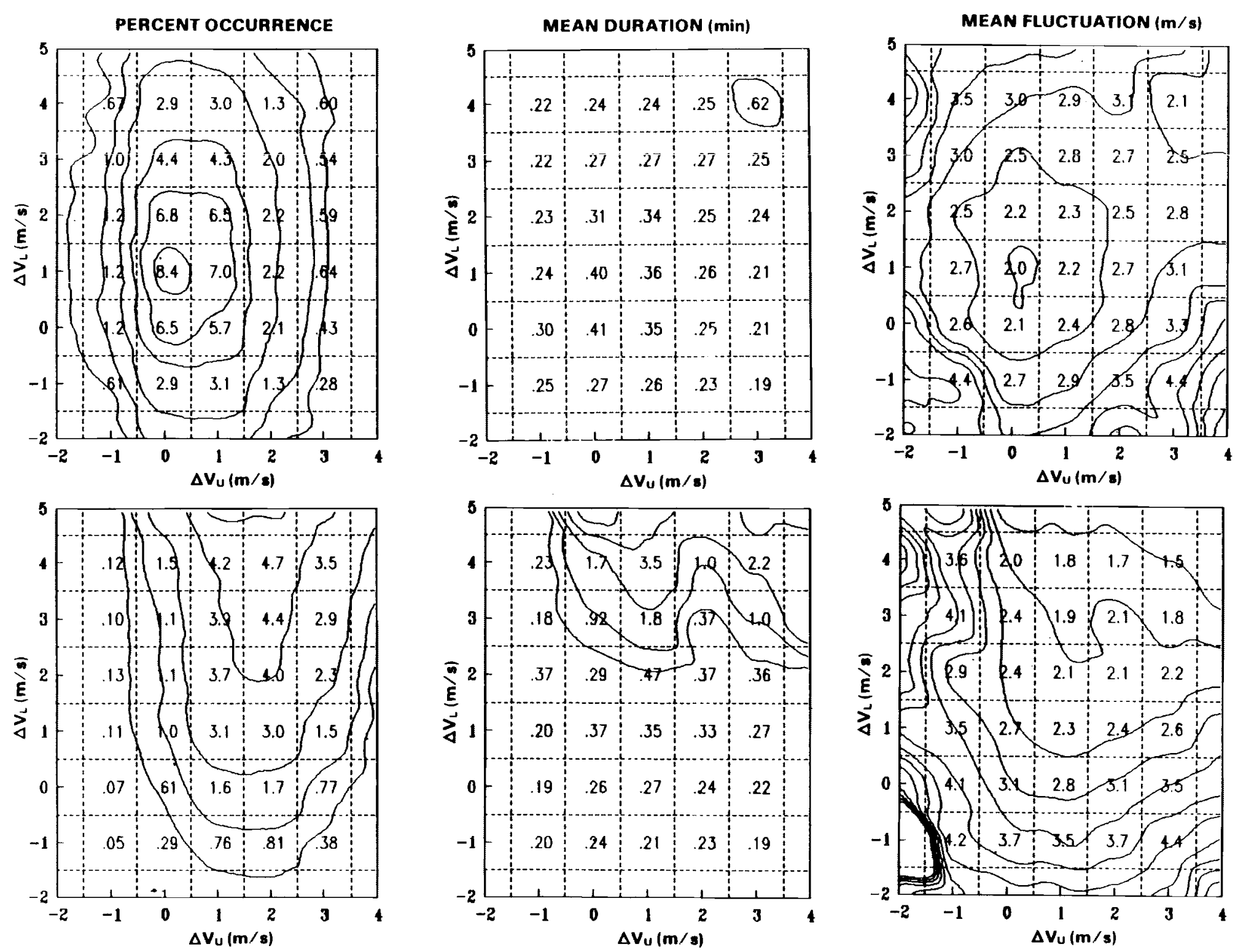

FIGURE 3-5. KYTV Oklahoma City, Oklahoma, Type 2 Turbine for (a) Winter Day and (b) Winter Night. See Figure 3-1 for detail. 
(a)
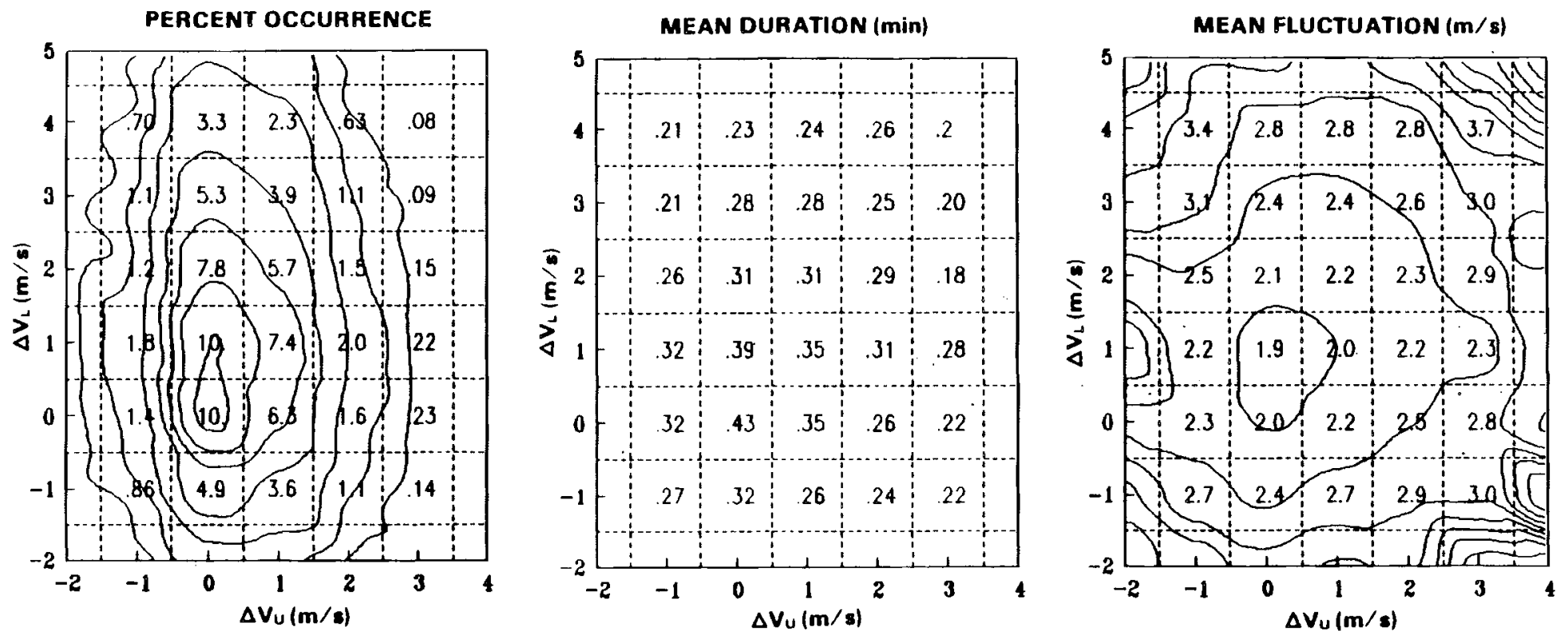

ณ
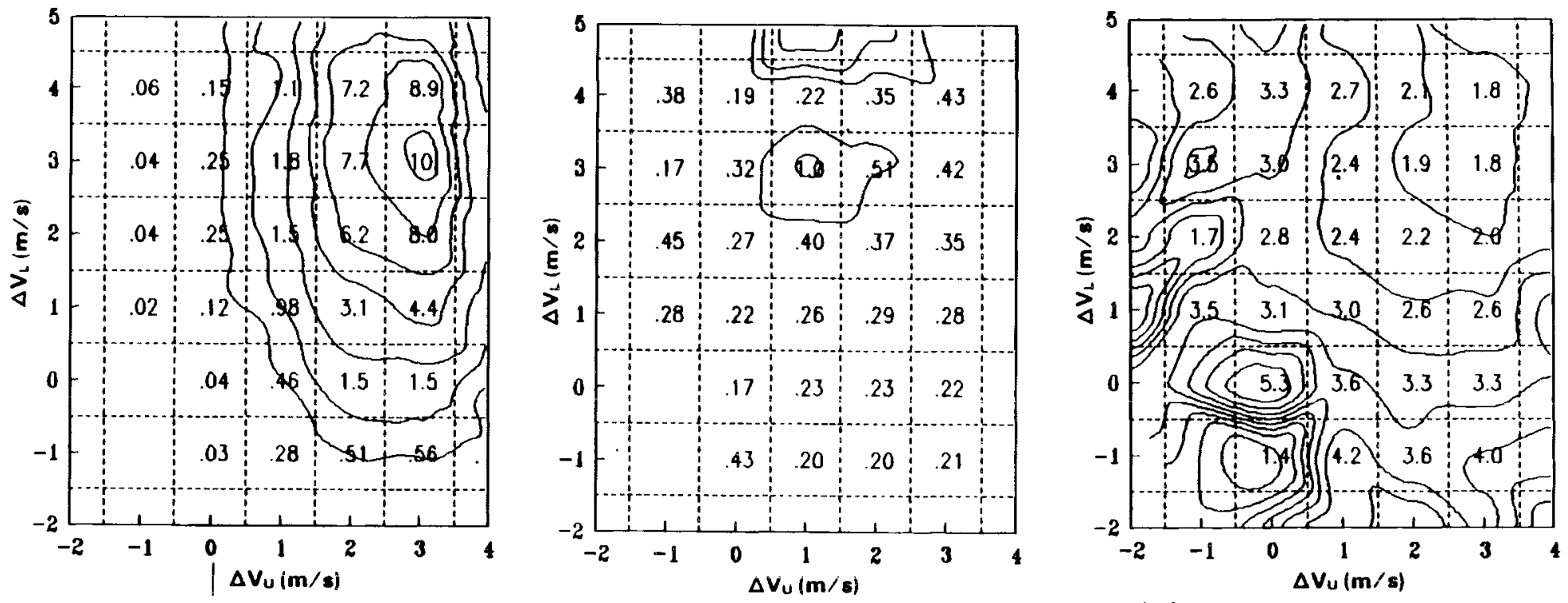

FIGURE 3-6. KYTV Oklahoma City, Oklahoma, Type 2 Turbine for (a) Summer Day and (b) Summer Night. See Figure 3-1 for detail. 
In summer, mean durations are short $(<0.5 \mathrm{~min})$ for the frequent strong shear profiles at night, such as $\Delta V_{L}=3$ and $\Delta V_{U}=3$, as well as for the no-shear or weak shear profiles in day, such as $\Delta V_{L}=0$ and $\Delta V_{U}=0$. Thus, the strong shears at night in summer appear to fluctuate almost as much as the weak shears (well-mixed conditions) of day in summer. The magnitudes of the mean fluctuations of the strong night shears and weak day shears are 1.8 to $2.0 \mathrm{~m} / \mathrm{s}$.

In winter, this is not the case as the majority of strong nighttime shear profiles have significantly longer mean durations than do the daytime profiles.

Infrequent occurrences of persistent shear profiles with large $\Delta V_{L}$ and negative $\Delta V_{U}$ (e.g., $\Delta V_{L}=4$ and $\Delta V_{U}=-1$ ) are evident in winter (all hours) in Figure 3-4. These shear profiles occurred in transition to day period and, for this reason, are not reflected in the winter day or nighttime analyses in Figure 3-5.

\subsubsection{Type 3 Turbine}

Analyses for the Type 3 turbine are shown in Figures 3-7 through 3-9. This turbine has the highest ground clearance $(41 \mathrm{~m}$ or $135 \mathrm{ft}$ ) and smallest rotor diameter $(78 \mathrm{~m}$ or $256 \mathrm{ft}$ ) of the three turbine configurations. In these analyses, $\Delta V_{L}$ represents a height range from $41 \mathrm{~m}$ to $80 \mathrm{~m}$ (135 ft to $263 \mathrm{ft}$ ), and $\Delta V_{U}$ represents a height range from $80 \mathrm{~m}$ to $119 \mathrm{~m}(263 \mathrm{ft}$ to $391 \mathrm{ft})$.

It is evident from an examination of Figures 3-7 through 3-9 that the Type 3 turbine exhibits a smaller frequency distribution of wind shear profiles, longer mean durations, and smaller mean fluctuations than the Type 1 and Type 2 turbines. Apparently, this is due to the significantly higher ground clearance and smaller rotor diameter of the Type 1 turbine. As with the Type 1 and Type 2 turbines, the frequency distribution of $\Delta V_{L}$ is significantly wider than that of $\Delta V_{U}$ for the Type 3 turbine, which indicates a greater range of shear profiles over the lower half than over the upper half of the rotor disk. 
(a)
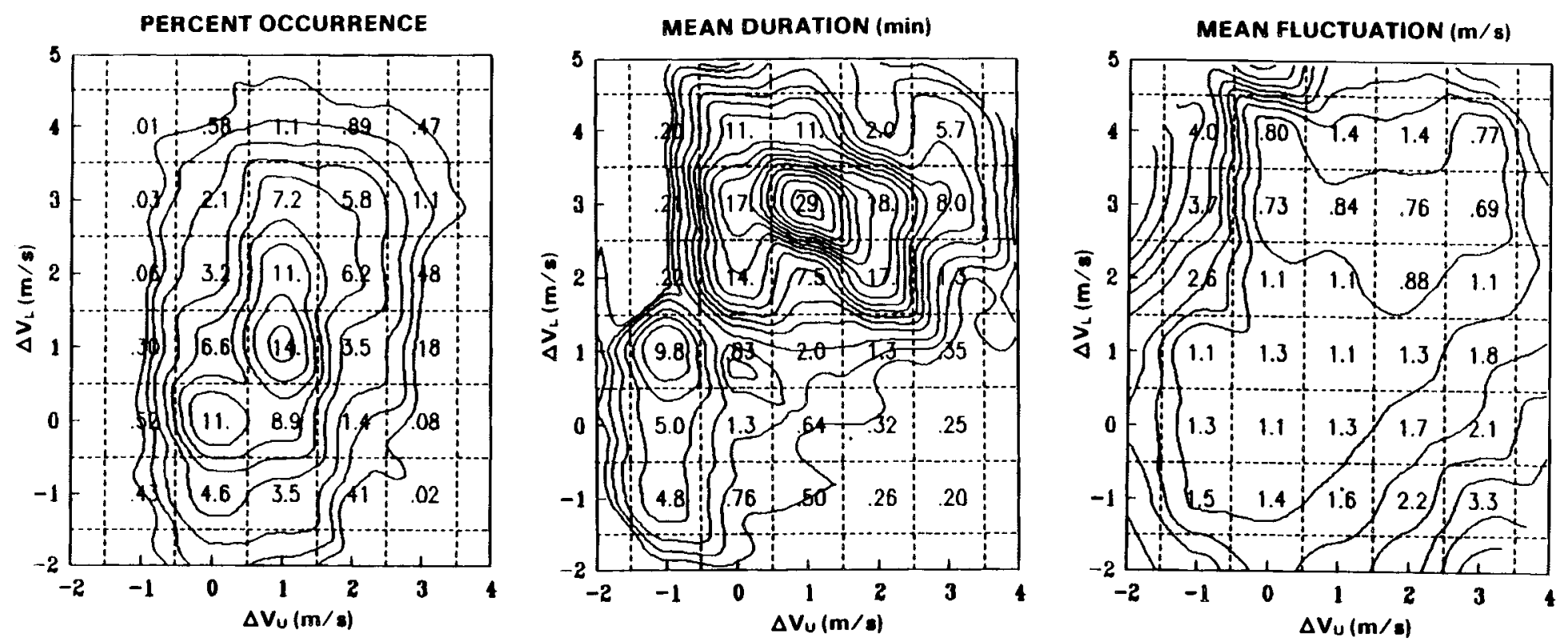

$\widetilde{\infty}$
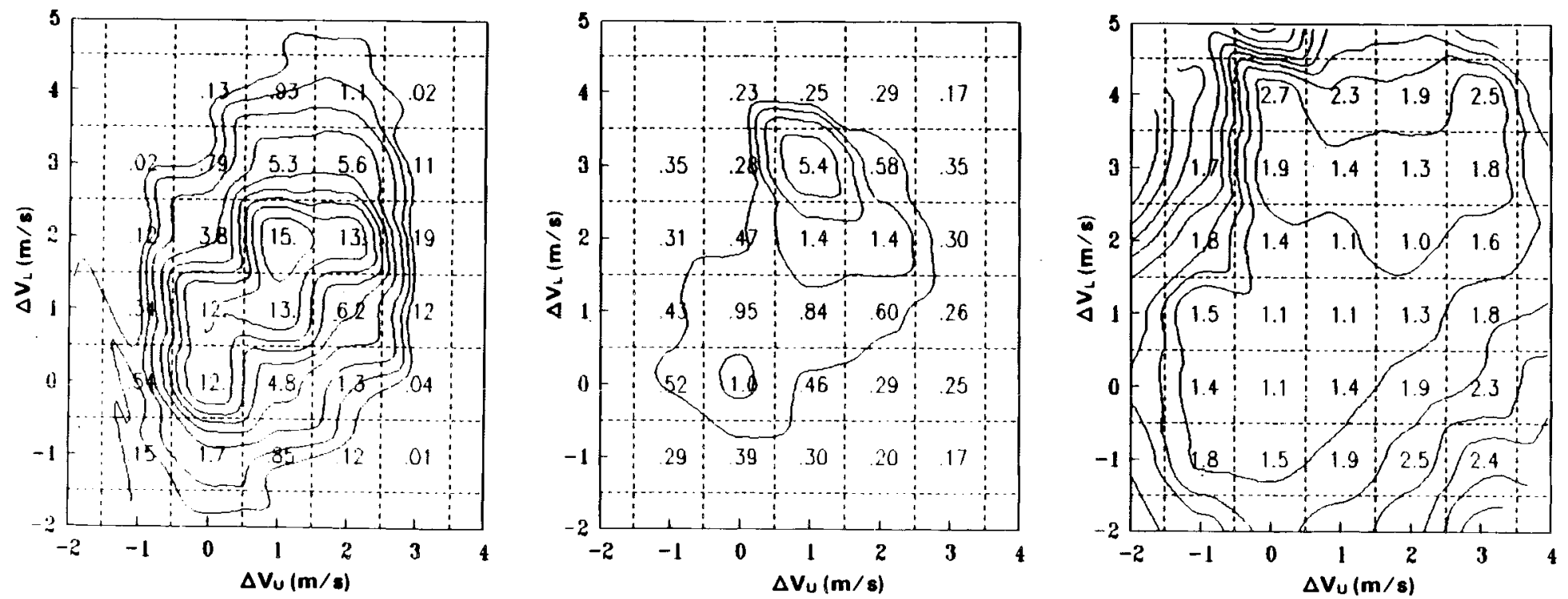

FIGURE 3-7. KYTV Oklahoma City, Oklahoma, Type 3 Turbine for (a) Winter and (b) Summer. See Figure 3-1 for detail. 
(a)

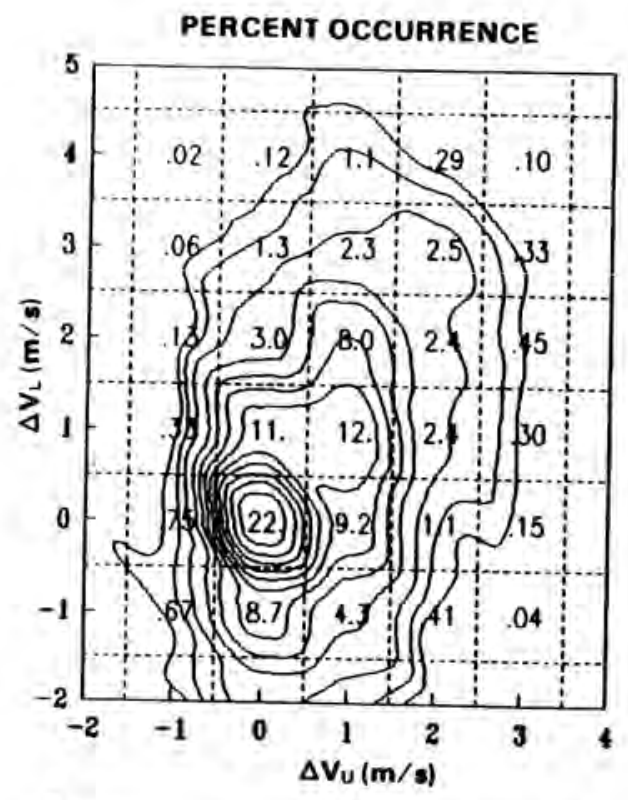

ก

(b)

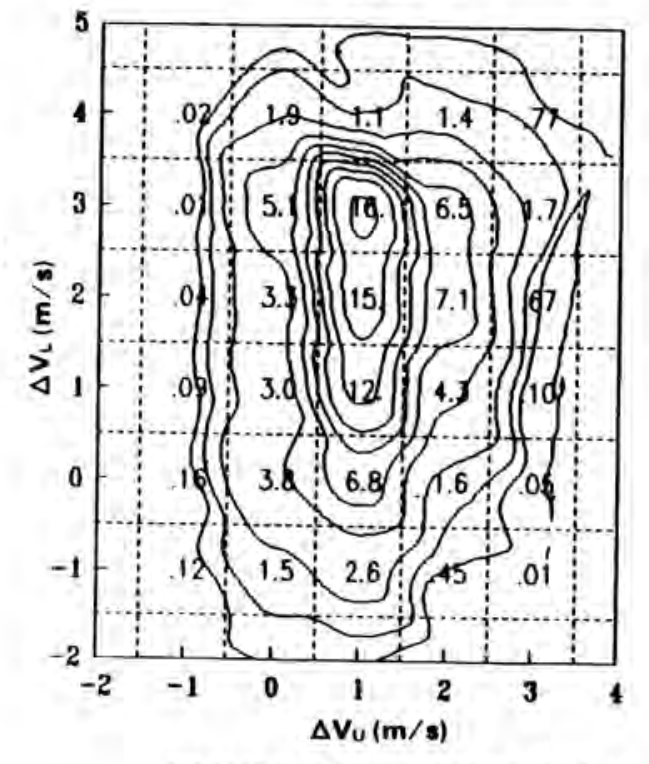

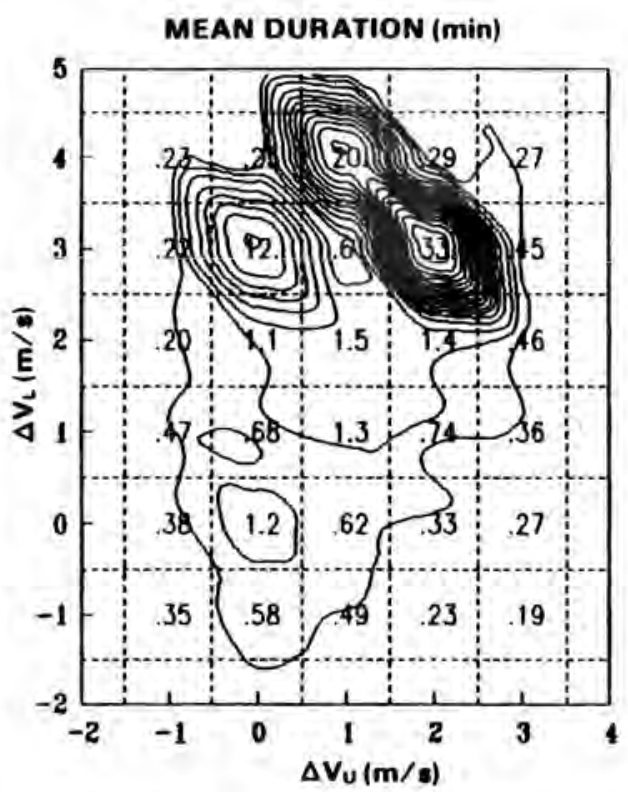
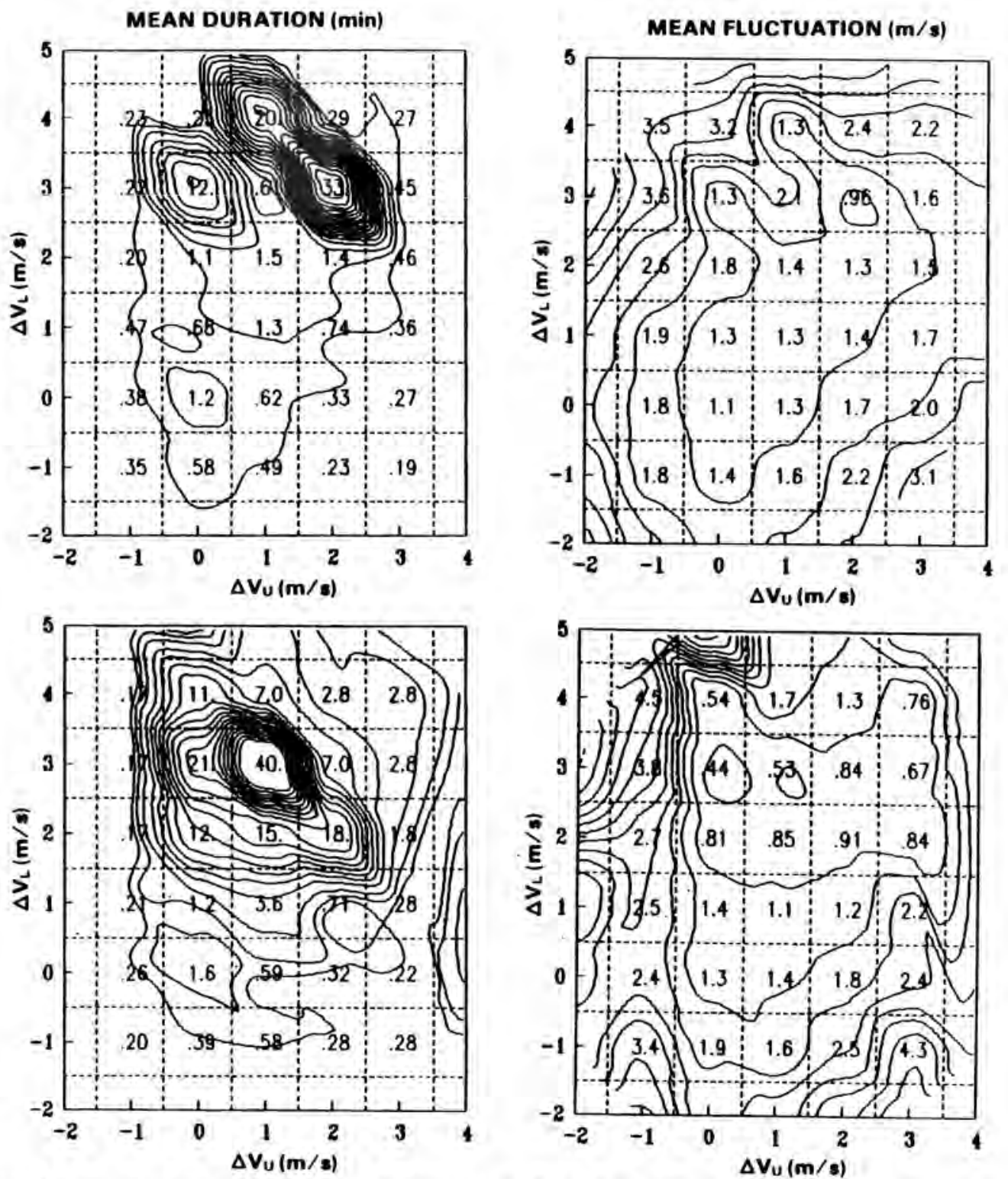

FIGURE 3-8. KYTV Oklahoma City, Oklahoma, Type 3 Turbine for (a) Winter Day and (b) Winter Night. See Figure 3-1 for detail. 
(a)

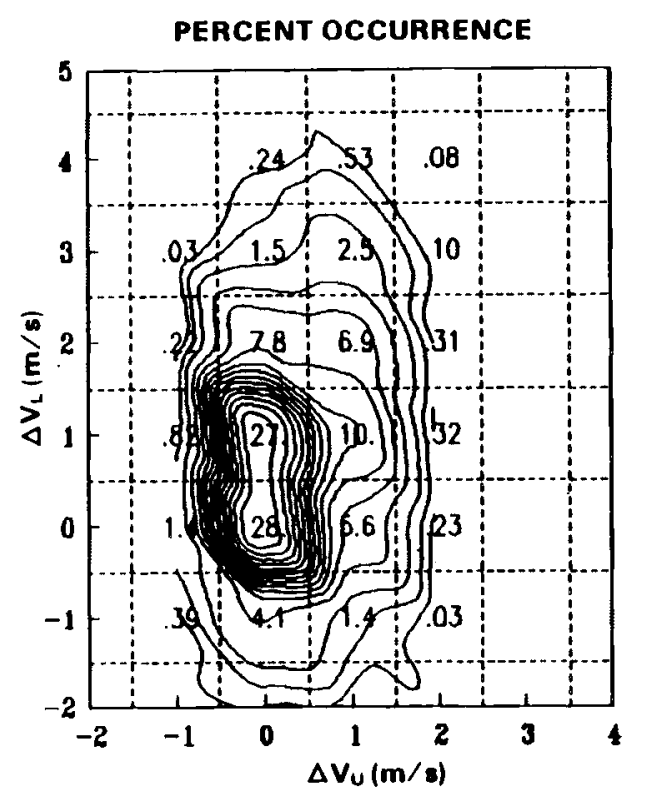

$\stackrel{\omega}{\circ}$

(b)

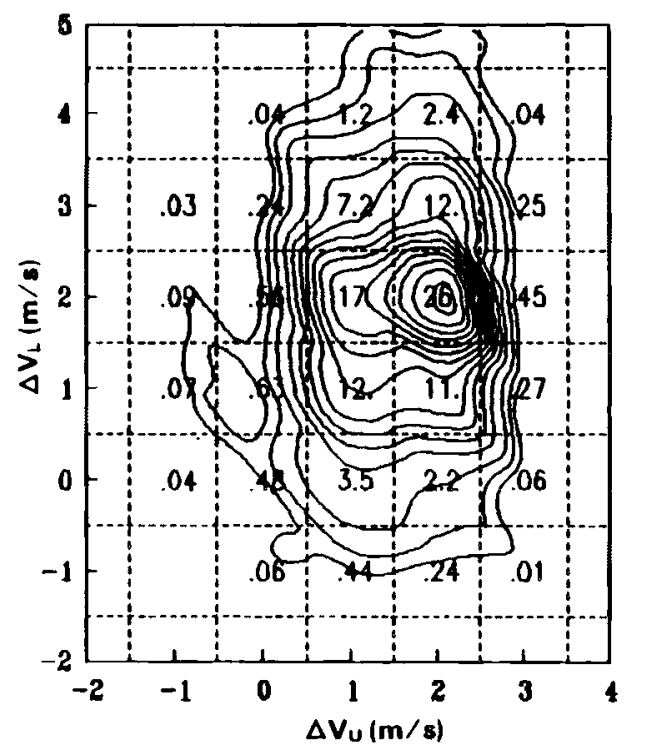

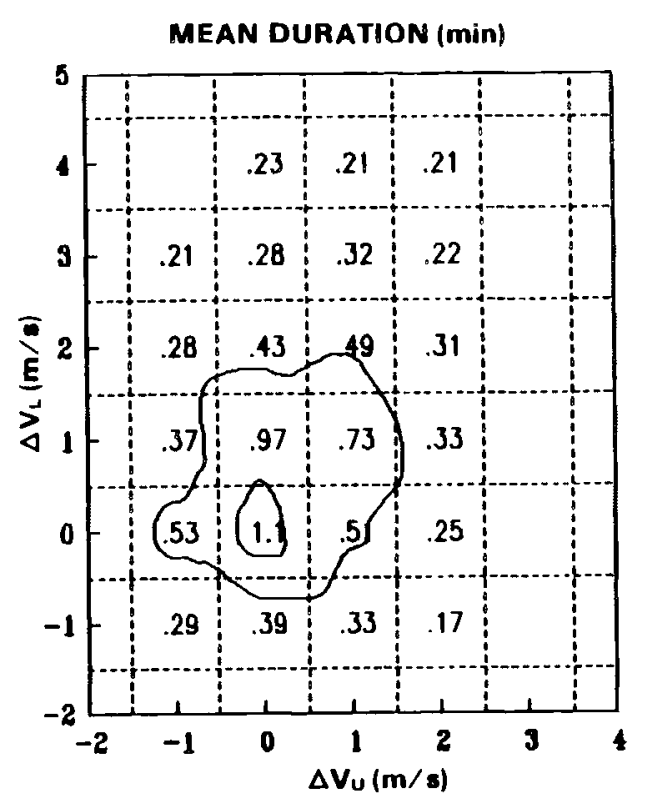
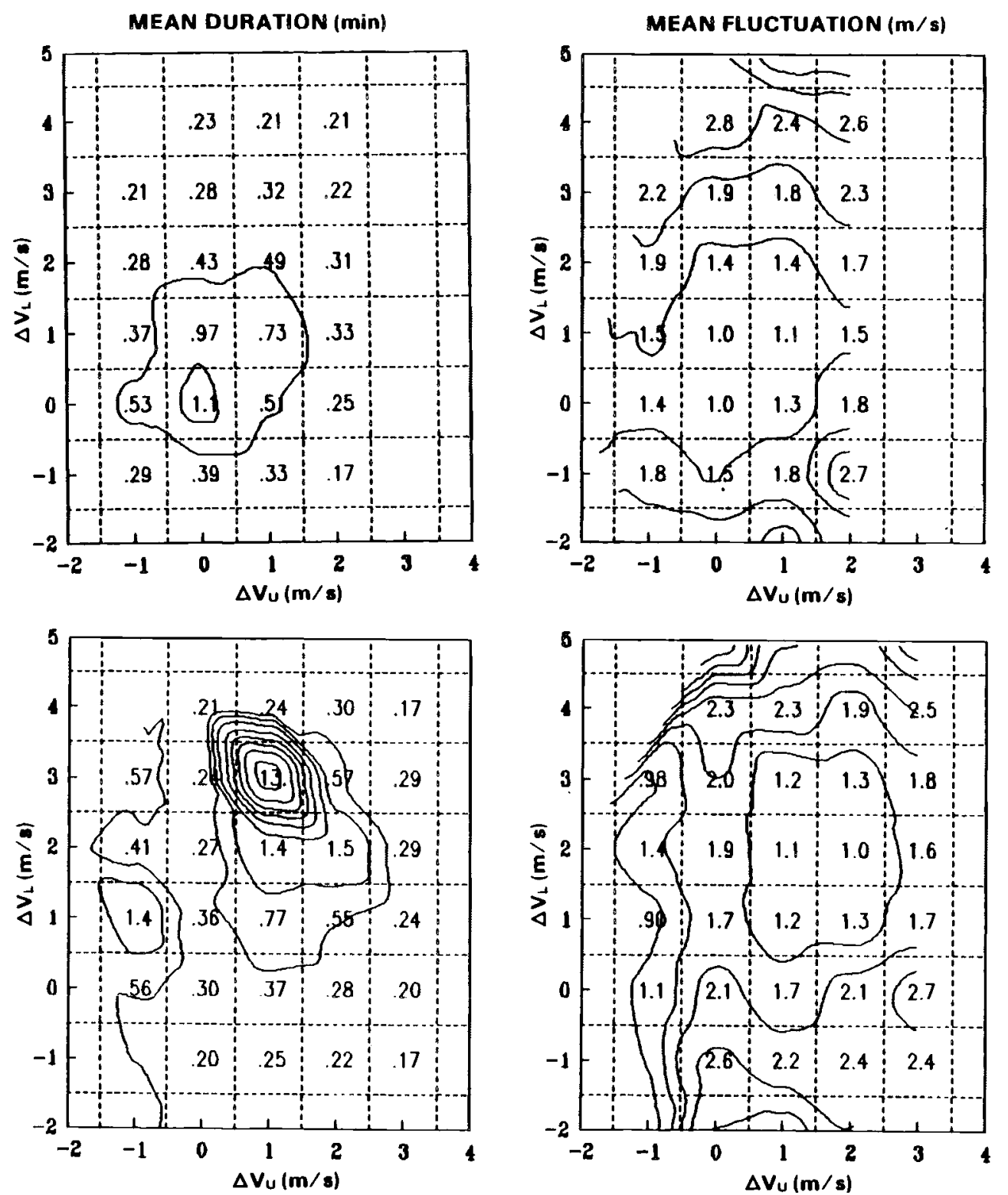

FIGURE 3-9. KYTV 0klahoma City, Oklahoma, Type 3 Turbine for (a) Summer Day and (b) Summer Night. See Figure 3-1 for detail. 
On the average, winter shear profiles have considerably longer mean durations and smaller mean fluctuations than summer profiles (see Figure 3-7). Strong shears in winter persist longer than strong shears in summer, whereas the weak and no-shear conditions show relatively short durations of 0.5 to $2.0 \mathrm{~min}$ in summer and winter [except for the infrequent $(<1 \%)$ wind shear profiles].

The most frequent winter nighttime shear profile $\left(\Delta V_{L}=3\right.$ and $\left.\Delta V_{U}=1\right)$ persists, on the average, for $40 \mathrm{~min}$ and has a mean fluctuation of only $0.5 \mathrm{~m} / \mathrm{s}$. On the other hand, the most frequent winter daytime shear profile $\left(\Delta V_{L}=0\right.$ and $\left.\Delta V_{U}=0\right)$ persists, on the average, for only 1.2 min and has a mean fluctuation of $1.1 \mathrm{~m} / \mathrm{s}$. Strong shears are much less frequent in day than at night in winter, but can be of long duration even during the day, as shown in Figure $3-8$.

In summer, there is a dramatic difference in the frequency distribution of shear profiles between day and night, as shown in Figure 3-9. Most frequent shear profiles during summer day rarely occur at night, whereas most frequent shear profiles in summer night rarely occur during day. Summer daytime profiles are characterized by relatively small velocity differences $(\Delta V \leq 1 \mathrm{~m} / \mathrm{s})$ across the rotor diameter. These profiles have short durations and fluctuate considerably, indicating turbulent well-mixed flow. Summer nighttime profiles are characterized by predominantly strong shear conditions. However, nighttime profiles in summer are substantially less persistent and are more fluctuating than nighttime profiles in winter. Thus, the summer nighttime flow appears more turbulent than the winter nighttime flow. 


\subsubsection{Duration Exceedance Curves}

Duration probability exceedance curves for a Type 1 turbine are presented in Figure 3-10 for winter and summer. From these curves, the average percentage of time that an individual wind shear profile exceeded a given duration can be determined. Exceedance curves are shown for five periods: all hours, day, night, transition to day, and transition to night.

It is apparent from Figure 3-10 that the duration exceedance curves for night and day are quite different in winter but very similar in summer. At night in winter, an individual wind shear profile exceeds a 1 -min duration an average of $25 \%$ of the time and exceeds a 10 -min duration an average of $6 \%$ of the time. The maximum duration of an individual shear profile was 60 min. During day in winter, an individual wind shear profile exceeds a $1-$ min duration an average of only $3 \%$ of the time and never exceeds a $3-\mathrm{min}$ duration. In another manner of speaking, a daytime wind shear profile in winter persists for less than $1 \mathrm{~min}$ an average of $97 \%$ of the time and for less than $0.3 \mathrm{~min}(20 \mathrm{~s})$ over $50 \%$ of the time. Profile duration curves during the transition to day are similar to those at night, and duration curves during transition to night are similar to those in day.

In summer, there is little difference in the duration exceedance curves between night and day. A daytime shear profile exceeds a 1-min duration only $4 \%$ of the time, and a nighttime profile exceeds a 1-min duration only $6 \%$ of the time.

Daytime exceedance curves are very similar in summer and winter. However, nighttime profiles persist for longer duration in winter than in summer. In winter, a nighttime shear profile exceeds a 1-min duration an average of $25 \%$ of the time, compared to an average of $6 \%$ of the time for a nighttime shear profile in summer.

Duration probability exceedance curves for selected wind shear profiles are presented for day and night in winter and summer in Figures 3-11 and 3-12. Five of the most frequent wind shear profiles, covering a variety of different shear intensities, were selected to compare the duration probability exceedance of different wind shear profiles for day and 
(a)

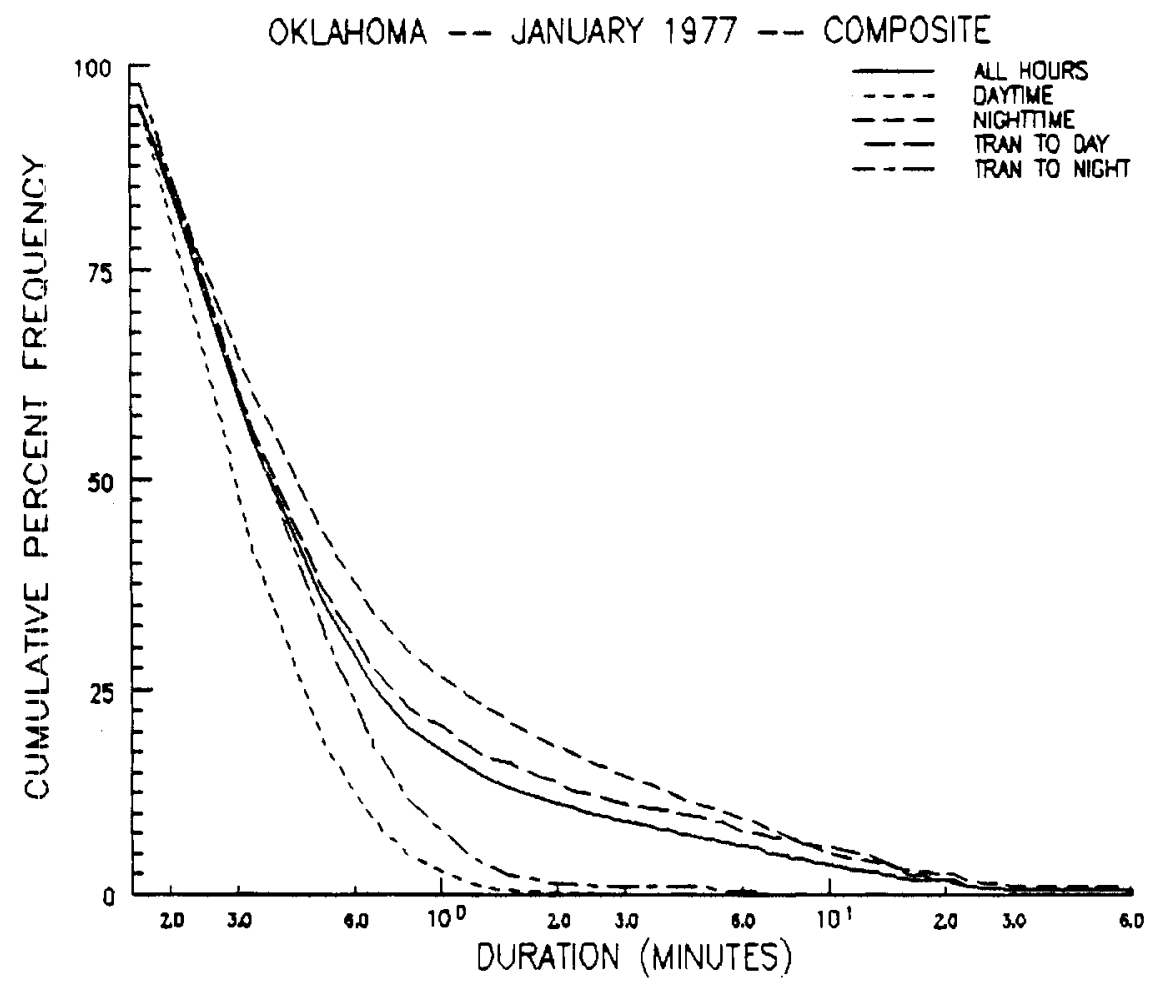

(b)

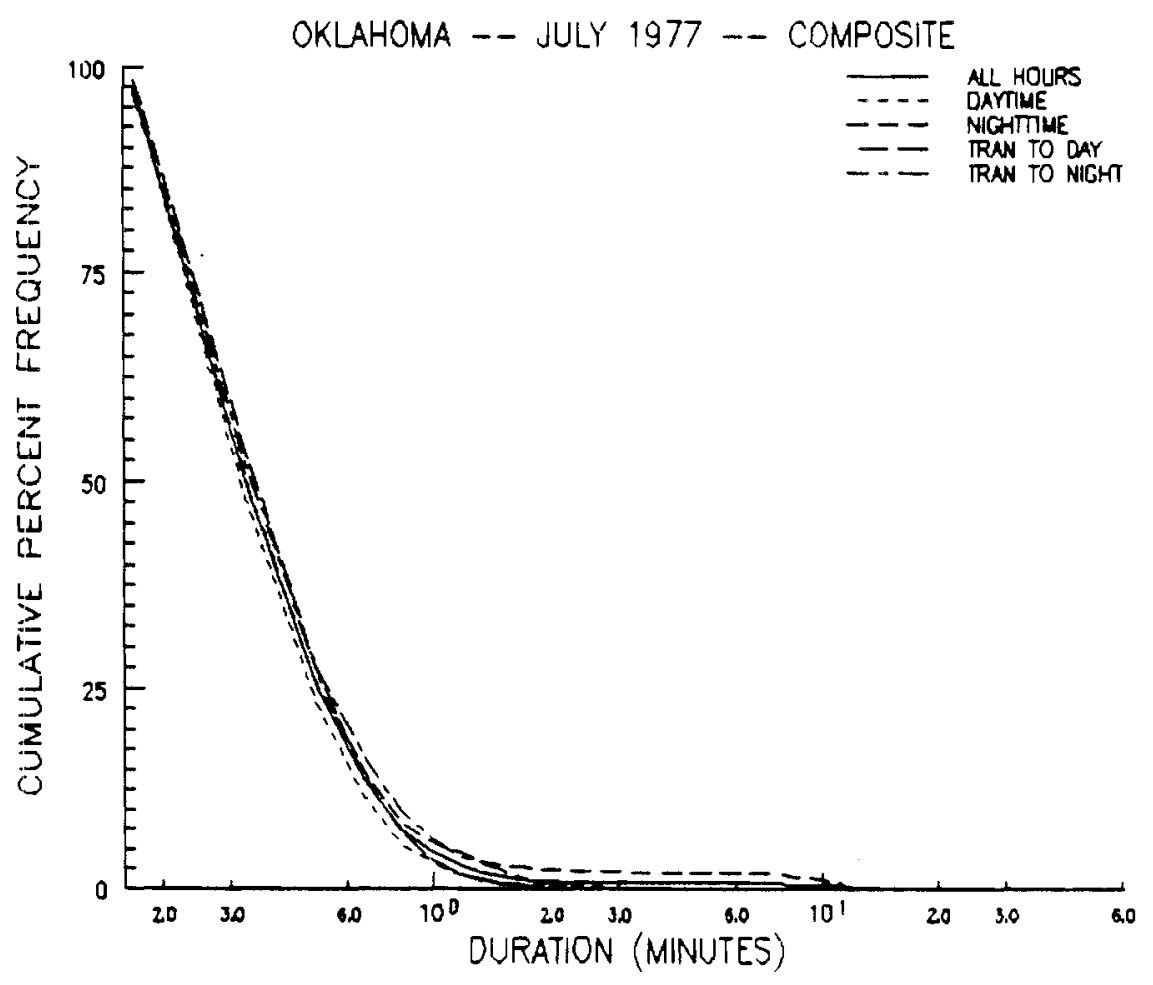

FIGURE 3-10 Average Percentage of Time That an Individual Wind Shear Profile Across a Type 1 Turbine Exceeded a Given Duration during (a) Winter and (b) Summer Using Instantaneous 10-s Sampled winds from KYTV Tower, Oklahoma. 
(a)

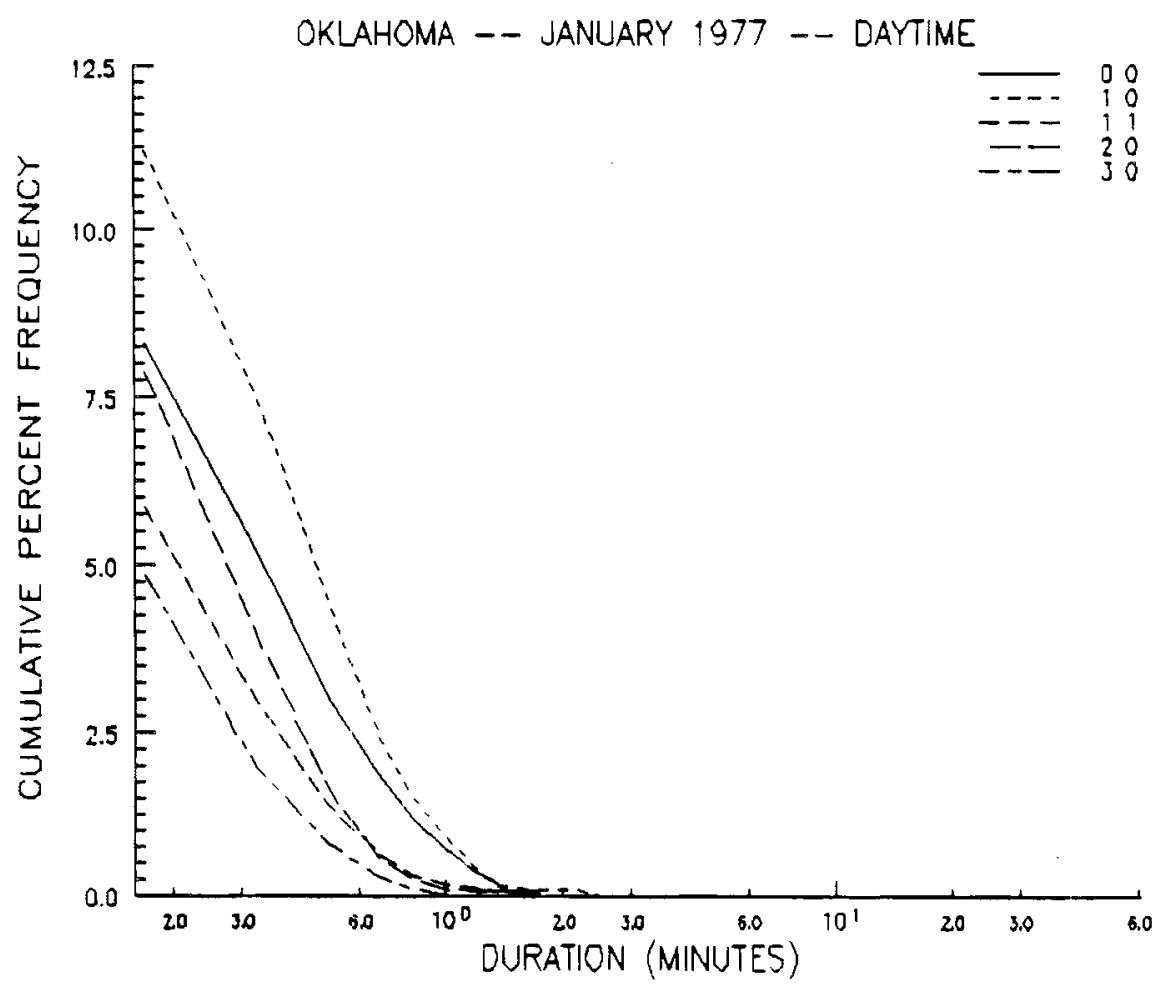

(b)

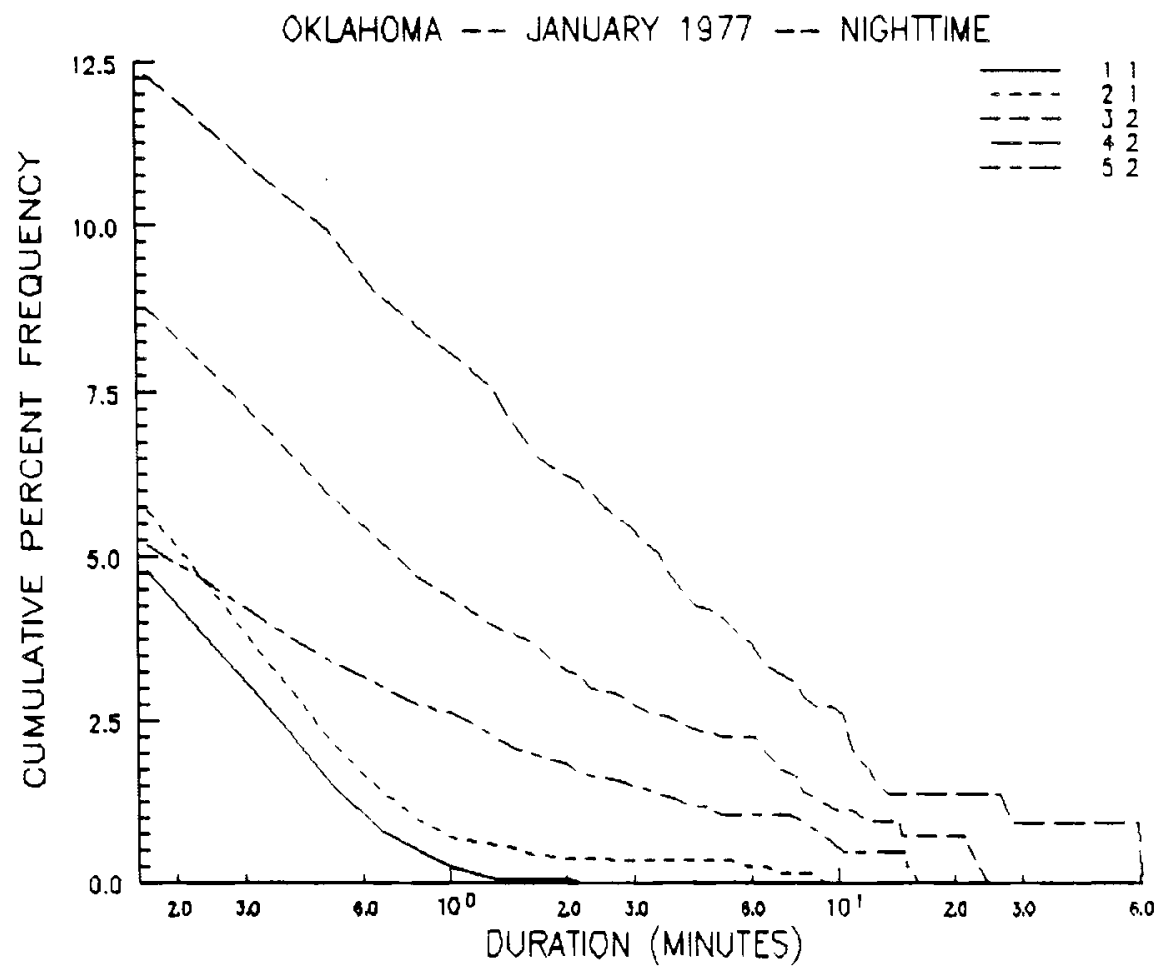

FIGURE 3-11. Percentage of Time That Selected wind Shear Profiles Across a Type 1 Turbine Exceeded a Given Duration during (a) Winter Day and (b) Winter Night Using Instantaneous 10-s Sampled winds from KYTV Tower, Oklahona. The snear profiles selected are defined in the upper right of each figure; the numbers represent $\Delta V_{L}$ and $\Delta V_{U}$, respectively. 
(a)
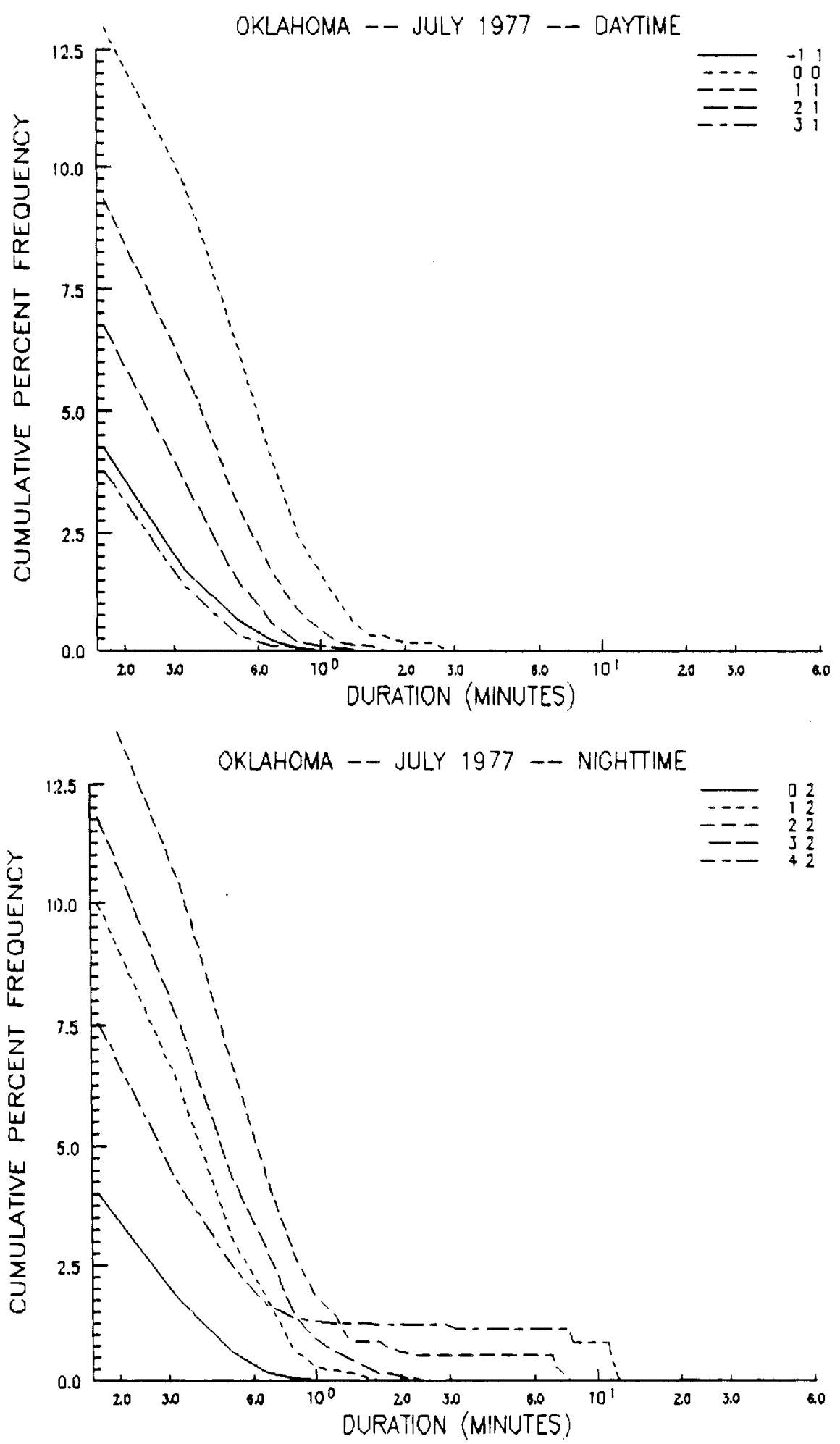

FIGURE 3-12. Percentage of Time That Selected Wind Shear Profiles Across a Type 1 Turbine Exceeded a Given Duration during (a) Summer Cay and (b) Summer Night Using Instantaneous 10-s Sampled winds From KYTV Tower, Oklahoma. The shear profiles selected are defined in the upper right of each figure; the numbers represent $\Delta V_{L}$ and $\Delta V_{L l}$, respectively. 
night in winter and summer. The shear profiles selected are shown in the upper right of each graph by the numbers following each line type. The numbers represent $\Delta V_{L}$ and $\Delta V_{U}$, respectively.

In winter, there is an enormous difference in the duration exceedance curves between day and night. In daytime, all shear profiles shown are of short duration. The durations of the nighttime profiles in winter, however, vary considerably. The three strongest shears have durations lasting more than $10 \mathrm{~min}$. The most frequently occurring shear profile at night $\left(\Delta V_{L}=4\right.$ and $\Delta V_{U}=2$ ) exceeds a 2 -min duration $50 \%$ of the time and has one duration lasting for $60 \mathrm{~min}$. On the other hand, the most frequent daytime shear profile $\left(\Delta V_{L}=1\right.$ and $\left.\Delta V_{U}=0\right)$ rarely exceeds a 2-min duration and persists less than 0.5 min $50 \%$ of time. It is interesting that the profile $\Delta V_{L}=1$ and $\Delta V_{U}=1$, which is a common profile in both day and night, has a very similar duration probability exceedance in both day and night. This profile is of relatively short duration and its duration appears independent of the time of day.

In summer (Figure 3-12), the difference in the duration exceedance curves between day and night is much smaller than that in winter. Shear profiles are of short duration (less than $1 \mathrm{~min}$ ) a high percentage of the time in both day and night. The most frequent nighttime shear profile $\left(\Delta V_{L}=2\right.$ and $\left.\Delta V_{U}=2\right)$ exceeds a 2 -min duration only $5 \%$ of the time. This contrasts drastically with the most frequent nighttime shear profile in winter, which exceeds a 2-min duration $50 \%$ of the time.

Selecting an identical profile common to both summer night and winter night, we can evaluate the variability of a particular profile duration between the two periods. The profile $\Delta V_{L}=3$ and $\Delta V_{U}=2$, which frequently occurs in both winter night and summer night, exceeds a 2-min duration $37 \%$ of the time during winter night and only $1 \%$ of the time during summer night. Thus, it appears that strong shears during night in summer are considerably more turbulent and fluctuating, on the average, than comparably strong shears during night in winter. 
Duration probability exceedance curves for Type 3 turbine during winter and summer are shown in Figure 3-13. Durations are considerably longer than for the Type 1 and 2 turbines. The maximum duration is almost two hours. A shear profile exceeds a 2-min duration an average of $25 \%$ of the time in winter and $10 \%$ of the time in summer. A 10-min duration is exceeded an average of $15 \%$ of the time in winter and $2 \%$ of the time in summer.

In conclusion, there is an enormous difference in winter between the night and day duration exceedance curves, but little difference in summer.

\subsubsection{Comparison of Results: 10-s Versus 2-min Data}

A comparison of the analysis results using 10-s instantaneous sampled wind data versus 2 -min instantaneous sampled wind data are presented for identical time periods at the KYTV tower. Analyses of the percent frequency of occurrence, mean duration, and mean fluctuation of wind shear profiles for a Type 1 turbine using 2-min instantaneous data are shown in Figure 3-14 for winter and summer. Analyses for the same identical time periods using 10-s instantaneous wind data are shown in Figure 3-1.

The frequency distributions of 10 -s versus 2 -min instantaneous wind shear profiles are very similar. The magnitudes of the mean duration are different because of the different data sampling intervals, but the distributions of the durations over the matrix are not significantly different between the 10-s and 2-min analyses. For example, the most persistent (longest mean duration) wind shear profiles are the same profiles in both the 10-s and 2-min analyses. Likewise, profiles of shortest durations generally match in both the $10-\mathrm{s}$ and 2 -min analyses.

There is generally better agreement in the mean durations for cells with short durations ( $\leq 30 \mathrm{~s}$ for 10 -s data and $\leq 4$ min for 2-min data) than for cells with long durations. Mean durations less than or equal to 4 min for 2-min data usually correspond to mean durations of less than $30 \mathrm{~s}$ for 10 -s data. Thus, highly fluctuating 2 -min instantaneous wind shear profiles are indicative of highly fluctuating 10-s instantaneous profiles. 
(a)

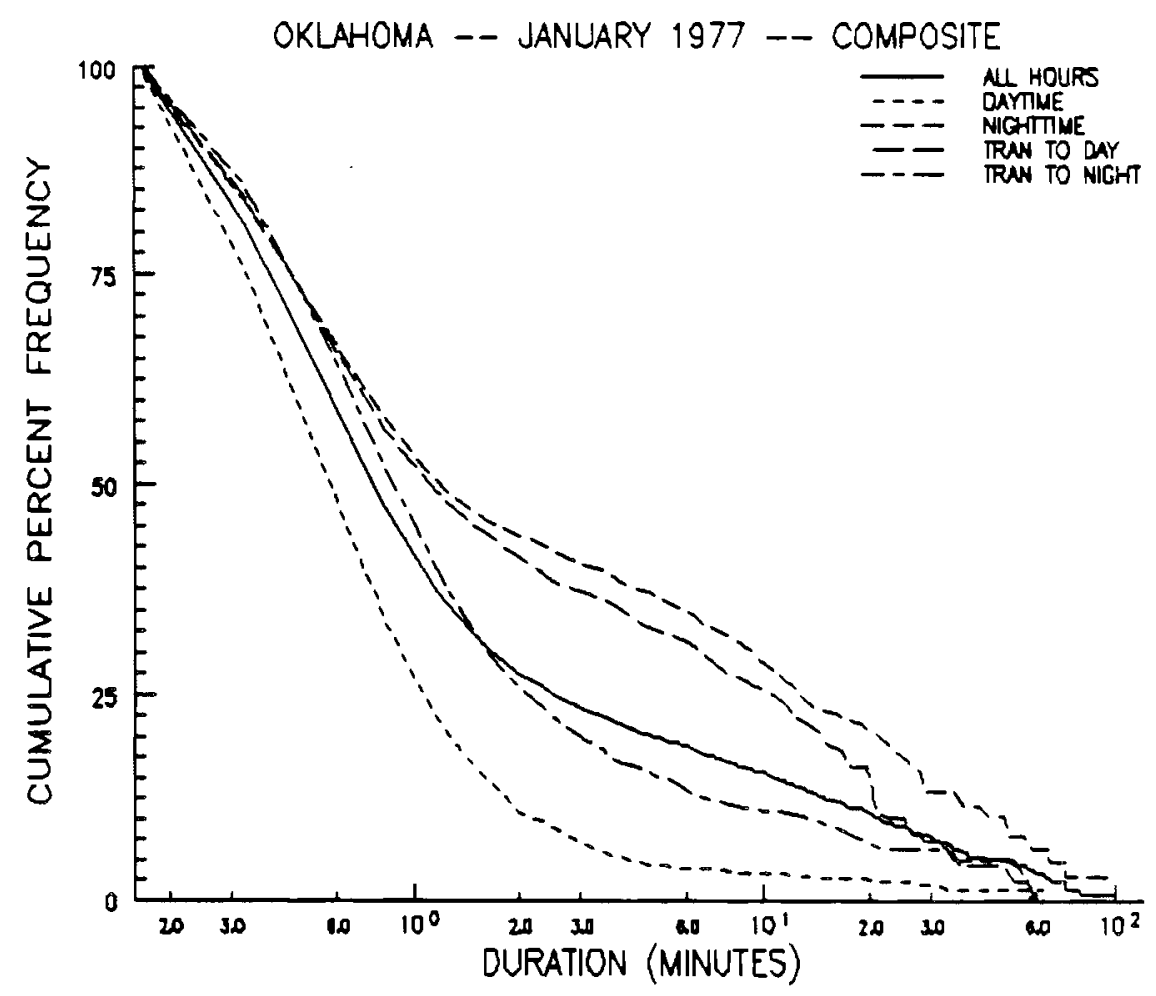

(b)

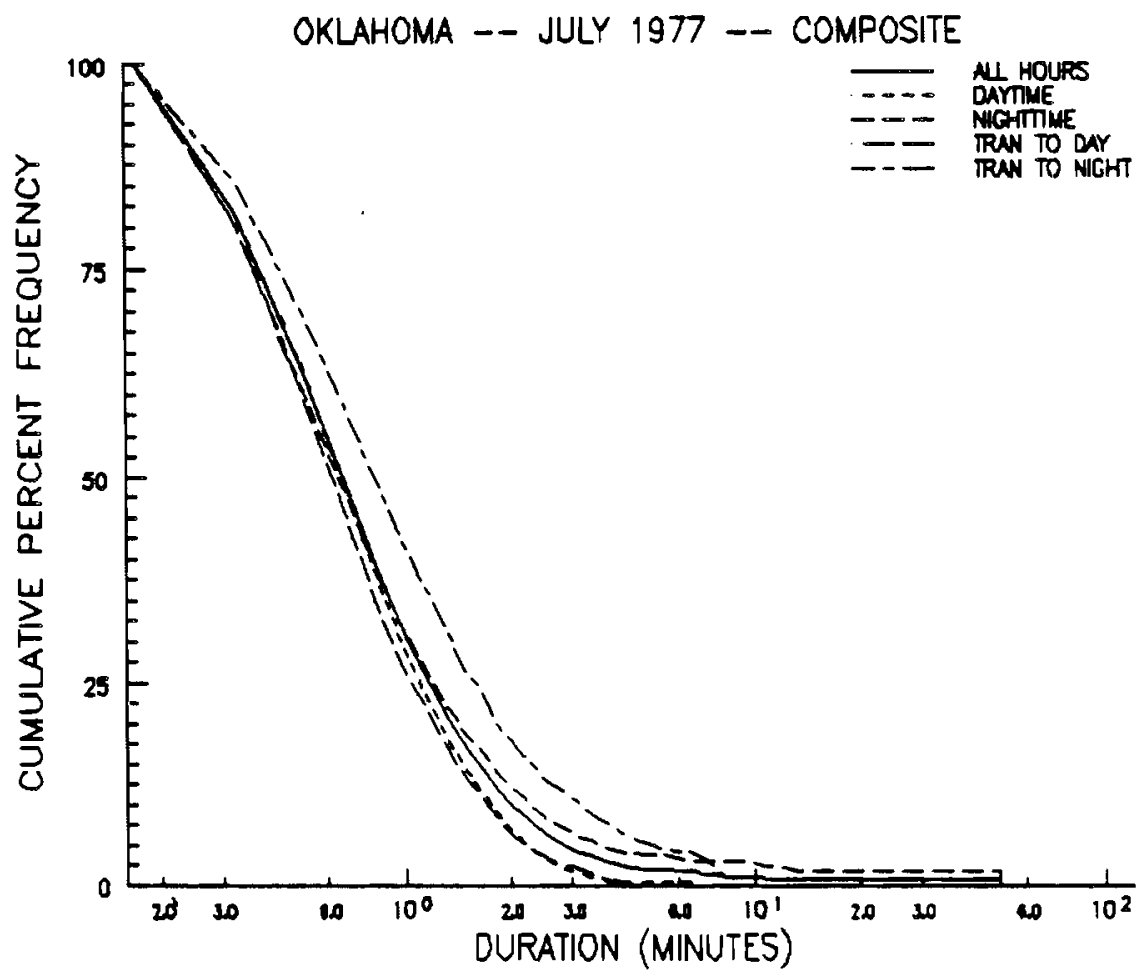

FIGURE 3-13. Average Percentage of Time That an Individual Wind Shear Profile Across a Type 3 Turbine Exceeded a Given Duration during (a) Winter and (b) Summer Using Instantaneous 10-s Sampled Winds From KYTV Tower, OKlahoma. 

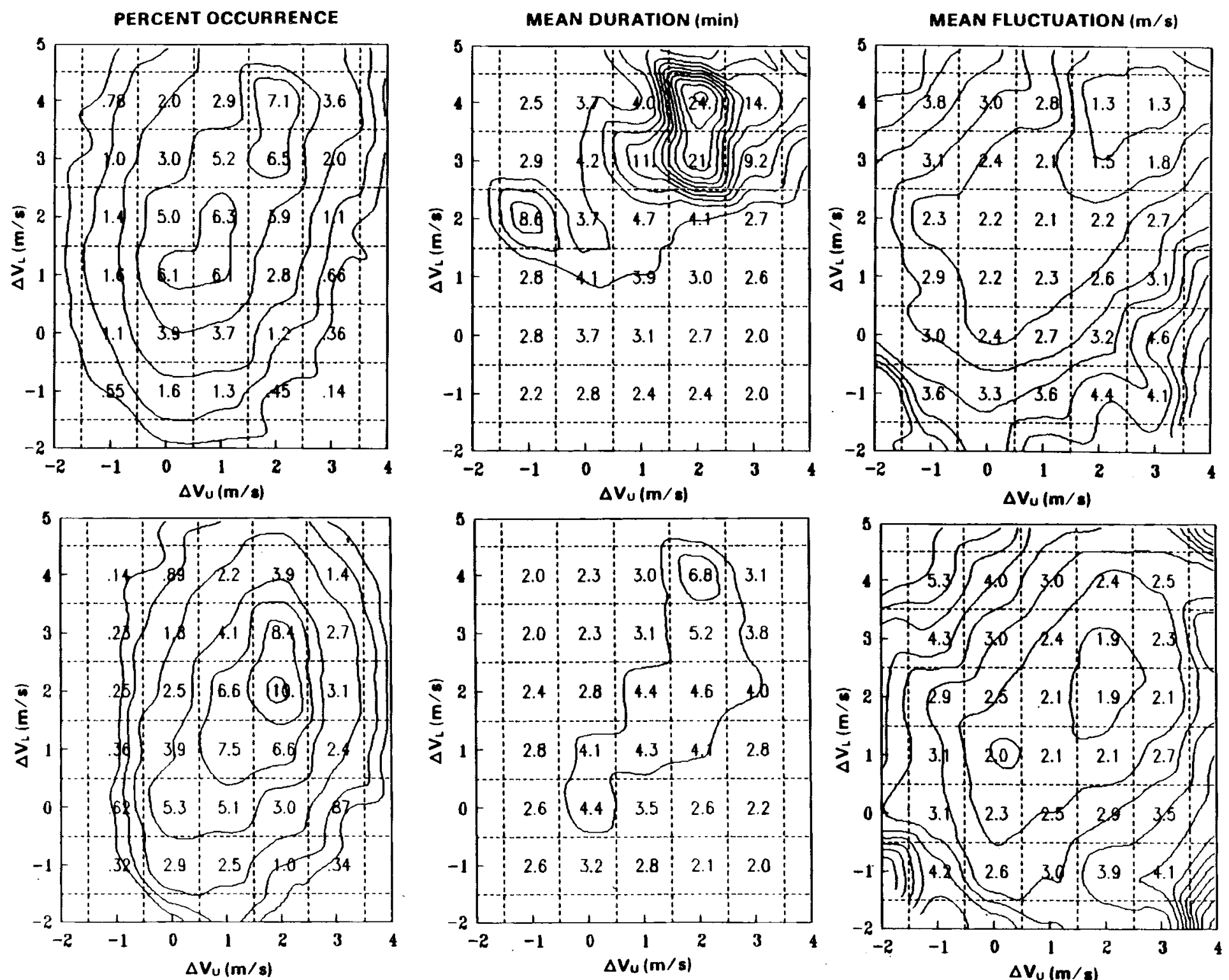

FIGURE 3.14. Frequency of Occurrence, Mean Duration, and Mean Fluctuation of Wind Shear Profiles for a Type 1 Turbine Using 2-min Instantaneous Winds from the KYTV Tower in 0klahoma City, Oklahoma, for a) Winter (January 1977) and b) Summer (July 1977). 
Mean durations longer than 6 min for 2-min data appear to be fairly indicative of mean durations greater than 1 min for 10-s data. Very long mean durations of 20 min or longer for 2-min data appear fairly indicative of mean durations exceeding $3 \mathrm{~min}$ for $10 \mathrm{-s}$ data. However, durations of $10-\mathrm{s}$ data can approach those of 2-min data for laminar flow conditions when there is little fluctuation in the shear profile.

Mean fluctuations of the 2-min instantaneous profiles are only about $10 \%$ greater than those of the 10-s profiles, on the average. The distribution of the mean fluctuations over the matrix is very similar for 10-s and 2-min data. Thus, the mean fluctuations of profiles using 2-min instantaneous data appear very indicative of the mean fluctuations of the 10-s profiles.

Duration probability exceedance curves derived from 2-min instantaneous data at KYTV tower are shown in Figure 3-15 for winter and summer for the Type 1 turbine. Duration exceedance curves derived from 10-s instantaneous data are shown for identical time periods as for 2-min data in Figure 3-10. Both the 10-s and 2-min analyses show the large day/night difference in the duration exceedance curves in winter and the relatively small difference in summer at KYTV.

The average percentage of time that 2-min instantaneous profiles exceed 10,20 , and $50 \mathrm{~min}$ is not significantly different than the percentage of time that $10-\mathrm{s}$ profiles exceed 1,3 , and $10 \mathrm{~min}$, respectively. For durations less than 10-min for 2-min data and less than 1 min for 10-s data there is roughly a one-to-one correspondence in the average number of consecutive profiles of the same type. For example, the average percentage of time that 2-min instantaneous profiles exceed 4 min ( 2 consecutive profiles) is within $5-10 \%$ of the time, for the most part, that 10 -s profiles exceed $30 \mathrm{~s}$ ( 2 consecutive profiles). This, again, implies that highly fluctuating 2-min instantaneous profiles are indicative of highly fluctuating 10-s profiles. 

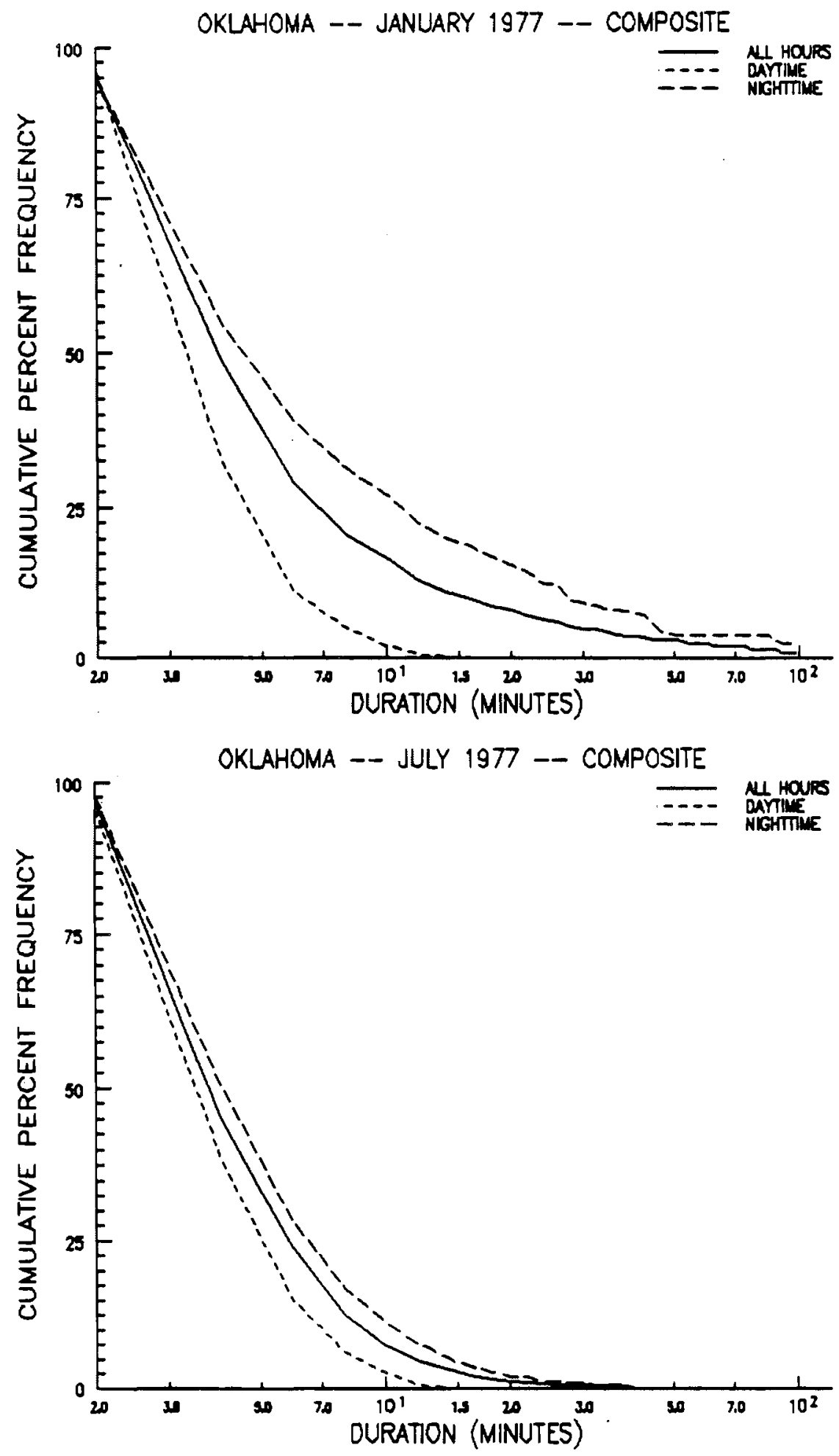

FIGURE 3-15 Average Percentage of Time That an Individual Wind Shear Profile Across a Type 1 Turbine Exceeded a Given Duration during (a) Winter and (b) Summer Using Instantaneous 2-min. Sampled Winds From KYTV Tower, Ok lahoma. 


\subsection{MEDICINE BOW TOWER - WYOMING}

Analyses of the percent frequency of occurrence, mean duration, and mean fluctuation of the matrix of wind shear profiles across a Type 1 turbine at Medicine Bow are shown for winter versus summer and day versus night in Figures 3-16 through 3-18. These analyses are based on 2-min instantaneous wind measurement samples from windy hours $(\bar{v} \geq 7 \mathrm{~m} / \mathrm{s})$ at the Medicine Bow tower.

Analyses of winter versus summer in Figure 3-16 show a greater frequency of strong shears ( $\Delta V \geq 6 \mathrm{~m} / \mathrm{s}$ over the rotor diameter) in winter than in summer; however, mean durations of the strong shears are longer and mean fluctuations smaller in summer than in winter. Shears are more frequently stronger over the lower half of the rotor disk than over the upper half.

In winter, wind shear profiles are outside the range of the matrix $12.5 \%$ of the time. The majority of these were strong shear profiles in which $\Delta V_{L} \geq 5.5 \mathrm{~m} / \mathrm{s}$ and/or $\Delta V_{U} \geq 4.5 \mathrm{~m} / \mathrm{s}$. Within the matrix, the most frequent winter shear profile is $\Delta V_{L}=3$ and $\Delta V_{U}=1$, occurring $6.3 \%$ of the time. Mean durations of the strong shears in winter are relatively short (for 2-min data), on the order of 4 to $8 \mathrm{~min}$. This corresponds to durations of roughly 0.4 to $1 \mathrm{~min}$ for $10 \mathrm{-s}$ data. Mean fluctuations are $1.7 \mathrm{~m} / \mathrm{s}$ to $2.2 \mathrm{~m} / \mathrm{s}$ for the more frequent shear profiles.

In summer, the most frequent shear profile is the weak shear $\Delta V_{L}=1$ and $\Delta V_{U}=0$, indicative of we11-mixed atmospheric conditions. The highest mean durations (12 to $13 \mathrm{~min}$ ) in summer are found under the strong shear profiles $\Delta V_{L}=4$ and $\Delta V_{U}=1$ and $\Delta V_{L}=3$ and $\Delta V_{U}=1$. Mean durations in summer are about twice those in winter for these strong shear profiles, and mean fluctuations are smaller in summer than in winter. This would indicate that the flow in winter is usually more turbulent than that in summer, when these strong shear conditions exist. 

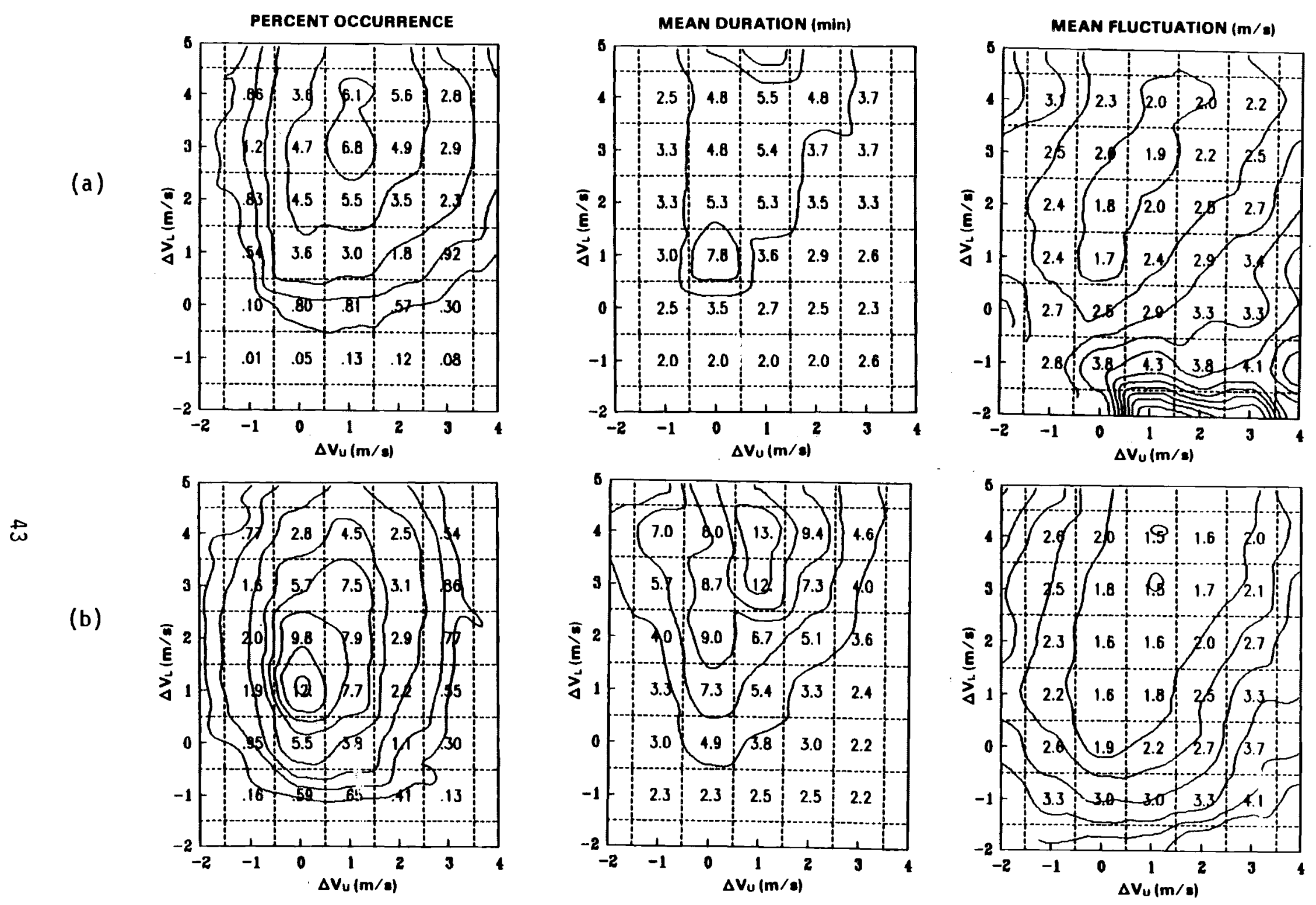

FIGURE 3.16. Frequency of Occurrence, Mean Duration, and Mean Fluctuation of Wind Shear Profiles for a Type 1 Turbine using 2-min Instantaneous Winds from Medicine Bow, Wyoming, for (a) Winter (December 1980 Through February 1981) and (b) Summer (June Through August 1980). 

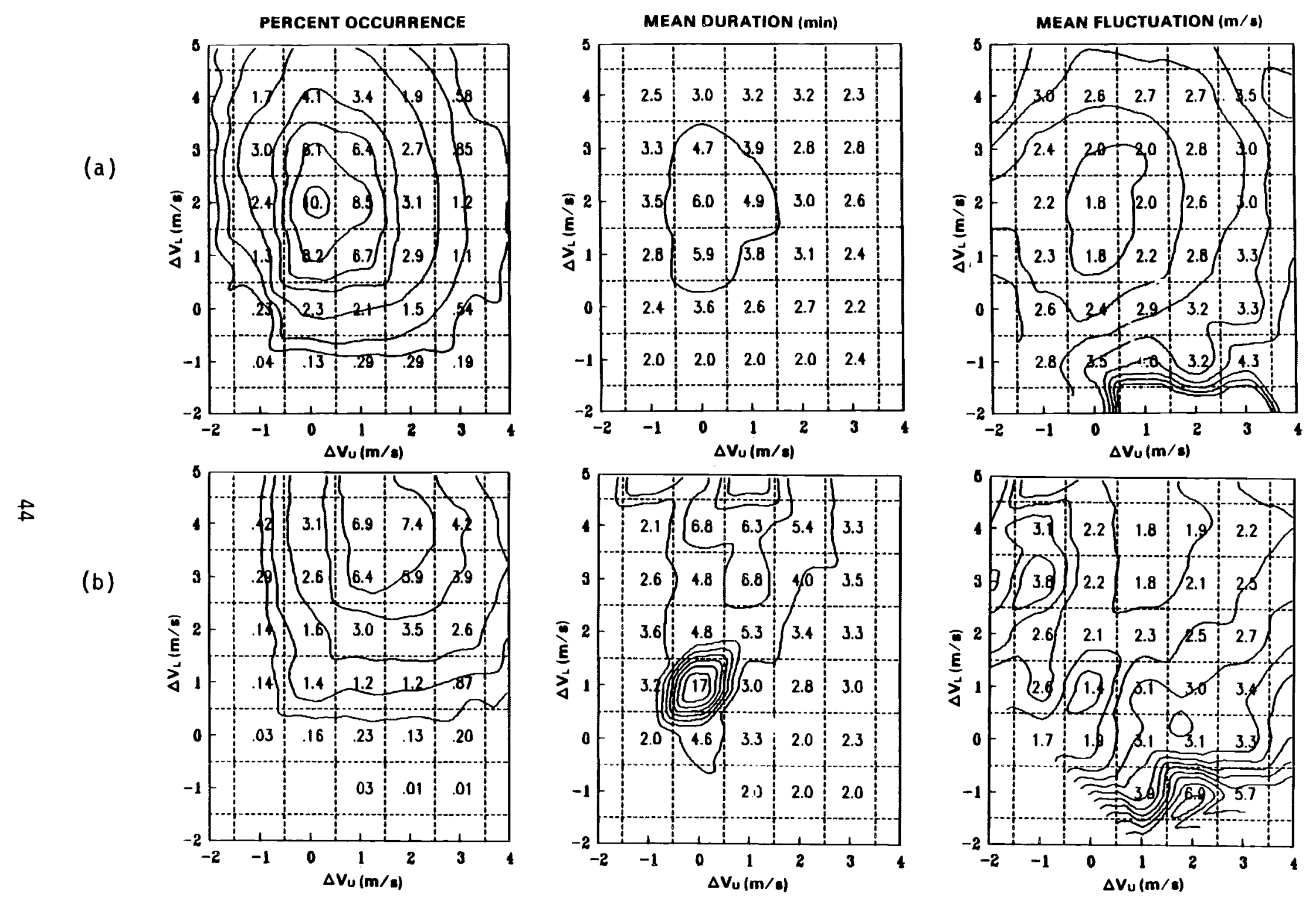

FIGURE 3-17. Medicine Bow, Wyoming, Type 1 Turbine for (a) Winter Day and (b) Winter Night. See Figure 3-14 for detail. 

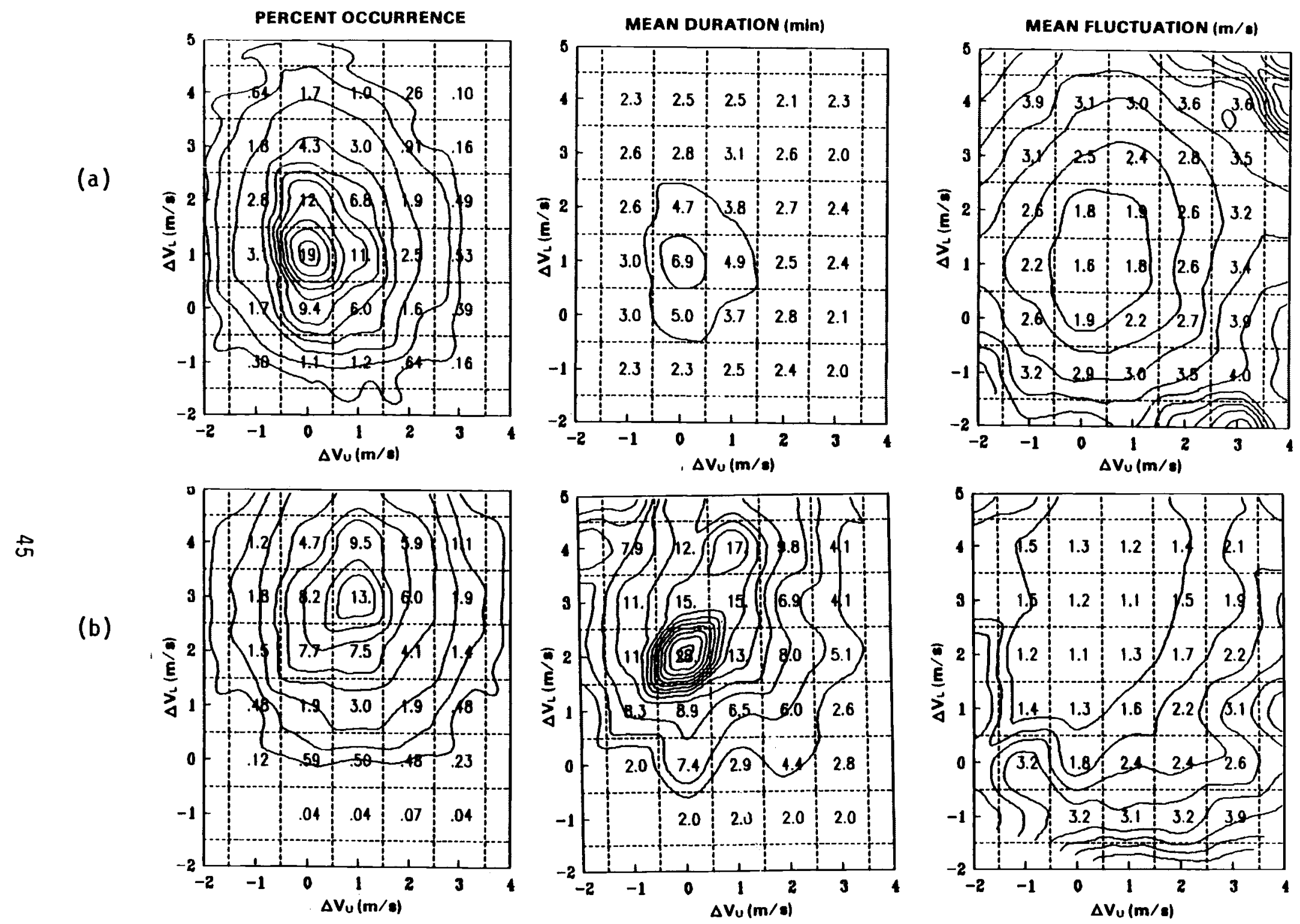

FIGURE 3-18. Medicine Bow, hyoming, Type 1 Turbine for (a) Summer Day and (b) Summer Night. See Figure 3-14 for detai1. 
In Medicine Bow in winter, there are frequent episodes of high winds speeds $(\geq 10 \mathrm{~m} / \mathrm{s})$, when there $c$ an be considerable mechanical mixing even during stable atmospheric conditions. The depth of the mean-mixed layer in winter was found by Martner and Gilmer (1981) to extend beyond the top of the Medicine Bow tower. Thus, the high occurrence of short durations (1arge fluctuations) of the relatively strong shear conditions in winter may be predominantly caused by strong mechanical mixing.

Analyses of the profiles for day versus night in winter and summer, shown in Figures 3-17 and 3-18, indicate a higher frequency of strong shears at night than in day. In winter, wind shears are outside the range of the matrix $17 \%$ of the time at night and $5 \%$ of the time in day. These are predominantly strong shear profiles in which $\Delta V_{L} \geq 5.5 \mathrm{~m} / \mathrm{s}$ and $/ 0 \mathrm{r} \quad \Delta V_{U} \geq 4.5 \mathrm{~m} / \mathrm{s}$. In summer, shears are outside the range of the matrix only $2.5 \%$ of the time at night and $1.5 \%$ of the time in day.

Daytime profiles in winter and summer are of short duration, averaging 3 to $7 \mathrm{~min}$. This corresponds to durations of only 0.3 to $0.8 \mathrm{~min}$ for $10-\mathrm{s}$ data. Nighttime mean durations are quite variable over the matrix, with anomalously high values occurring with the shear profile $\Delta V_{L}=1$ and $\Delta V_{U}=0$ in winter and at $\Delta V_{L}=2$ and $\Delta V_{U}=0$ in summer. However, shear profiles usually persist longer and fluctuate less during summer night than during winter night.

Duration probability exceedance curves at Medicine Bow are presented in Figure 3-19 for winter and summer. From these curves, the average percentage of time that an individual wind shear profile exceeded a given duration can be determined. Exceedance curves are shown for all hours, and day- and nighttime hours.

The duration exceedance curves for night and day show greater differences in summer than in winter. At night in summer, an individual wind shear profile exceeds a 10-min duration an average of $40 \%$ of the time and exceeds 
(a)

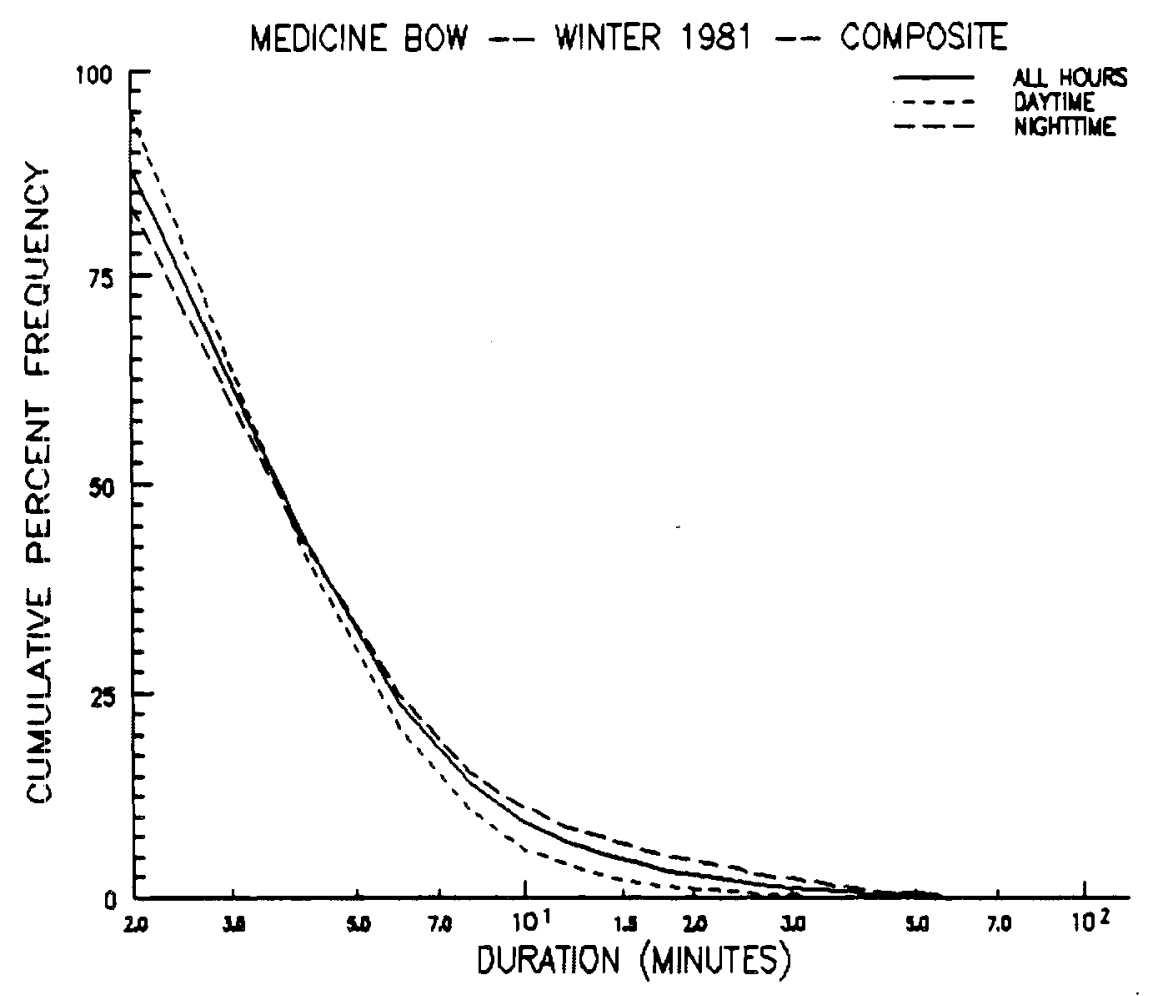

(b)

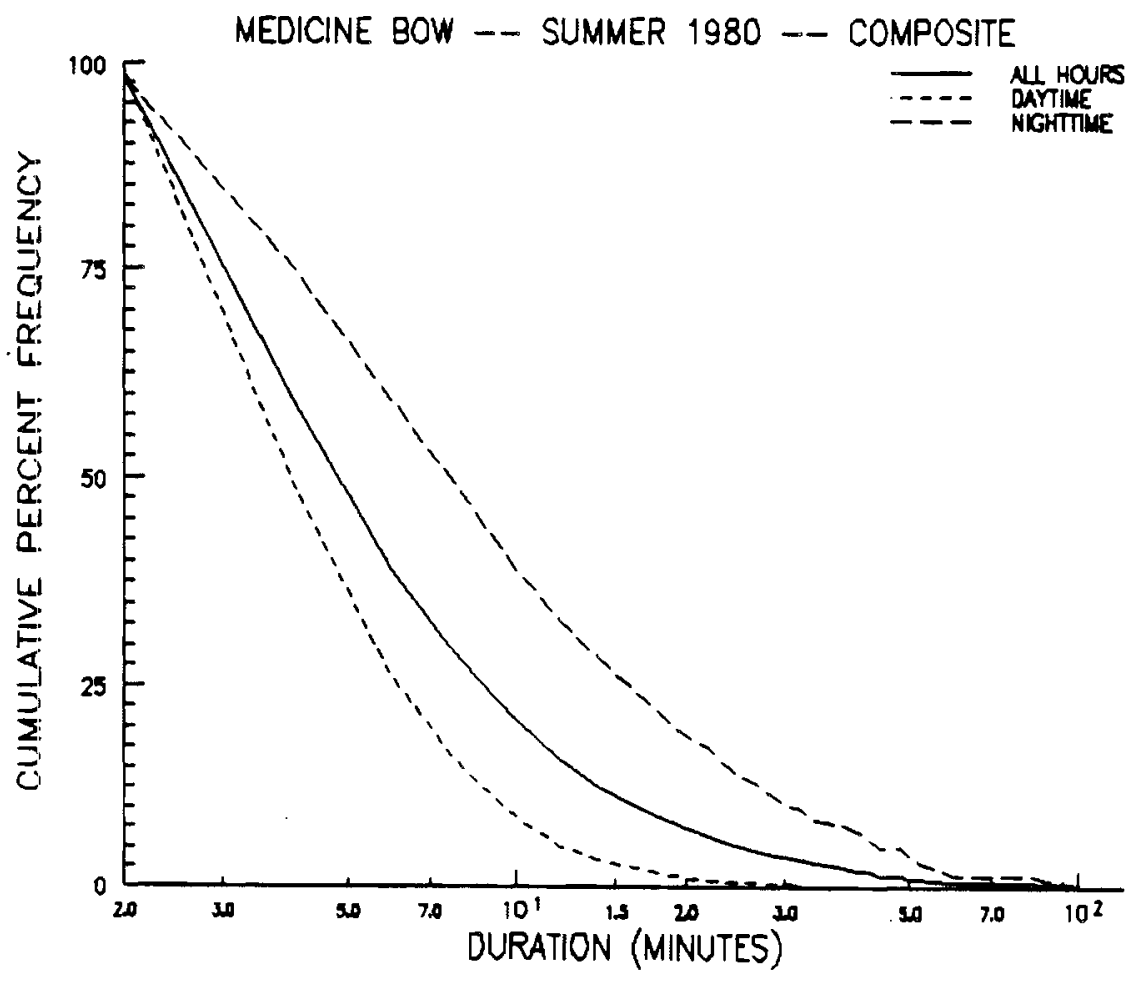

FIGURE 3-19. Average Percentage of Time That an Individual Wind Shear Profile Across a Type 1 Turbine Exceeded a Given Duration during (a) winter and (b) Surmer Using Instantaneous 2-min Sampled Winds From Medicine Bow. 
a $30-$ min duration an average of $10 \%$ of the time. The maximum duration of an individual shear profile was $100 \mathrm{~min}$. During day in summer, an individual wind shear profile exceeds a 10-min duration an average of only $8 \%$ of the time and rarely ( $<0.5 \%$ of the time) exceeds a 30 -min duration.

In winter, nighttime durations are longer than daytime durations by a smaller margin than in summer. A shear profile exceeds a 10-min duration $11 \%$ of the time at night and $6 \%$ of the time in day during winter.

Daytime exceedance curves are very similar in summer and winter. However, nighttime profiles persist for longer duration in summer than in winter. A nighttime shear profile exceeds a 10-min duration an average of $40 \%$ of the time in summer and an average of only $6 \%$ of the time in winter.

\subsection{GOODNOE HILLS TOWER - WASHINGTON}

Analyses of the percent frequency of occurrence, mean duration, and mean fluctuation of the matrix and wind shear profiles across a Type 1 turbine at Goodnoe Hills are shown for winter versus summer and day versus night in Figures 3-20 through 3-22. These analyses are based on 2-min instantaneous wind measurement samples from windy hours $(\bar{V} \geq 7 \mathrm{~m} / \mathrm{s})$ at the Goodnoe Hills tower.

The frequency distribution of wind shear profiles is quite different in winter and summer. In winter, shears are more frequently stronger over the upper half of the rotor disk than over the lower half, whereas in summer, shears are more frequently stronger over the lower half than over the upper half.

Wind shears are within the range of the matrix approximately $90 \%$ of the time in winter and summer.

In summer, mean durations are very short, on the order of 3 to $5 \mathrm{~min}$. This corresponds to mean durations of approximately 0.3 to 0.6 min for $10-s$ data. Mean fluctuations are 2 to $2.5 \mathrm{~m} / \mathrm{s}$ for the more frequent wind profiles. 

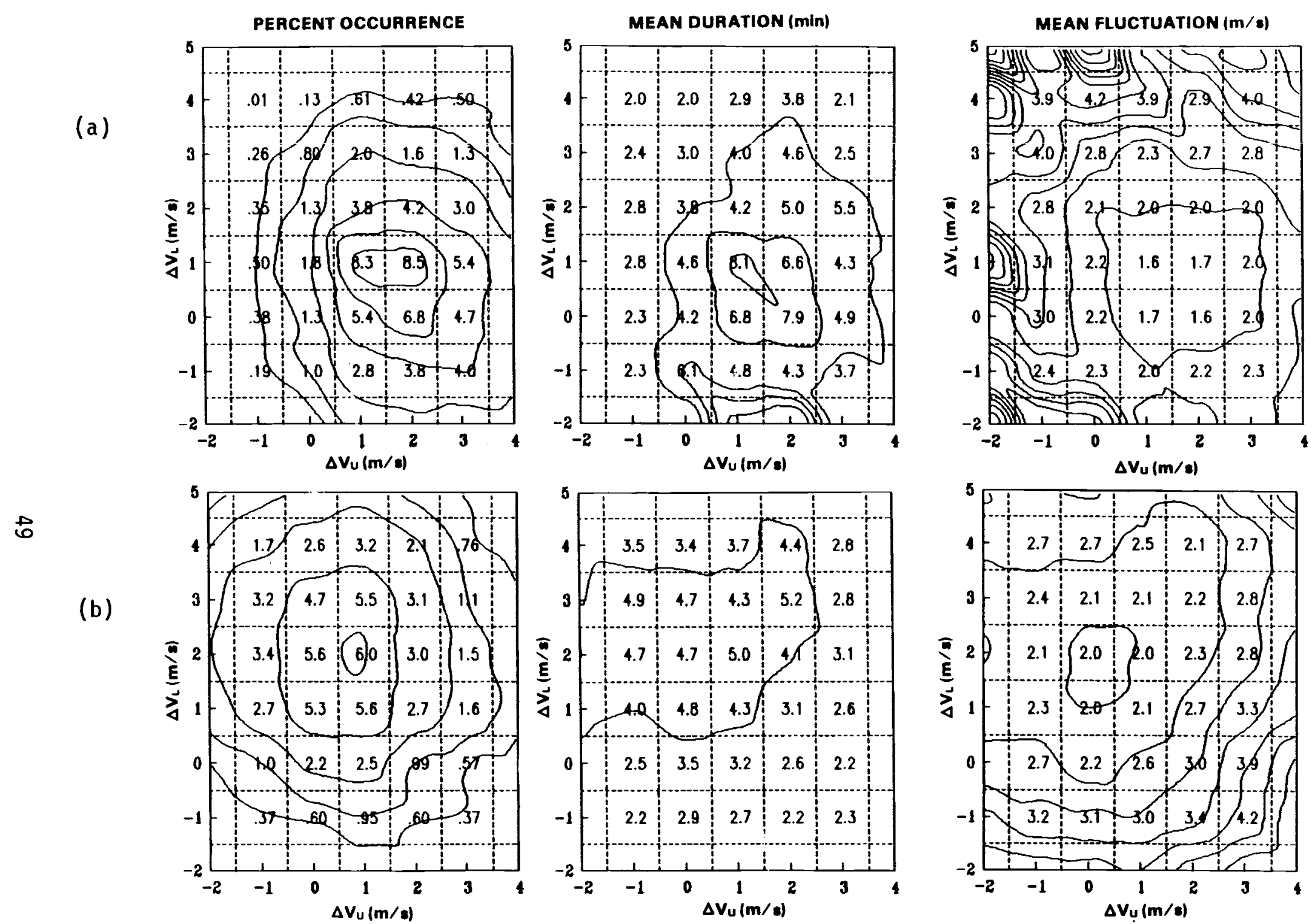

FIGURE 3-20. Frequency of Occurrence, Mean Duration, and Mean Fluctuation of Wind Shear Profiles for a Type 1 Turbine Using 2-min Instantaneous Winds from Goodnoe Hills, Washington, for (a) Winter (November and December 1980) and (b) Summer (July and August 1980). 
(a)
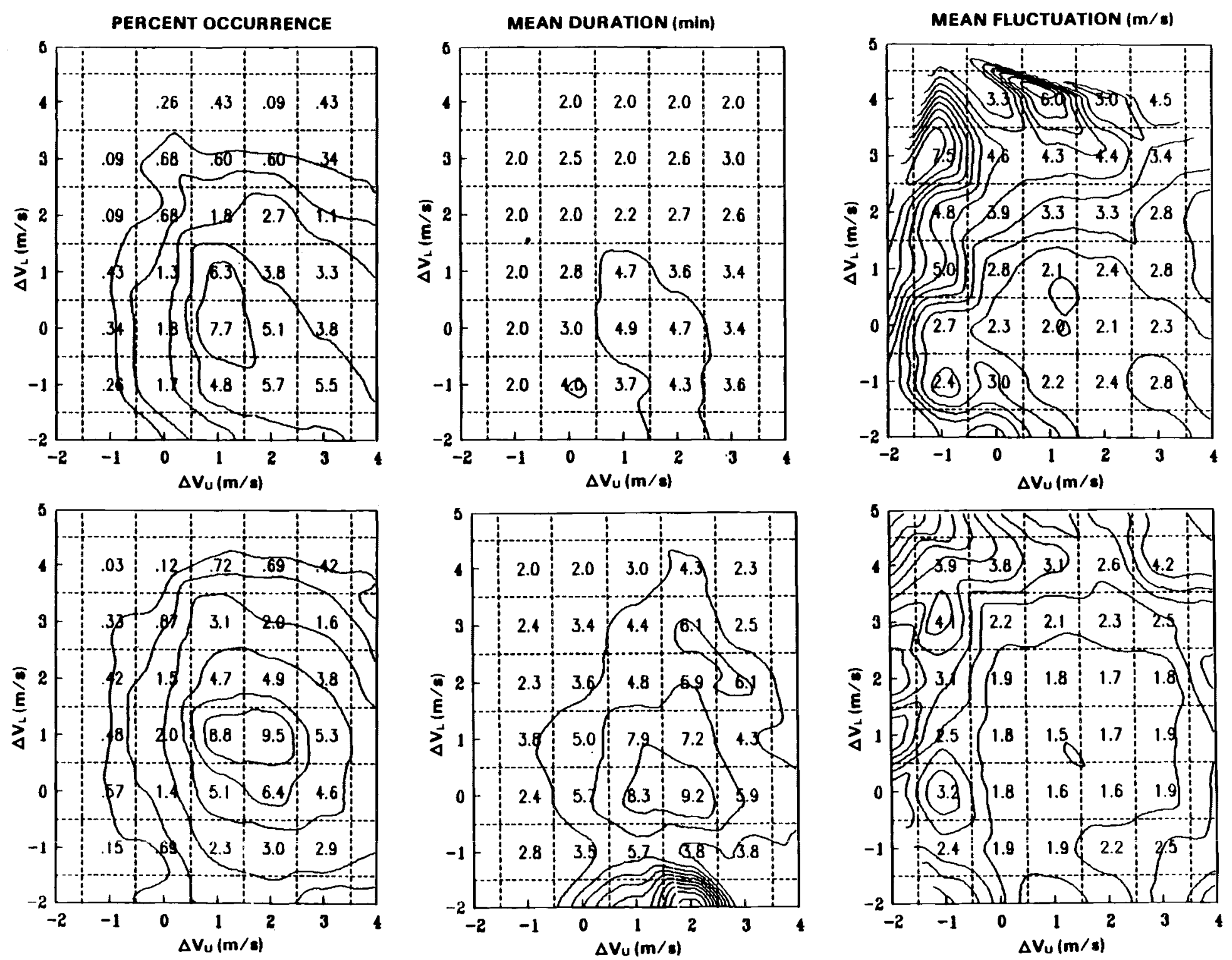

FIGURE 3-21. Goodnoe Hills, Washington, Type 1 Turbine for (a) Winter Day and (b) Winter Night. See Figure 3-18 for detail. 
(a)
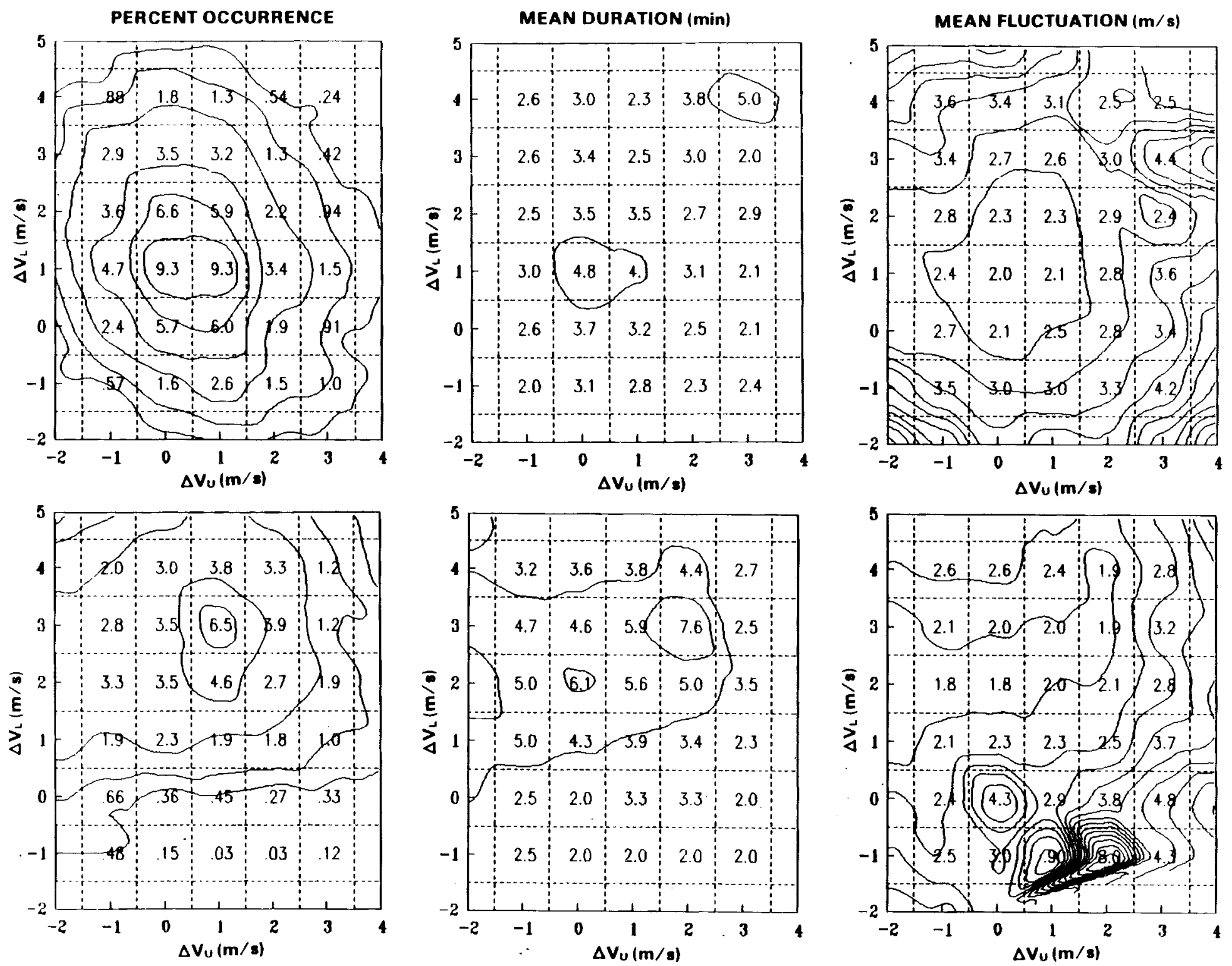

FIGURE 3-22. Goodnoe Hills, Washington, Type 1 Turbine for (a) Summer Day and (b) Summer Night. See Figure 3-18 for detail. 
In winter, the maximum mean durations for the matrix are associated with negative shears over the lower half of the disk $\left(-\Delta V_{L}\right)$ and positive shears over the upper half. The shear profile $\Delta V_{L}=-2$ and $\Delta V_{U}=2$ has a mean duration of $12.0 \mathrm{~min}$ and a single individual duration lasting $44 \mathrm{~min}$.

On the average, wind shear profiles persist longer and fluctuate less in winter than in summer. Shears are stronger over the upper half of the rotor disk in winter than in summer, whereas shears are stronger over the lower half in summer.

Analysis of the profiles for day versus night in winter and summer, shown in Figures 3-21 and 3-22, indicate a wide variety in the frequency distributions of wind shear profiles.

In winter, shears are more frequently stronger over the upper than the lower half in both daytime and nighttime. Winter daytime shears are outside the range of the matrix $15 \%$ of the time. It is apparent from Figure 3-21 that these were predominantly shears with $\Delta V_{L} \leq-2.5 \mathrm{~m} / \mathrm{s}$ and/or $\Delta V_{U} \geq 4.5 \mathrm{~m} / \mathrm{s}$ 。

Shear profiles with negative $\Delta V_{L}$ and positive $\Delta V_{U}$, as those in lower right of the matrix, occur when the wind speed at hub height is less than the upper and lower level wind speeds. These profiles occurred $33 \%$ of the time in day and $14 \%$ of the time at night in winter.

Wind shear profiles persist longer and fluctuate less at night than during day in winter. Mean durations are 3 to 5 min for frequent daytime profiles. This corresponds to mean durations of approximately 0.3 to 0.6 min for 10 -s data.

At night, the longest mean durations are associated with negative shears over the lower half and positive shear over the upper half (minimum wind speed at hub-height level). The longest mean duration is $23.4 \mathrm{~min}$, occurring with the shear profile $\Delta V_{L}=-2$ and $\Delta V_{U}=2$. 
In surmer, there is a dramatic difference in the frequency distribution of wind shear profiles for day versus night. At night, there is a wide variation in the shears over the upper half of the rotor disk. Nighttime shears are outside the range of the matrix $18 \%$ of the time; most of these are shears with $\Delta V_{U} \leq-2.5 \mathrm{~m} / \mathrm{s}$ and $\Delta V_{L}>1 \mathrm{~m} / \mathrm{s}$, large negative shears over the upper half of the rotor disk and positive shears over the lower half. These shear profiles occur when the wind speed at hub height is greater than the upper and lower level wind speeds. Profiles with a maximum wind speed at hub height occurred about $35 \%$ of the nighttime during summer.

However, shear profiles with moderate-to-strong positive shear over the lower half and weak-to-moderate positive shear over the upper half of disk were also prevalent during summer night. The most frequent nighttime shear profile in summer is $\Delta V_{L}=3$ and $\Delta V_{U}=1$.

Shear profiles persist longer and fluctuate less, on the average, during night than during day. However, shear profiles are not very persistent and fluctuate considerably during both day and night in summer.

Duration probability exceedance curves at Goodnoe Hills are presented in Figure 3-23 for winter and summer. From these curves, the average percentage of time that an individual wind shear profile exceeded a given duration can be determined. Exceedance curves are shown for all hours, and day- and nighttime hours.

Wind shear profiles persist longer, on the average, in winter than in summer. An individual wind shear exceeds a 10-min duration an average of $14 \%$ of the time in winter and $7 \%$ of the time in summer. Maximum durations of individual shear profiles are $44 \mathrm{~min}$ and 34 min for winter and summer, respectively.

Wind shear profiles persist longer, on the average, at night than in day in winter and summer. In winter, a shear profile exceeds a 10-min duration an average of $17 \%$ of the time at night and $5 \%$ of the time in day. In summer, a shear profile exceeds a 10-min duration an average of $9 \%$ of the time at night and $2.5 \%$ of the time in day. 
(a)

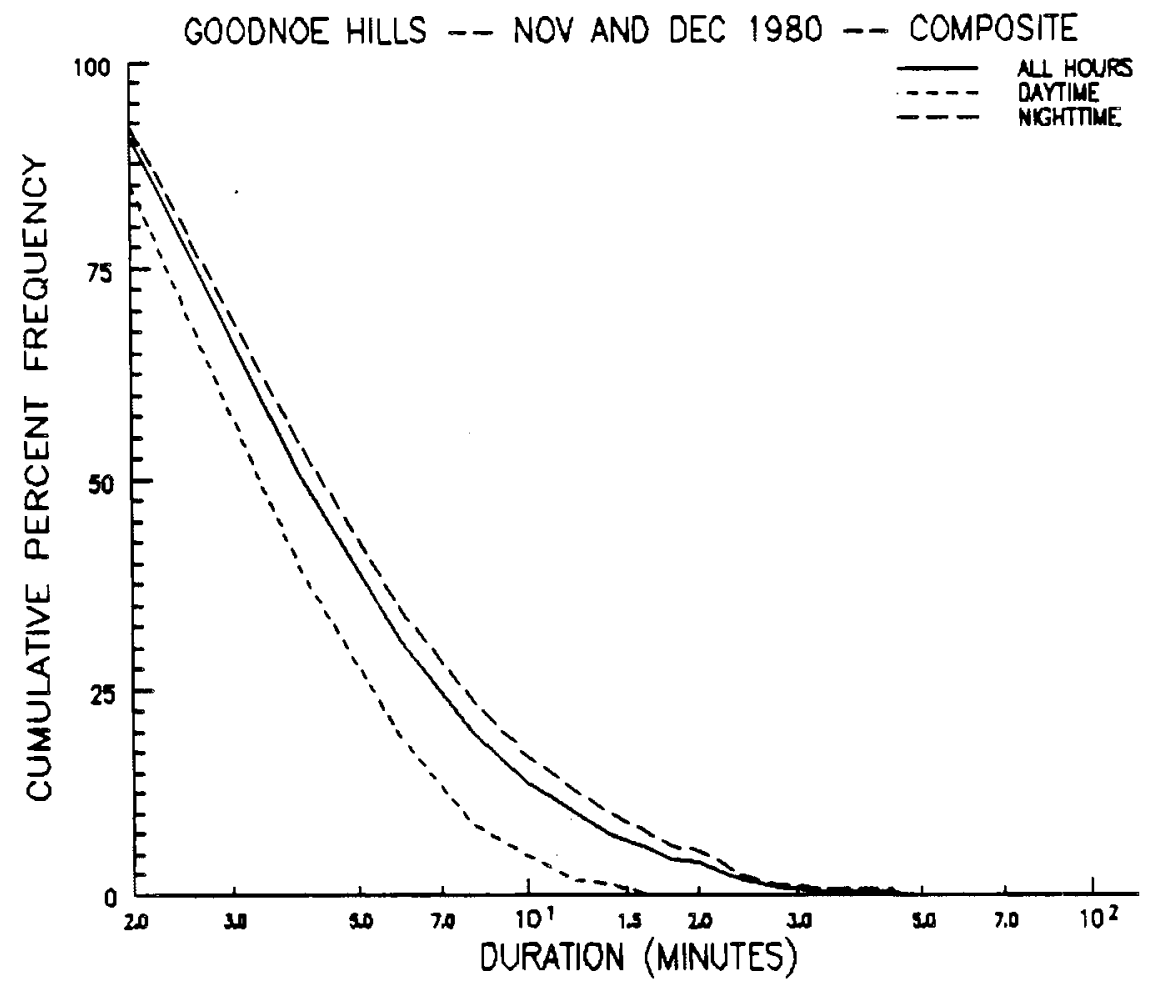

(b)

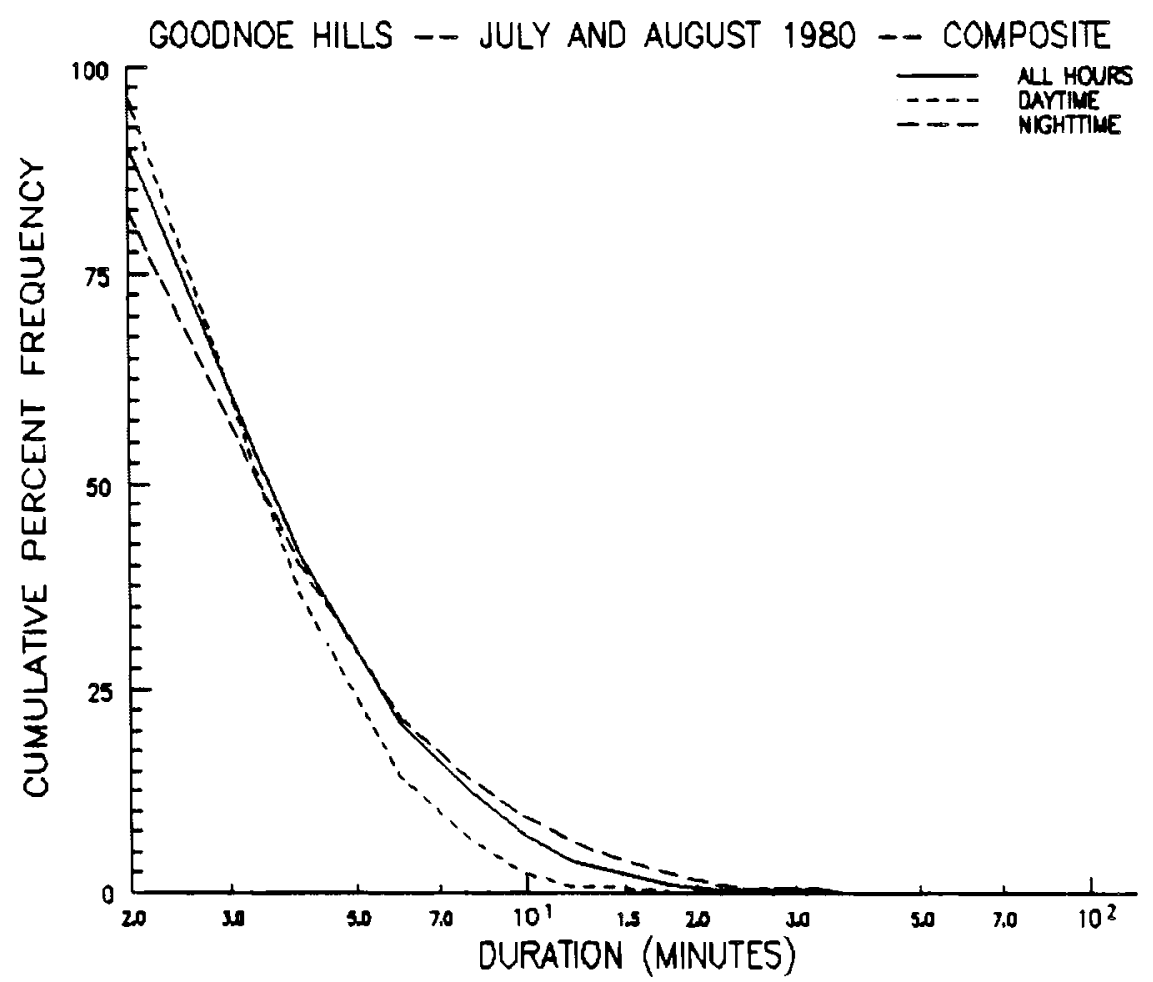

FIGURE 3-23. Average Percentage of Time That an Individual Wind Shear Profile Across a Type 1 Turbine Exceeded a Given Duration during (a) Winter and (b) Summer Using Instantaneous 2-min Sampled Winds From Goodnoe Hills. 
The percentage of time that wind shear profiles are within the matrix is determined by the intersection of the duration exceedance curve with the $y$-axis. Approximately $90 \%$ of the wind shear profiles in winter and in summer are within the matrix. However, less than $85 \%$ of the summer day and winter night profiles are within the matrix.

\subsection{COMPARISON OF SHEAR PROFILES AT THE THREE LOCATIONS}

Analyses of the percent frequency of occurrence, mean duration, and mean fluctuation of the matrix of wind shear profiles across a Type 1 turbine are shown for winter and summer for the three locations in Oklahoma, Wyoming and Washington in Figures 3-24 and 3-25. The analyses from all locations are based on 2-min instantaneous wind measurement samples from windy hours $(\bar{V} \geq 7 \mathrm{~m} / \mathrm{s}$ at hub-height level).

There are considerable differences in the frequency distribution of wind shear profiles, the mean durations, and mean fluctuations among the three locations. Summaries of the wind shear profile characteristics at each location, along with comparisons of the profile characteristics among the three locations, are presented below for winter and summer periods.

\subsubsection{Winter Profiles}

The distributions of the frequency of occurrence of wind shear profiles in winter (see Figure 3-24) are considerably different at the three 1ocations. At KYTV, there is a broad range in the distribution of the most frequent shear profiles (e.g. profiles with $\geq 6 \%$ occurrence). This is due to the large variation in profiles between day and night. Strong shears prevail at night, whereas weak shears (well-mixed conditions) prevail in day. Strong shears occur more frequently across the lower half of the rotor disk than across the upper half.

At Medicine Bow, strong shears are the most prevalent, and the day/ night variation in shear profiles is less than at KYTV. Daytime shears are, on the average, greater at Medicine Bow than at KYTV. Shears across the lower half of the rotor are greater than over the upper half approximately $88 \%$ of the time. Negative shears $(\Delta V<0)$ occur less than $5 \%$ of the time. 
(a)
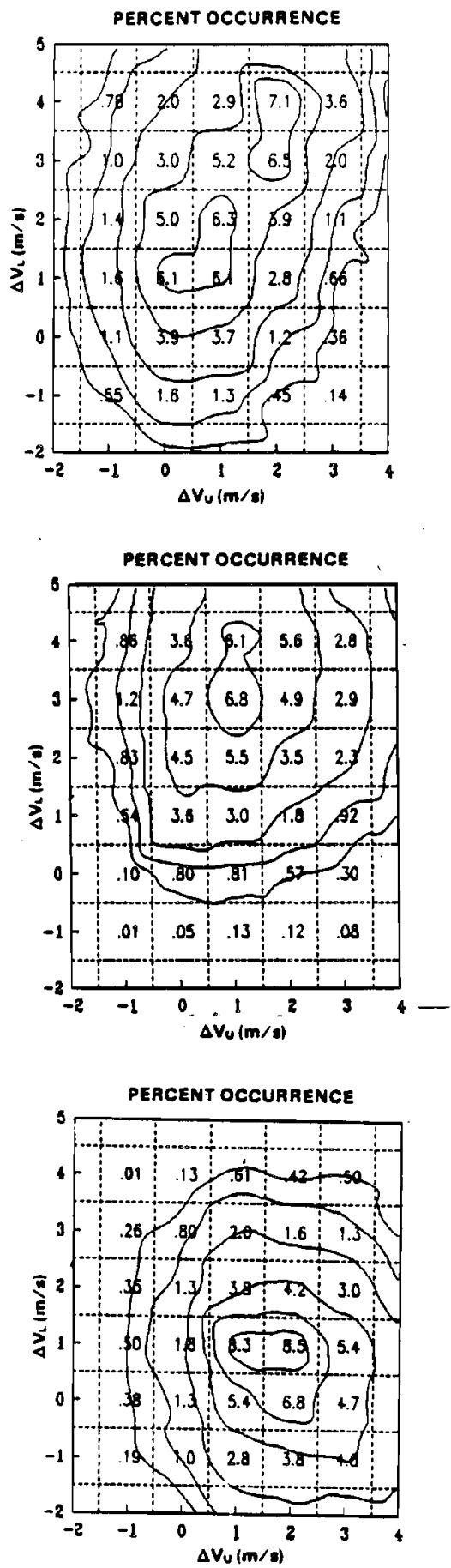
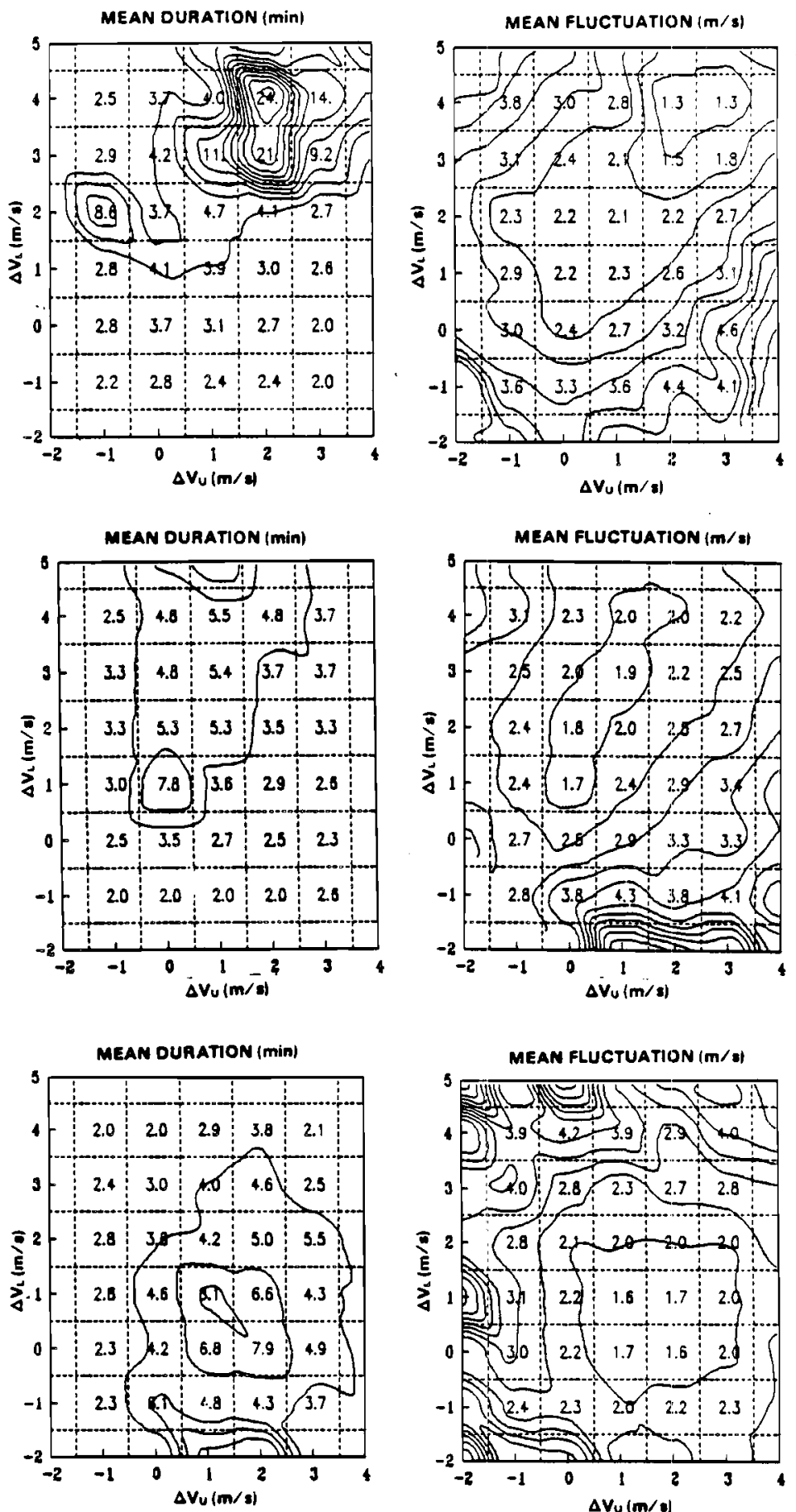

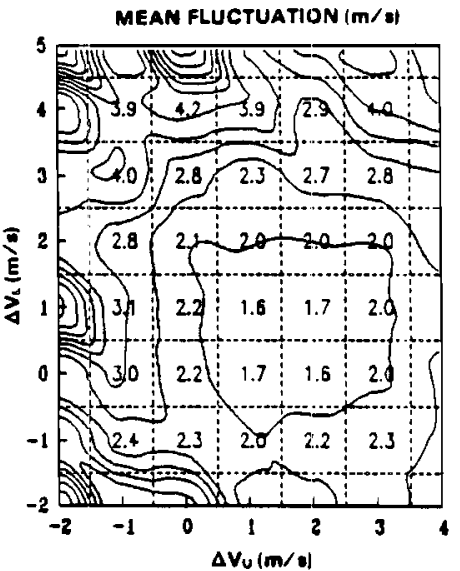

FIGURE 3-24. Frequency of Occurrence, Mean Duration and Mean Fluctuation of Wind Shear Profiles in Winter for a Type 1 Turbine using 2-min Instantaneous Winds from (a) KYTV Tower, Oklahoma, (b) ivedicine Bow, Wyoming, and (c) Goodnoe Hills, Washington. 
(a)
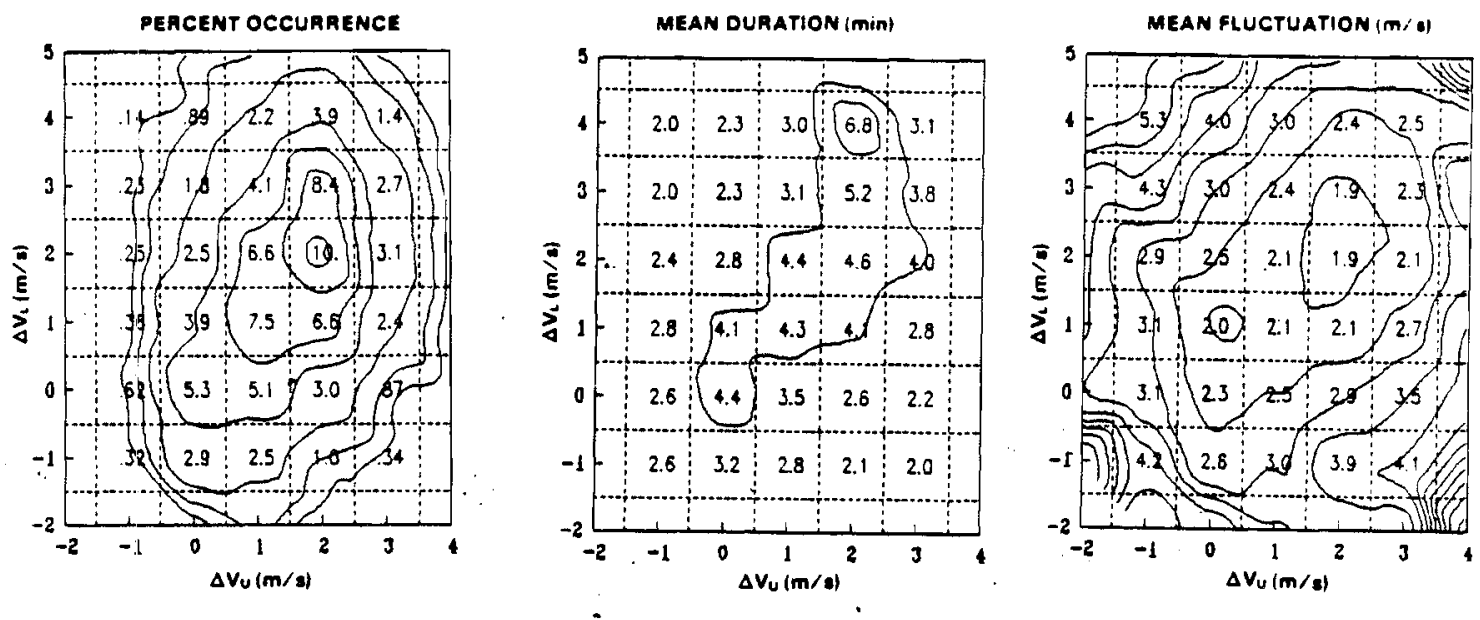

PEACENT OCGUARENCE

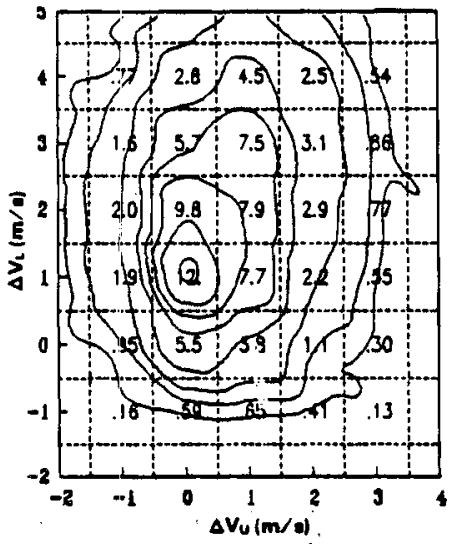

MEAN DURATION (min)

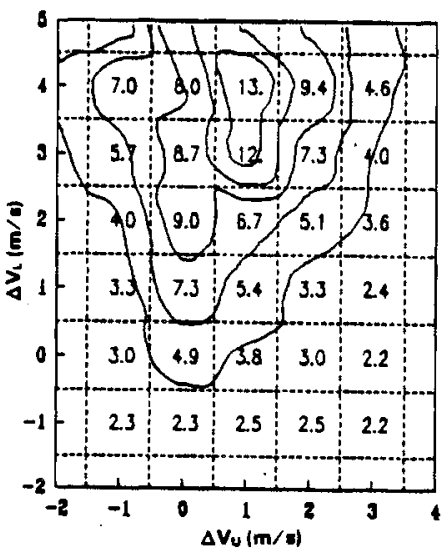

MEAN FLUCTUATION (m/a)

(b)
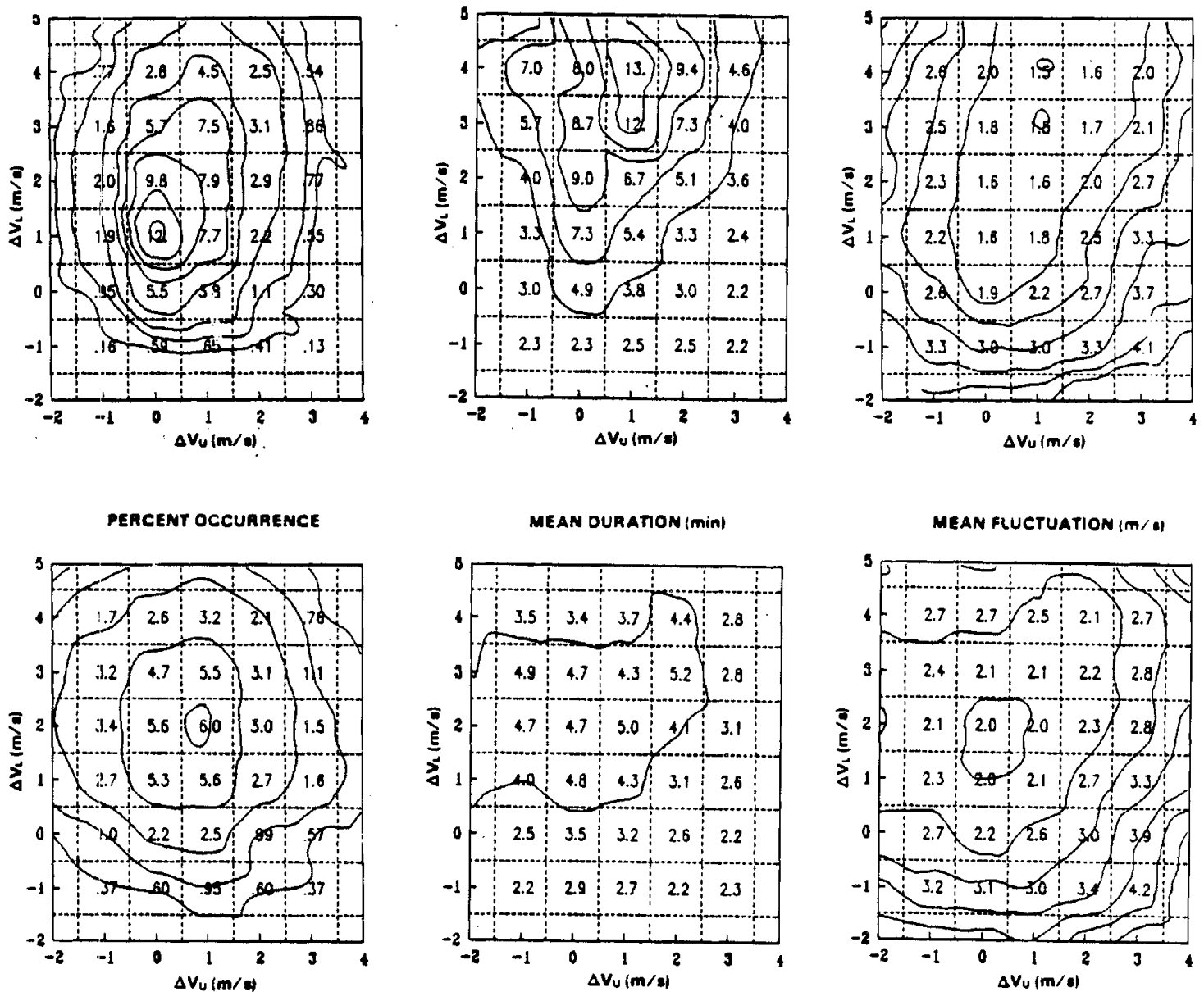

FIGURE 3-25. Frequency of Occurrence, Mean Duration and Mean Fluctuation of Wind Shear Profiles in Summer for a Type 1 Turbine using 2-min Instantaneous Winds from (a) KYTV Tower, Oklahoma,

(b) Medicine Bow, Wyoming, and (c) Goodnoe Hills, Washington. 
At Goodnoe Hills, the distribution of shear profiles is much unlike that at KYTV and Medicine Bow. Shears across the upper half of the rotor are more frequently greater than shears over the lower half, whereas the reverse is true at Medicine Bow and KYTV. Shear profiles with a minimum wind speed at hub height $\left(-\Delta V_{L}\right.$ and $\left.+\Delta V_{U}\right)$ occur about $20 \%$ of the time. These shear profiles are very infrequent at Medicine Bow and KYTV.

Mean durations of the wind shear profiles also show considerable variability among the three locations. At KYTV, strong shear profiles persist up to five times longer and fluctuate less than comparable strong shear profiles at Medicine Bow. However, these profiles of long duration occur only at night at KYTV and are associated with strong shear conditions and, occasionally, with profiles of maximum wind speed at hub height $\left(+\Delta V_{L}\right.$ and $\left.-\Delta V_{U}\right)$. Shear profiles at KYTV with small $\Delta V$, which are frequent in daytime, have much shorter durations and larger fluctuations than strong shear profiles (large $\Delta V$ ).

At Medicine Bow, there is much less variation in the mean durations over the matrix than at KYTV. Differences in mean duration between strong shear profiles (large $\Delta V$ ) and weak shear profiles (small $\Delta V$ ) are small compared to those at KYTV. Although night time shear profiles have, on the average, longer durations than daytime profiles, the day/night variation in profile durations is much less than at KYTV.

At Goodnoe Hills, the distribution of mean durations over the matrix is quite different from Medicine Bow and KYTV. The most persistent profiles at Goodnoe Hills are those in which wind speeds at hub height are lower than at the top and bottom of the rotor disk (e.g., $\Delta V_{L}=-2$ and $\left.\Delta V_{U}=2\right)$. Long durations of these shear profiles occur only at night. For the more frequent profiles, such as $\Delta V_{L}=1$ and $\Delta V_{U}=1$, mean daytime durations are approximately half the night time durations. 


\subsubsection{Summer Profiles}

As with the winter profiles, there is considerable variation among the three locations in the frequency distributions of the wind shear profiles in summer (see Figure 3-25). Moveover, the distribution of profiles in summer is quite different from the distribution in winter at all three locations. .

At KYTV, there is a greater occurrence of strong shears in summer than at Medicine Bow or Goodnoe Hills. These strong shears are most prevalent at night. Weak shears, indicative of well-mixed flow, are most frequent in daytime. The range in $\Delta V_{L}$ is about 1.5 to 2 times larger than that of $\Delta V_{U}$ at KYTV. This indicates that shears fluctuate more over the lower half of the rotor disk than over the upper half.

At Medicine Bow, there is greater occurrence of weak shear profiles (e.g., $\Delta V_{\mathrm{L}}=1$ and $\Delta V_{U}=0$ ) than at KYTV or Goodnoe Hills. These profiles are most prevalent in day and indicate well-mixed flow. Days are longer and usually more windy than nights, which probably explains the greater occurrence of weak daytime shears over the strong nighttime shears.

At Goodnoe Hills, the frequency distribution of wind shear profiles in summer is much broader than at either KYTV or Medicine Bow. There is a dramatic clifference in the day/night distribution of profiles at Goodnoe Hills. In the day there is a prevalence of weak shear profiles, whereas at night there is a wide variation of shears over the upper half of the rotor disk with $\Delta V_{U}$ widely varying from $-3 \mathrm{~m} / \mathrm{s}$ to $+3 \mathrm{~m} / \mathrm{s}$. Profiles in which the hub-height wind speed exceeded the upper and lower wind speeds occurred about $35 \%$ of the time during summer night at Goodnoe Hills. These profiles, which also occur in the day but not as frequently as in the night, are 5 to 10 times more frequent at Goodnoe Hills than at Medicine Bow and KYTV.

Mean durations and fluctuations also show considerable variability among the three locations. Wind shears profiles in summer persist longer and fluctuate less, on the average, at Medicine Bow than at KYTV and 
Goodnoe Hills. However, shear profiles of long duration and small fluctuation at Medicine Bow occur predominantly at night, as daytime profiles are of much shorter duration and larger fluctuation than nighttime profiles. Oddly, nighttime shear profiles in summer at KYTV and Goodnoe Hills are much less persistent and more fluctuating than at Medicine Bow.

At all three locations, daytime profiles in summer are generally of short duration and large fluctuation. This is characteristic of the turbulent, well-mixed flow which prevails on summer days.

\subsubsection{Duration Exceedance Curves}

Duration probability exceedance curves for a Type 1 turbine are presented in Figure 3-26 for winter and summer at KYTV, Medicine Bow, and Goodnoe Hills. These duration exceedance curves are based on 2-min instantaneous wind measurement samples. The average percentage of time that an individual wind shear profile exceeded a given duration $c$ an be determined from the curves. Exceedance curves are shown for all hours, daytime and nighttime hours.

It is apparent from Figure 3-26 that there is considerable variability among the three locations in the shear profile durations. The longest durations and largest day/night differences are in winter at KYTV and in summer at Medicine Bow. In winter, profile durations are substantially longer, on the average, at KYTV than at Medicine Bow and Goodnoe Hills. In summer, profile durations are substantially longer, on the average, at Medicine Bow than at KYTV and Goodnoe Hills.

Daytime profiles are, on the average, of shorter duration and larger fluctuation than nighttime profiles at all locations in winter and summer. However, the day/night differences are relatively small in summer at Goodnoe Hills and KYTV and in winter at Medicine Bow. Large day/night differences in the duration exceedance curves occur at KYTV in winter and at Medicine Bow in summer. 
(a)
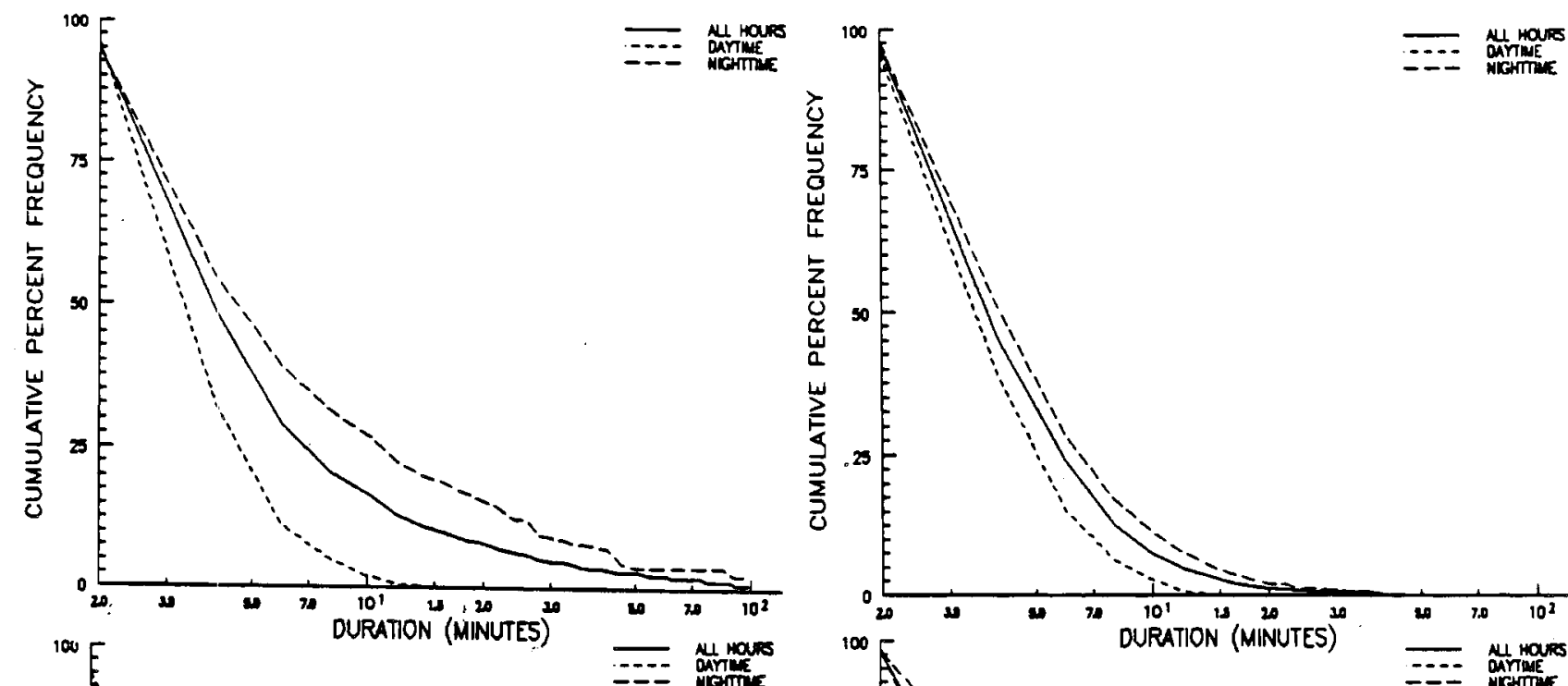

(b)
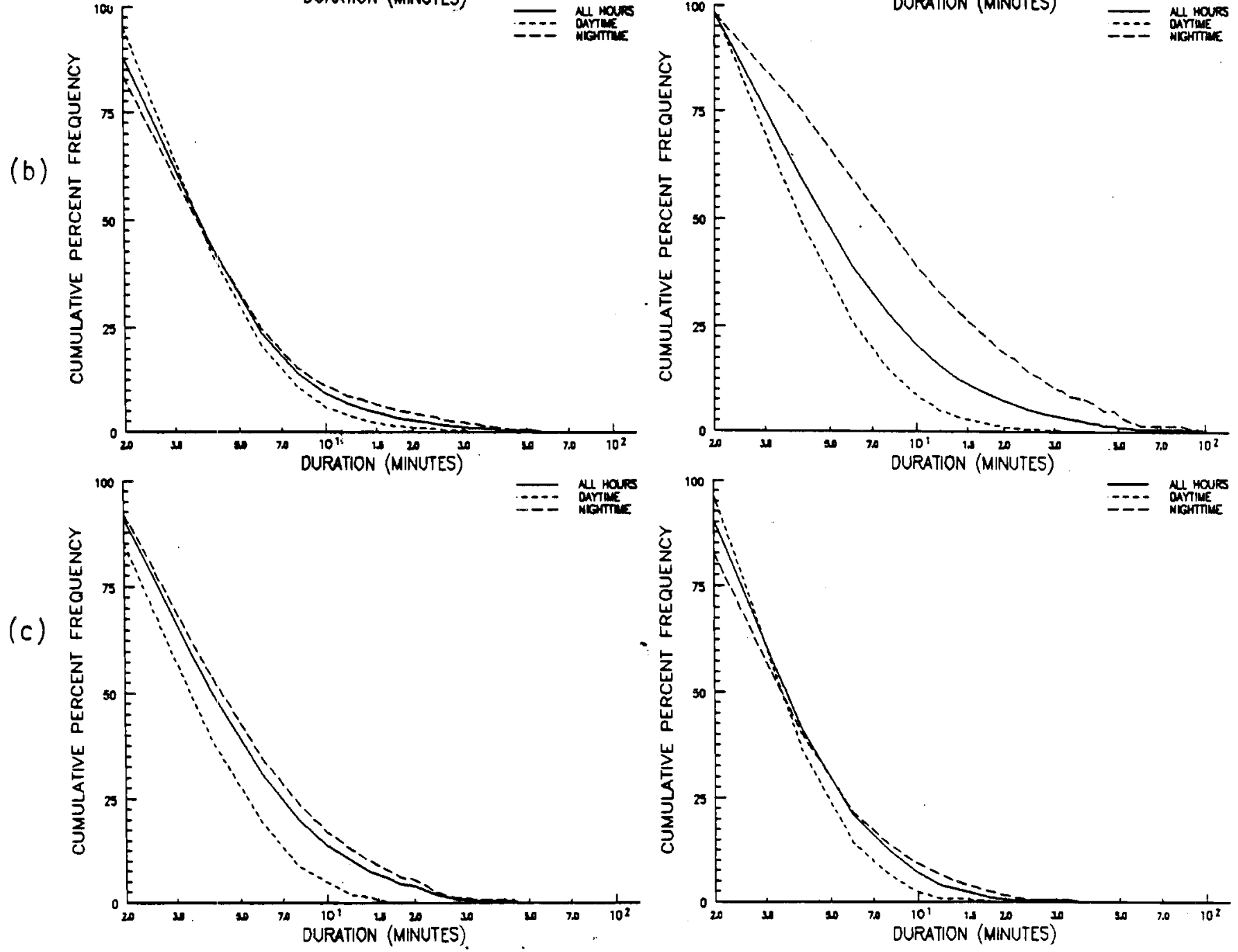

FIGURE 3-26. Average Percentage of Time That an Individual ivind Shear Profile Across a Type 1 Turbine Exceeded a Given Duration during Winter (left) and Summer ( $r$ ight) Using Instantaneous 2-min Winds from (a) KYTV Tower, Ok iahoma, (b) Medicine Bow, Wyoming, and (c) Goodnoe Hills, washington. 
Nighttime profiles persisting longer than one hour are infrequent but occur at KYTV in winter and at Medicine Bow in summer. Nighttime profiles persisting longer than 10 min occur about $38 \%$ of the time at Medicine Bow in summer and $25 \%$ of the time at KYTV in winter.

Dayt ime profiles in winter and summer persist less than 10 min $95 \%$ or more of the time at KYTV and Goodnoe Hills and $90 \%$ or more of the time at Medicine Bow. Daytime profiles persist less than $5 \mathrm{~min} 75 \%$ to $80 \%$ of the time at KYTV and Goodnoe Hills and $65 \%$ to $75 \%$ of the time at Medicine Bow. A 5-min and 10-min duration for 2-min data corresponds roughly to a duration of $30 \mathrm{~s}$ and $60 \mathrm{~s}$, respectively, for 10-s data. 


\subsection{CONCLUSIONS AND RECOMMENDATIONS}

The major conclusions that can be drawn from the analyses of wind shear profiles at the three selected locations and for the selected wind turbine configurations are:

- Comparisons using KYTV 10-s instantaneous wind data and 2-min instantaneous wind data indicate that 2-min instantaneous winds may be used to estimate the frequency distribution of wind shear profiles and the duration and fluctuation of the profiles as reliably as 10-s sampled winds.

- Significant differences exist among the three types of wind turbines in the distribution of shear profiles and in the duration and fluctuation of the profiles. The Type 3 turbine experiences considerably less variability in the occurrence of shear profiles and fewer extreme profiles than either the Type 1 or Type 2 turbines. Shear profiles persist longer and fluctuate less over the disk of rotation of the. Type 3 turbine than either the Type 1 or Type 2 turbine.

- Large differences exist among the three locations in the distribution of shear profiles and in the duration and fluctuation of the profiles. All three locations show a large variety of wind shear profiles; however, Goodnoe Hills experiences a greater variety of wind shear profiles than either Medicine Bow or KYTV.

- Most of the time, wind shear profiles have relatively short durations and fluctuate considerably. Sequential occurrences (either 10-s or 2-min instantaneous data) of the same wind profile happen only $35 \%$ to $55 \%$ of the time, considering the range over all three locations. Five consecutive sequential occurrences of the same profile happen only $10 \%$ to $20 \%$ of the time. Extremely long durations of over $30 \mathrm{~min}$ of the same profile occur less than $5 \%$ of the time and occur only at night. However, durations of over an hour are very infrequent $1<1 \%$ of the time). 
- Unusual and infrequent profiles are usually of very short duration and large fluctuation. However, there are some notable exceptions of infrequent and unusual shears persisting for long durations (e.g., for 20 or more consecutive, sequential occurrences) at Goodnoe Hills and KYTV.

- There is no good correlation between the magnitude of wind shear and the duration and fluctuation of wind shear profiles. Strong wind shears at some sites and in some seasons have long durations and small fluctuations, on the average, whereas at other sites or in other seasons, strong wind shears have short durations and large fluctuations, on the average. For example, the second most frequent profile (out of 56 different profiles) during both winter nights and summer nights at KYTV is the strong wind shear profile $\Delta V_{L}=3 \mathrm{~m} / \mathrm{s}, \Delta V_{U}=2 \mathrm{~m} / \mathrm{s}$. However, this profile persists for 10 times longer, on the average, during winter nights than during summer nights, when this profile fluctuates nearly as much as turbulent daytime profiles of relatively small shear (e.g., $\Delta V_{L}=0$ and $\Delta V_{U}=0$ ).

- Large variations exist between winter and summer at all three locations in the distribution of shear profiles and in the duration and fluctuation of the profiles. The winter-summer variation is greater at Goodnoe Hills than at KYTV or Medicine Bow. A substantially higher percentage of strong shears ( $\Delta V$ greater than $5 \mathrm{~m} / \mathrm{s}$ over the height of the rotor disk) occurs in winter than in summer at KYTV and Medicine Bow.

- The distribution of wind shear profiles varies dramatically between day and night at each location. Wind shears are, on the average, much stronger at night than in day. However, there is a large variety of wind shear profiles during both day and night at all three locations. 
- Daytime wind shear profiles are generally of short duration and large fluctuation at all three locations. The analyses of the duration exceedance probabilities of daytime profiles show little difference between the three locations and between winter and summer. Sequential occurrences of the same profile in daytime happen only $30 \%$ to $45 \%$ of the time. A profile persists for $30 \mathrm{~s}$ (3 consecutive occurrences) approximately $25 \%$ of the time and for 1 min ( 6 consecutive occurrences) only $10 \%$ of the time.

- Nighttime wind shear profiles vary considerably in duration and fluctuation, in contrast to daytime profiles. Duration exceedance probabilities of nighttime profiles show large variations among the three locations and between winter and summer. Winter nighttime profiles persist longer than summer nighttime profiles at KYTV and Goodnoe Hills, and vice versa at Medicine Bow. Nighttime profiles are of short duration and of only slightly longer duration than daytime profiles, on the average, in summer at KYTV and Goodnoe Hills and in winter at Medicine Bow. However, nighttime profiles of very long duration (e.g., 30 min. or longer) occur in winter at KYTV and in summer at Medicine Bow.

The analyses presented in this study showed remarkably different wind shear profile characteristics among the three locations. The analyses are not intended, however, to represent climatological (long-term) averages of these locations. Their primary purpose is to provide insight into the variety of wind shear profiles and their fluctuations and the nature of the seasonal and diurnal variations of the profile characteristics that can occur in different regions of the United States.

The variety of profile shapes, and the variations in durations and fluctuations of the profiles, indicate that the consideration of the wind shear profiles and their fluctuations over the upper and lower halves of the rotor disk is an important factor in estimating the fatigue life and 
power quality of large horizontal-axis wind turbines. These types of information are presented for evaluation and comment from turbine design engineers for the purpose of making the development of the input for an analysis of fatigue and power quality more effective and appropriate.

While rotational sampling provides a more accurate description of the wind shear and turbulence experienced by a rotating blade, use of conventional tower data such as these used in this study are valuable in a preliminary estimation of the variety of wind shear profile conditions and in the identification of extreme shear conditions that could be experienced by a rotating blade. This information would be useful in making siting decisions and in determining under what conditions more detailed and accurate measurements may be needed.

Therefore, it is recommended that measurements appropriate to this type of analysis be considered as a part of the siting criteria for the installation of large turbines, especially in regions where terrain features or land-water proximity suggest the possibility of physical phenomena conducive to severe and unusual wind shear profiles. Additionally, these types of information may also be important and useful for smaller turbines than addressed in this study. Considerable data from more than 20 locations throughout the United States are available for carrying out these types of wind shear analyses for heights up to $50 \mathrm{~m}$. Much of these data were collected for the U.S. Department of Energy Candidate Site Program. 


\subsection{REFERENCES}

Connell, J.R. 1982. "The Spectrum of Wind Speed Fluctuations Encountered by a Rotating Blade of a Wind Energy Conversion System". Solar Energy, Vol. 29, No. 5, pp. 363-375.

Connell, J.R. and R.L. George. 1983. Scaling Wind Characteristics for Designing Small and Large Wind Turbines. Presented at the Sixth Biennial Wind Energy Conference and Workshop, Minneapol is, Minnesota, June 1-3, 1983.

Elliott, D.L., L.L. Wendell and S.K. Heflick. 1982. Wind Shear Climatology for Large Wind Turbine Generators. PNL-4308, Pac if $i$ C Northwest Laboratory, Richland, Washington 99352.

Martner, B.E. and J.W. Gilmer. 1981. Wind Characteristics in Southern Wyoming, Part II Vertical Profiles. Report No. AS 128, University of Wyoming, Laramie, Wyoming 82071 .

Pacific Northwest Laboratory. 1980-1981. Wind Energy Resource At las: Volumes 1 through 12. PNL-3195 WERA-1 through 12, Pacific Northwest Laboratory, Richland, Washington 99352.

Water and Power Resources Service. 1979. Environmental Assessment Report for System Verification Units: Wind Energy Project Wyoming. WPRS, Lower Missouri Region, Denver, Colorado. 



\section{DISTRIBUTION}

No. of

Copies

OFFS ITE

C. I. Aspliden

Battelle Memorial Institute Washington Operations Office 2030 M Street, N.W. Washington, DC 20036

G. P. Tennyson

Department of Energy

Albuquerque Operations office 4501 Iridian School Road N.E. Albuquerque, NM 87110

D. Ancona

Department of Energy

Wind Energy Technology Division

1000 Iridependence Avenue

Forrestal Building, Room $5 \mathrm{H048}$

Washington, DC 20585

J. Cadogan

Wind Eriergy Technology Division

1000 Independence Avenue

Forrestal Building, Room 5H048

Washington, DC 20585

\section{DOE Technical Information Center}

R. Nolan Clark

U.S. Department of Agriculture Research Center

Bushland, TX 79012

M. L. Bovarnick

Boeing Engineering and Construction

P.0. Box 3707

Mail Stop 9A-65

Seattle, WA 98124

N. Butler

Bonneville Power Administration

P.0. Box 3621

Portland, OR 97208
No. of

Copies
S. J. Hightower

Bureau of Reclamation Denver Federal Center

Building 67, Code 254

Denver, CO 80225

Dave Waco

California Energy Commission

Wind Program

1516 9th Street, MS-43

Sacramento, CA 95814

Frank Goodman, Jr.

Electric Power Research Institute

P.0. Box 10412

Palo Alto, CA 94025

W. R. Barchet

Environmental Protection Agency

Acid Deposition Staff, RD676

401 M Street S.W.

Washington, DC 20460

Tom Hiester

Flow Wind Corporation 21414-68th Avenue South

Kent, WA 98031

Stanley Mackl is

Genera1 Electric Company

Advanced Energy Systems

P.0. Box 8661

Philadelphia, PA 19101

J. M. Kos

Hamilton Standard

Bradley Field Road

windsor Locks, CT 06096

Jean Mayhew

Hamilton Standard, MS-IM3

Bradley Field Road

Windsor Locks, CT 06095 
Bill Marlatt

Marlatt and Associates

3611 Richmond Drive

Fort Collins, C0 80521

David Spera

NASA/Lewis Research Center

21000 Brookpark Road

Cleveland, $\mathrm{OH} 44135$

Joe Savino

NASA/Lewis Research Center

21000 Brookpark Road

Cleveland, $\mathrm{OH} 44135$

Phillip French

NASA Scientific and Technical Information Facility

P.0. Box 8757

Baltimore/Washington International Airport

Baltimore, MD 21240

M. J. Changery

National Oceanic and Atmospheric Administration

National Climatic Center

Federal Building

Asheville, NC 28801

R. Thresher

Department of Mechanical Engr.

Oregon State University

Corvallis, OR 97331

J. E. Wade

Department of Atmospheric Sciences

Oregon State University

Corvaliis, OR 97331

Robert Swanson

Pacific Gas and Electric

245 Market Street

San Francisco, CA 94106
J. Dutton

Department of Meteorology

Pennsylvania State University

University Park, PA 16902

Jim Tangler

Rockwe11 International

Rocky Flats Plant

P.0. Box 464

Golden, CO 80401

Dr. Peter F. Lester

Department of Meteorology

San Jose State University

San Jose, CA 95192

P. K1imas

Sandia National Laboratories

P. 0. Box 5800

Albuquerque, NM 87185

D. Lobitz

Sandia National Laboratories

P. 0. Box 5800

Albuquerque, NM 87185

Paul Veers

Sandia National Laboratories

P.0. Box 5800

Albuquerque, NM 87185

Amir Mikhail

Solar Energy Research Institute 1617 Cole Boulevard Golden, C0 80401

R. H. Kirchhoff Department of Mechanical Engr. University of Massachusetts

Amherst, MA 01003

Dr. J. Marwitz Department of Atmospheric Science University of Wyoming

Laramie, WY 82071 
No. of

No. of

Copies

Copies

D. Mah

ONSITE

Western Area Power Administration

P.0. Box 3402

Golden, CO 80401

DOE Richland Operations Office

M. Silverman

Western Area Power Administration

P.0. Box 3402

Golden, C0 80401

T. Anderson

Westinghouse Electric Co.

P.0. Box 10824

Pittsburgh, PA 15236

Earl L. Davis

U.S. Windpower, Inc.

6421 B. South Front Road

Livermore, CA 94550

Farrell Smith Seiler

Wind Energy Report

Box 14 - 104 S. Village Avenue

Rockville Centre, NY 11571

Dr. Neil Cherry

Lincoln College

Canterbury

NEW ZEALAND

H. E. Ransom/D. R. Segna

48 Pacific Northwest Laboratory

J. W. Buck

W. C. Cliff

J. R. Connell

D. W. Dragnich

C. E. Elderkin

D. L. Elliott (10)

R. L. George

D. L. Hadley

P. C. Hays

S. K. Heflick

T. E. Michener

A. H. Miller

V. R. Morris

D. C. Powe 1.1

H. L. Wegley

L. L. Wendel 1

R. K. Woodruff

Technical Information Library (5)

Publishing Coordination (2)

WCPE Program Office (15) 
